\title{
Geología e historia eruptiva de algunos de los grandes volcanes activos de México
}

\author{
José Luis Macías \\ Departamento de Vulcanología, Instituto de Geofísica, Universidad Nacional Autónoma de México, Del. Coyoacán, 04510, \\ México D. F. \\ macias@geofisica.unam.mx
}

\section{Resumen}

La mayor parte de los grandes volcanes de nuestro país se encuentran ubicados en la parte frontal de la Faja Volcánica Transmexicana y en otras zonas volcánicas aisladas. En este trabajo se consideraron algunos de los grandes volcanes, éstos son el volcán de Colima, Nevado de Toluca, Popocatépetl, Pico de Orizaba (Citlaltépetl) y Tacaná. También se incluyó al volcán Chichón debido a su erupción catastrófica de 1982. El edificio actual de estos volcanes, o parte de éste, se ha formado en tiempos relativamente recientes; en menos de 2500 años el volcán de Colima, 16500 el Pico de Orizaba, 23000 el Popocatépetl, 26000 el Tacaná, y >50 000 el Nevado de Toluca. Los volcanes Colima, Popocatépetl, Pico de Orizaba y Tacaná se encuentran construidos al interior de antiguos cráteres originados por el colapso de edificios ancestrales. Los primeros tres representan los volcanes meridionales activos de cadenas volcánicas orientadas aproximadamente $\mathrm{N}$-S. A pesar de que todos estos edificios volcánicos han sufrido el colapso del edificio volcánico, únicamente en el Pico de Orizaba se han realizado estudios de alteración hidrotermal y estabilidad de pendientes, indispensables para pronosticar las zonas potencialmente peligrosas en el futuro.

Los magmas que han construido estos volcanes tienen una composición que va de andesítica (volcán de Colima), andesítica-dacítica (Nevado de Toluca, Popocatépetl, Pico de Orizaba, Tacaná) a traquiandesítica (Chichón). Estos magmas son el resultado de varios procesos magmáticos que van desde la fusión del manto, contaminación cortical, mezcla de magmas y cristalización fraccionada. Se conoce muy poco sobre los procesos que ocurren entre el sitio fuente del magma y la corteza inferior, mientras que se han logrado algunos avances sobre los procesos más superficiales. Existen evidencias claras de que los magmas que han alimentado a estos volcanes se estacionaron en cámaras magmáticas someras antes de alcanzar la superficie, a profundidades que varían de 3 a $4 \mathrm{~km}$ en el volcán de Colima, $\sim 6 \mathrm{~km}$ en el Nevado de Toluca y 6-12 km en el volcán Chichón.

Durante los últimos 15 años se han logrado avances importantes en el conocimiento estratigráfico y la historia eruptiva de estos volcanes; desafortunadamente, en ninguno de éstos se ha iniciado un análisis integral de toda la información geológica, geofísica, sísmica, vulcanológica, geoquímica y petrológica, para generar modelos conceptuales de su funcionamiento. Todavía necesitamos determinar con mayor precisión la posición y tamaño de la cámara magmática, los procesos de evolución del magma y sus tiempos de ascenso a la superficie, completar los estudios estratigráficos, evaluar los peligros y elaborar mapas de peligros, para finalmente establecer redes de monitoreo para su vigilancia. Actualmente, solamente los volcanes Colima y Popocatépetl cuentan con una red de monitoreo confiable, mientras que los volcanes Pico de Orizaba, Tacaná y Chichón cuentan con redes incompletas compuestas por algunas estaciones sísmicas. Sólo los volcanes Popocatépetl, Colima y Pico de Orizaba cuentan con mapas de peligros, los cuales, representan una de las herramientas fundamentales para las autoridades de Protección Civil, para elaborar programas de información a la población y de emergencia en caso de una erupción futura.

Palabras clave: Geología, cronología eruptiva, volcanes activos, México. 


\section{Abstract}

Most of the largest volcanoes in Mexico are located at the frontal part of the Transmexican Volcanic Belt and in other isolated areas. In this paper were considered some of these volcanoes as follows: Colima, Nevado de Toluca, Popocatépetl, Pico de Orizaba (Citlaltépetl) and Tacaná. El Chichón volcano was also considered within this group because of its 1982 catastrophic eruption. The volcanic edifice of these volcanoes or part of it, has been constructed during late Pleistocene or even during the Holocene: Colima during the last 2500 years, Pico de Orizaba 16500 yr. Popocatépetl 23000 yr, Tacaná 26000 yr, and Nevado de Toluca >50 000 yr. The modern cones of Colima, Popocatépetl, Pico de Orizaba and Tacaná are built inside or besides the remains of older caldera structures left by the collapse of ancestral cones. Colima, Popocatépetl, and Pico de Orizaba represent the youngest volcano of nearly N-S volcanic chains. Despite the repetitive history of cone collapse of these volcanoes, only Pico de Orizaba has been subjected to some studies of hydrothermal alteration and slope stability crucial to understand future potential events of this nature.

The magmas that have fed these volcanoes have a general chemical composition that varies from andesitic (Colima and Tacaná), andesitic-dacitic (Nevado de Toluca, Popocatépetl, and Pico de Orizaba) to trachyandesitic (Chichón). These magmas are the result of several magmatic processes that include partial melting of the mantle, crustal assimilation, magma mixing and fractional crystallization. So far, we know very little about the deep processes that occurred between the upper mantle source and the lower crust. However, new data have been acquired on shallower processes between the upper crust and the surface. There exist clear evidences, that most of these magmas have stagnated at shallow magma reservoirs prior to erupt; these depths vary from 3-4 km at Colima volcano, $6 \mathrm{~km}$ at Nevado de Toluca, and 6-12 km at Chichón volcano.

Over the past 15 years, there has been a surge of studies dealing with the volcanic stratigraphy and eruptive history of these volcanoes. Up today no efforts have been achieved to integrate all the geological, geophysical, chemical, and petrological information to produce conceptual models of these volcanoes. Therefore, we still have to precise the size and location of the magma chambers, magma ascent paths and time intervals prior to an eruption, to construct hazard maps to finally establish permanent long-running monitoring systems. Today, only Colima and Popocatépetl have permanent monitoring networks, while Pico de Orizaba, Tacaná, and Chichón have a few seismic stations. Of these, Popocatépetl, Colima, and Pico de Orizaba have volcanic hazard maps that constitute the basic information needed by the Civil Defense authorities, to elaborate information programs to the population as well as evacuation plans in case of a future eruption.

Key words: Geology, eruptive chronology, active volcanoes, Mexico.

\section{Introducción}

Los primeros reportes sobre eventos de índole volcánica en México aparecen en los códices náhuatl; los volcanes que merecen tal atención fueron el Pico de Orizaba (Citlaltépetl) y el Popocatépetl. Sus erupciones fueron representadas en los códices como un cerro con un copete de humo en su cima. El mejor registro de este tipo pertenece al Popocatépetl, que significa en lengua náhuatl "La montaña que humea". Los aztecas reportaron la ocurrencia de erupciones en 1363, 1509, 1512 y 1519-1528 (De-la Cruz et al., 1995). Después de la conquista, los volcanes de nuestro país recibieron varias menciones, la mayoría enfocadas a la actividad del Popocatépetl. Sin embargo, fue desde inicios del siglo XIX cuando se hicieron estudios científicos como el de Humboldt en 1804, el de los geólogos Del Río en 1842, Del Castillo en 1870 y Sánchez en 1856. Otros viajeros, entre los cuales había diversos artistas, plasmaron imágenes de nuestros volcanes como Echeverría en 1793, Rugendas entre 1831 y 1834 , Baptiste en 1834, Egerton en 1834, Pieschel en 1856, Sattler en 1862 y White entre 1862 y 1863. Aunque sus cuadros nos proveen de información sobre el estado de actividad de varios de los grandes volcanes de México, éstos no representan estudios científicos encaminados a comprender su comportamiento.

No es sino hasta 1890 cuando viajeros europeos visitaron nuestro país y realizaron importantes observaciones sobre la disposición de los grandes volcanes de México (Felix y Lenk, 1890). En su informe estos autores propusieron que los volcanes Popocatépetl, Cerro del Ajusco, Nevado de Toluca, así como los volcanes de Patzcuaro, el Patambán y la Bufa de Mascota (Bufa de Real Alto), estaban asociados genéticamente a la presencia de una sola grieta. En su ensayo también apuntaron la presencia de volcanes alineados en grietas secundarias, como el Pico de Orizaba-Cofre de Perote, el Telapón, Tlamacas, Iztaccíhuatl y Popocatépetl, y el Ceboruco-Cerro de la Bufa. Sin tener un fin particular sino el de comprender la naturaleza de nuestros volcanes, las observaciones realizadas por Felix y Lenk produjeron un gran escepticismo entre la pequeña comunidad geológica de México, dando paso a los primeros cuestionamientos sobre el origen, edad y distribución de 
nuestros volcanes, de los cuales ya existían estudios muy generales sobre su geología, con algunas notas sobre la edad relativa de algunas cadenas volcánicas.

En aquellos años, nuestro país contaba con un número reducido de geólogos que en su mayoría estaban adscritos al Servicio Geológico Nacional, el cual había abierto una brecha importantísima para la creación de la Comisión Geológica de México. Ordóñez, entonces miembro de esta Comisión, y uno de los geólogos más prestigiados del país, había ya puesto un gran énfasis en el estudio de varios de nuestros volcanes. Ordóñez se preguntó la veracidad de las observaciones de Felix y Lenk, y revisó con mucho cuidado el reporte de estos viajeros, planteándose además las mismas preguntas.

Fue así como Ordóñez (1894) puntualizó que no existía una sola grieta que hubiera formado a todos estos volcanes. Con descripciones generales sobre la forma de los volcanes, Ordóñez resaltó la enorme diferencia entre el Nevado de Toluca con su cráter destruido y las erupciones cuaternarias del Popocatépetl con respecto al volcán Ajusco, el cual no contaba con un cráter central que había desaparecido por completo. El mismo Ordóñez también cuestionó de manera aguda, la contemporaneidad y la génesis común entre estos volcanes. En cuanto a la existencia de volcanes ubicados a lo largo de grietas N-S, consideró que las andesitas de piroxeno del volcán Iztaccíhuatl, así como las de otros volcanes de nuestro país, estaban asociadas a volcanes en donde el cráter había sido destruido; en otras palabras, eran volcanes antiguos, lo cual contrastaba con las andesitas de hornblenda del Popocatépetl, el cual contaba con un cráter con una morfología joven y actividad superficial notoria. De esta forma, Ordóñez rechazó la existencia de grietas secundarias con una orientación N-S. A pesar de esta conclusión, él demostró que contaba con un enorme conocimiento de los principales volcanes de México y esto se vio reflejado en la publicación de una serie de estudios sobre los ventisqueros del Iztaccíhuatl (Ordoñez, 1894), las fumarolas del Popocatépetl (Aguilera y Ordóñez, 1895), Colima y Ceboruco (Ordoñez, 1898), el Cofre de Perote (Ordoñez, 1905) y el Nevado de Toluca (Ordoñez, 1902). En sus estudios, definió las características morfológicas de los edificios volcánicos, la petrografía de sus rocas y una serie de descripciones estratigráficas y productos piroclásticos. Su obra sentó las bases del estudio de los volcanes de nuestro país, a fines del siglo XIX, y dio paso a una nueva generación de estudios geológicos en la víspera del inicio del siglo XX, los cuales se vieron favorecidos con la ocurrencia de varias erupciones volcánicas en todo el mundo, pero en particular en Latinoamérica y México.

El primer observatorio meteorológico y vulcanológico en nuestro país fue fundado en 1893 en Zapotlán, Jal., por los presbíteros Arreola y Díaz, quienes realizaron observaciones sistemáticas del volcán de Colima entre 1893 y 1905. En 1895, el mismo padre Arreola fundaba el Observatorio Vulcanológico de Colima (Díaz, 1906), hecho sorprendente si consideramos que el primer observatorio en el mundo fue establecido en 1841, en Italia en el volcán Vesubio por Palmieri, después de una serie de erupciones.

La primera década del siglo XX tuvo un gran impacto en la comunidad geológica mundial dado que ocurrieron varias erupciones importantes en Latinoamérica. El 8 de mayo de 1902, la Montaña Pelée en la isla de la Martinica hizo erupción produciendo una oleada piroclástica que destruyó por completo a la ciudad de San Pedro, acabando con la vida de más de 25000 personas (Perret, 1937). Un día antes, el 7 de mayo de 1902, el volcán Soufrière devastó la isla de San Vincente terminando con la vida de 2000 personas (Anderson y Flett, 1903). Finalmente en octubre del mismo año, el volcán Santa María en Guatemala despertó violentamente con una erupción pliniana que cubrió con piedra pómez la porción noroeste de Guatemala y con ceniza hasta el centro de México. Esta erupción produjo un volumen de magma de $12 \mathrm{~km}^{3}$, por lo que representó una de las erupciones más voluminosas del planeta durante el siglo XX (Williams y Self, 1983). La catástrofe de 1902 de la Montaña Pelée atrajo la atención de varios geólogos de todo el mundo, que por primera vez estudiarían de manera detallada la evolución de erupciones subsecuentes y establecerían el Observatorio Vulcanológico de Morne des Cadets en 1903.

Estas erupciones abrieron una brecha importante en el estudio de algunos de los volcanes activos del país, tal es el caso de los estudios realizados por Böse (1903) sobre el volcán Tacaná en el estado de Chiapas. Böse observó que el edificio del Tacaná estaba compuesto por tres cúspides que él interpretó como partes de edificios antiguos; además realizó agudas descripciones de la cúspide, así como de pequeños cráteres adventicios que interpretó como el resultado de erupciones recientes. Asimismo, Waitz (1909) concluyó que el volcán Nevado de Toluca representaba la ruina de un volcán andesítico estratificado con un domo central ya apagado y el cual, probablemente, estuvo sujeto a la acción glacial debido a la presencia de canchales o depósitos de morrenas.

Durante la segunda década del siglo XX tuvieron lugar dos erupciones trascendentales para el desarrollo de los estudios vulcanológicos en México. Estas fueron la erupción de 1913 del volcán de Fuego de Colima, que destruyó su domo central y dejó un cráter de $400 \mathrm{~m}$ de diámetro, y la erupción del Popocatépetl en 1919-1927. A pesar de que ambas erupciones acontecieron precisamente después del inicio de la Revolución Mexicana, las dos gozaron de atención por parte de geólogos nacionales y extranjeros. Después de dos décadas de relativa quietud volcánica en nuestro país, surgió la noticia del nacimiento de un volcán en un campo de cultivo en el estado de Michoacán el 20 de febrero de 1943, en el poblado de San Juan Parícutin. Del terreno de cultivo se había formado un volcán pequeño de $424 \mathrm{~m}$ de elevación que sepultó a los poblados de Parícutin y San Juan Parangaricutiro (Flores-Covarrubias, 1945). Esta erupción fue seguida muy de cerca por vulcanólogos de todo el mundo (Wilcox, 1954; Foshag y González- 
Reyna, 1956; Segerstrom, 1956), por lo que el Parícutin se convirtió en el volcán más estudiado de nuestro país en esos años (Luhr y Simkin, 1993). El día de hoy, el Parícutin forma parte de nuestros libros de texto de educación básica y es un ejemplo del nacimiento de un volcán a nivel mundial. En 1956, una erupción espectacular tuvo lugar en la isla de San Benedicto, en el archipiélago de las islas de Revillagigedo, dando lugar a la formación del volcán Bárcena. Debido a su lejanía de la costa, unos $1000 \mathrm{~km}$ al oeste de las costas de Colima, esta erupción fue estudiada por un número menor de vulcanólogos (Richards, 1959, 1965) que sin embargo, dieron un registro fehaciente de la erupción. Para 1962, el cráter del volcán de Colima, formado en 1913, había sido rellenado por lava, marcando el inicio de su actividad moderna con la emanación de flujos de lava y flujos piroclásticos, con erupciones en 1962, 1976, 1981, 1987, 1991, 1994, 1998-2000 y 2002-2005.

La erupción que forma el parteaguas de los estudios vulcanológicos en México es la erupción catastrófica del 28 de marzo de 1982 del volcán Chichón, en el estado de Chiapas. La reactivación violenta (Macías et al., 2003) de un volcán prácticamente desconocido después de 550 años, tomó a la población y a los científicos por sorpresa. Esta erupción le quitó la vida a más de 2000 personas, destruyó nueve poblados, y causó importantes efectos globales con la emisión de más de $7 \mathrm{Mt}$ de $\mathrm{SO}_{2}$ a la atmósfera y la reducción de la temperatura del planeta en $0.5{ }^{\circ} \mathrm{C} \mathrm{du}-$ rante varios meses (Espíndola et al., 2002). La erupción del Chichón representa, hoy en día, la peor catástrofe de índole volcánica en nuestro país. Como consecuencia de esta erupción y del sismo devastador de 1985, se crea el Sistema Nacional de Protección Civil y surge la inquietud por el estudio y monitoreo constante de nuestros volcanes activos. La actividad volcánica continuó en nuestro país con eventos pequeños. En 1986, en el mismo estado de Chiapas, se reactiva el volcán Tacaná con una pequeña erupción freática que origina una fumarola. Esta erupción alertó a las autoridades estatales para iniciar el monitoreo geofísico del volcán.

En la década de los 90 tuvo lugar una pequeña erupción submarina del volcán Everman en las islas Revillagigedo (Siebe et al., 1995a). Otro acontecimiento importante fue la reactivación del Popocatépetl, ocurrida el 21 de diciembre de 1994, la cual representa un paso importante no sólo para el avance de los estudios vulcanológicos de nuestro país, sino también para la mitigación de los desastres volcánicos. Inmediatamente después de iniciada la crisis, se creó un comité científico que se encargó de evaluar su estado de actividad. Uno de los primeros temas que este comité científico consideró necesario para mitigar la crisis volcánica, fue la construcción de un mapa de peligros volcánicos, el cual debería servir a las autoridades de protección civil como base fundamental para crear sus planes de respuesta, localizar rutas de evacuación, albergues, etc. De esta forma, se publicó el mapa de peligros del Popocatépetl (Macías et al., 1995). Al mapa de peligros del Popocatépetl le si- guieron los mapas de los volcanes de Colima (Martín-del Pozzo et al., 1995; Navarro et al., 2003) y Pico de Orizaba (Sheridan et al., 2002).

\section{Ubicación de los volcanes activos de México}

La mayor concentración de volcanes en México se encuentra en la Faja Volcánica Transmexicana (FVTM), en donde se tiene una gran variedad de formas volcánicas como campos de conos monogenéticos, estratovolcanes majestuosos con elevaciones en torno a los $4000 \mathrm{~m}$, volcanes en escudo, volcanes compuestos, calderas, lavas fisurales y domos (Figura 1). Al interior de la misma FVTM existen cadenas de estratovolcanes y volcanes compuestos, que tienen una alineación general N-S y NE-SW en donde, aparentemente, ha ocurrido una migración de la actividad volcánica durante los últimos $2 \mathrm{Ma}$ hacia la porción frontal del arco volcánico. En otras palabras, los volcanes activos de estas cadenas están ubicados en el extremo sur de las mismas. Estas cadenas están formadas por los volcanes Cántaro-Nevado de Colima-Colima, TlálocTelapón-Iztaccíhuatl-Popocatépetl y Cofre de Perote-Las Cumbres-Pico de Orizaba-Sierra Negra. En este trabajo se consideran sólo algunos de los grandes volcanes de México y de esta forma se tratarán a los volcanes Colima, Nevado de Toluca, Popocatépetl, Pico de Orizaba y Tacaná. Por sus repercusiones catastróficas, también se incluye en este grupo al volcán Chichón que entró en erupción en 1982. A continuación se realiza la descripción de cada uno de estos volcanes, recopilando y analizando los estudios realizados y se reflexiona sobre las limitaciones de los mismos y los que quedan pendientes.

\section{Volcán de Colima}

El volcán de Colima o Fuego de Colima (19³0’45"; $\left.103^{\circ} 37^{\prime}\right)$ tiene una elevación sobre el nivel del mar de $3860 \mathrm{~m}$, por lo que representa la octava cima más alta del país (Figura 2). Su nombre Colima proviene de la lengua náhuatl que significa "El Dios del fuego que domina". El volcán está ubicado a unos $100 \mathrm{~km}$ al sur de la ciudad de Guadalajara y a $30 \mathrm{~km}$ al norte de la ciudad de Colima. El volcán de Colima forma parte de una cadena volcánica con orientación N-S, que está constituida por los volcanes: Cántaro, Nevado de Colima y el volcán de Colima.

\subsection{Estudios previos}

Los primeros estudios geológicos sobre el volcán de Colima fueron realizados por Waitz (1906, 1915, 1935) quien realizó observaciones generales y describió la formación de flujos piroclásticos durante la erupción de 1913. Desde esa fecha hasta fines de la década de los cincuentas, 


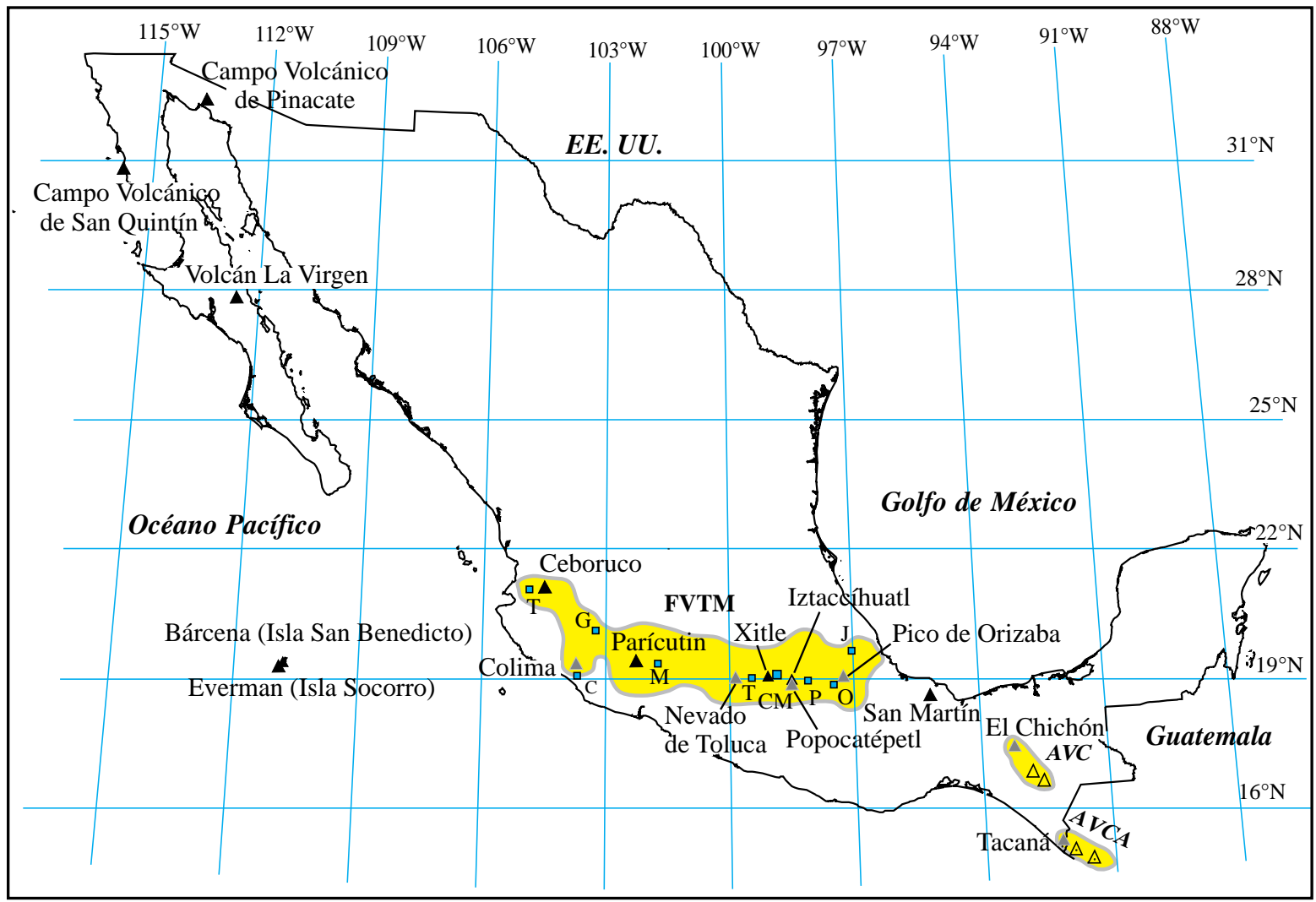

Figura 1. Localización de los principales volcanes de México (triángulos negros), éstos se agrupan entre el paralelo 19 y $20^{\circ}$ de latitud norte para formar la Faja Volcánica Transmexicana (FVTM). Sin embargo existen otras regiones volcánicas aisladas como: las islas Revillagigedo, el complejo volcánico de Tres Vírgenes, el campo volcánico de Los Tuxtlas, el arco volcánico Chiapaneco. Los volcanes que se tratan en este trabajo aparecen como triángulos grises. AVC=arco volcánico Chiapaneco y AVCA=arco volcánico de Centroamérica.

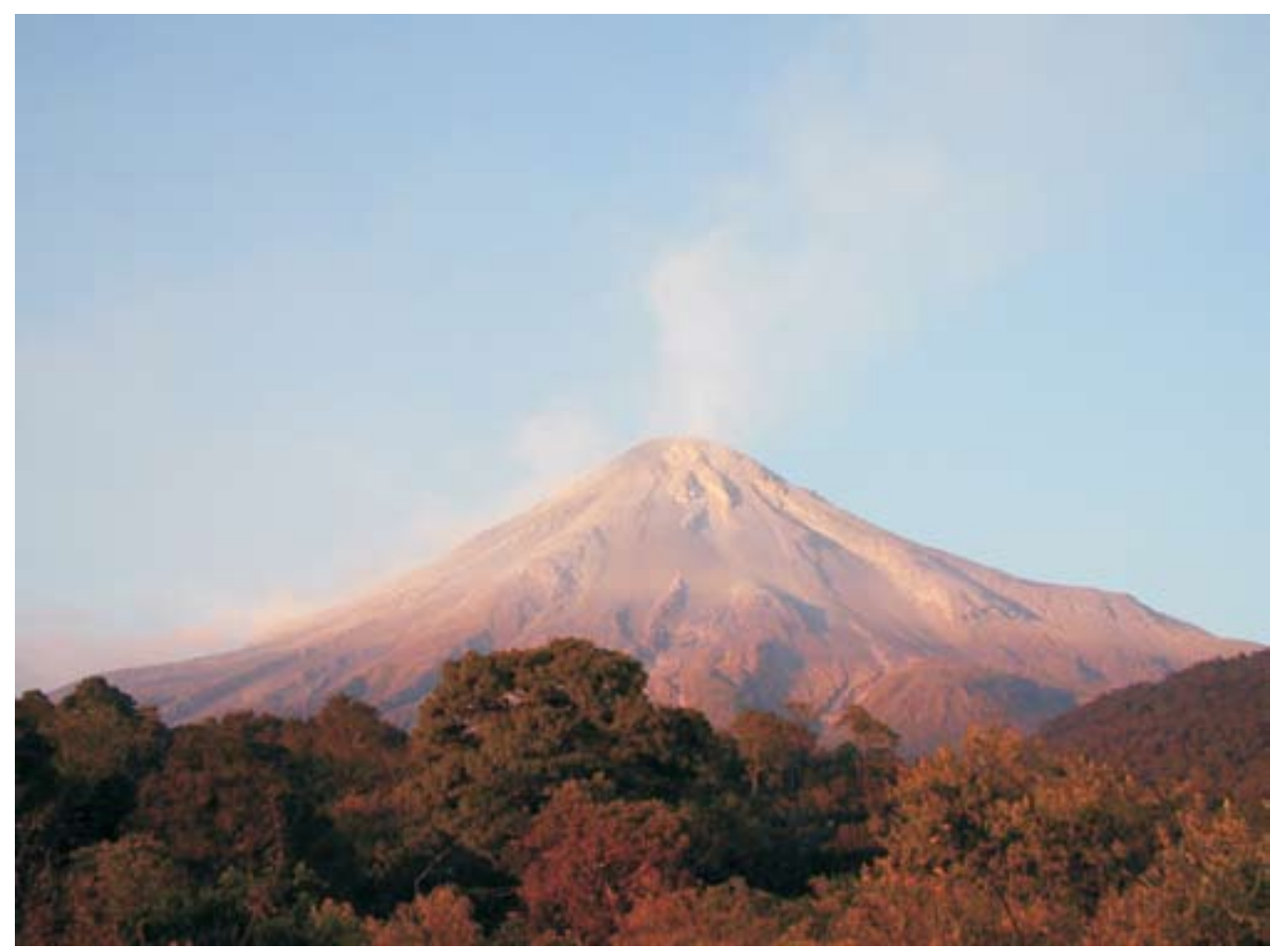

Figura 2. Vista panorámica del flanco sur del volcán de Colima tomada en diciembre de 1998. En esta imagen se aprecian las pendientes empinadas del cono por donde descienden bloques de lava que colapsan desde su cima. 
la actividad del volcán de Colima quedó restringida al interior del cráter. En 1962 el cráter del volcán estaba completamente lleno con lo que inició la emisión evidente de lavas en los flancos del volcán atrayendo la atención de varios investigadores que estudiaron la morfología y características generales del complejo volcánico (Mooser, 1961), sobre flujos piroclásticos tipo Merapi (Thorpe et al., 1977), y la primera evolución geológica del volcán (Demant, 1979). La década de 1980 representa el punto de partida de los estudios modernos del volcán de Colima. Después de la erupción de 1981, Medina-Martínez (1983), presentó el primer análisis sobre la recurrencia eruptiva del volcán de Colima durante los últimos 400 años. Asimismo, se realizaron una serie de estudios químicos y petrológicos de los productos del volcán y aparatos adventicios (Luhr y Carmichael, 1980, 1981, 1982, 1990a) y sobre los colapsos del edificio volcánico (Robin et al., 1987) los cuales crearon un gran interés sobre el volcán y continuaron durante los años sucesivos (Luhr y Prestegaard, 1988; Stoopes y Sheridan, 1992; Komorowski et al., 1997; Capra y Macías, 2002; Cortés-Cortés, 2002). La década de los noventa quedó marcada por erupciones pequeñas provocadas por la intrusión de cuerpos de magma, que al abrirse paso hacia la superficie originaron flujos de lava y flujos piroclásticos de bloques y cenizas. Estas erupciones fueron estudiadas desde diversos ángulos que incluyen estudios sísmicos (NúñezCornu et al., 1994; Jiménez et al., 1995; Domínguez et al., 2001; Zobin et al., 2002), petrológicos (Connor et al., 1993; Luhr, 2002; Macías et al., 1993; Mora et al., 2002; Valdez-Moreno et al., 2006), geoquímicos de gases (Taran et al., 2002) y estratigráficos (Martín-del Pozzo et al., 1987; Rodríguez-Elizarrarás et al., 1991; Rodríguez-Elizarrarás, 1995; Navarro-Ochoa et al., 2002; Saucedo et al., 2002; Saucedo et al., 2004a). Durante los últimos 25 años se han presentado varios mapas geológicos del volcán de Colima (Demant, 1979; Luhr y Carmichael, 1990b; RodríguezElizarrarás, 1991; Cortés et al., 2005). Dado el peligro que representa el volcán para las poblaciones circundantes, también se han presentado mapas de peligros volcánicos (Sheridan y Macías, 1995; Martín-del Pozzo et al., 1995; Navarro et al., 2003; Saucedo et al., 2004b).

\subsection{Evolución de la cadena volcánica}

Desde un punto de vista tectónico, la porción NW de la FVTM está sujeta a la subducción de la placa de Rivera por debajo de la placa de Norteamérica, y a la presencia de un triple sistema de rift: el rift de Tepic-Zacoalco al noroeste, el rift de Chapala al este y el graben de Colima al sur (Luhr et al., 1985; Garduño y Tibaldi, 1990) (Figura 3). Los primeros dos sistemas delimitan al norte y al este el llamado bloque Jalisco, y se consideran antiguas estructuras corticales reactivadas por efecto de las fuerzas aplicadas

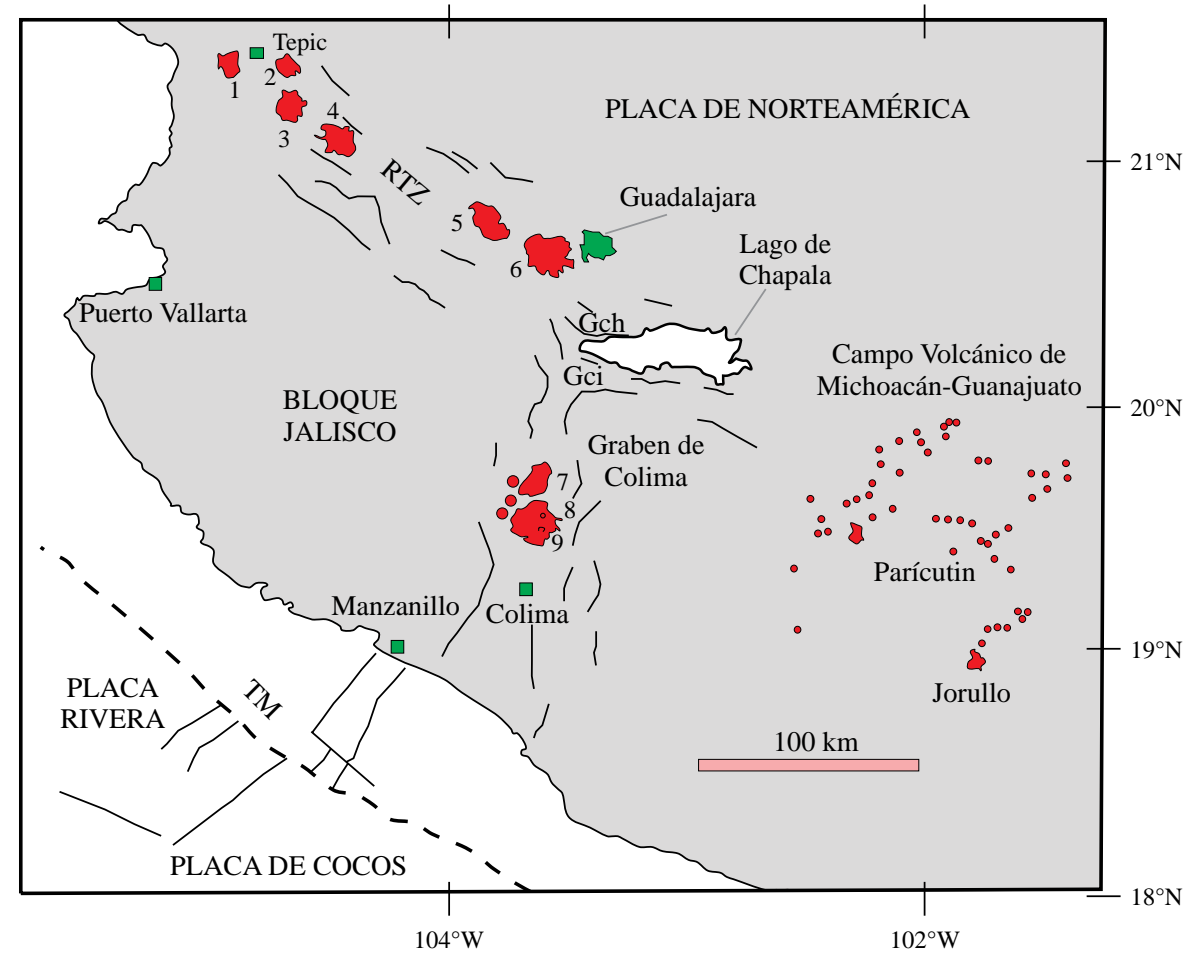

Figura 3. Esquema de la porción oeste de la FVTM (modificado de DeMets y Stein, 1991; Lange y Carmichael, 1991 y Luhr et al., 1989). Las estructuras volcánicas son: 1) San Juan, 2) Sangangüey, 3) Tepetiltic, 4) Ceboruco, 5) Tequila, 6) Caldera de la Primavera. Complejo volcánico de Colima: 7) Cántaro, 8) Nevado de Colima y 9) volcán de Colima. Las abreviaciones son: RTZ- rift Tepic-Zacoalco, GCh- graben de Chapala, GCi graben de Citala, y TM- Trinchera Mesoamericana (línea discontinua). Las líneas delgadas representan fracturas. 
en los límites de placas (Rosas-Elguera et al., 1996). De acuerdo con Cortés et al. (2005), el complejo volcánico de Colima (CVC) está construido sobre un basamento de andesitas y volcaniclásticos del Cretácico Inferior de la Formación Tecalitlán, areniscas y lutitas de la Formación Encino, calizas masivas de la Formación Tepames, lechos rojos del Cretácico Superior de la Formación Coquimatlán, intrusivos cretácicos y una secuencia volcánica del Terciario, constituida por derrames de basaltos, andesitas, brechas volcánicas dacíticas e ignimbritas (Figura 4).

La actividad volcánica cuaternaria en el graben de Colima inició hace aproximadamente $1.6 \mathrm{Ma}$ con la formación del estratovolcán Cántaro (Allan, 1986). Allan y Carmichael (1984) reportaron edades de K-Ar para este volcán que varían de $1.66 \pm 0.24,1.52 \pm 0.20$ y $1.33 \pm 0.20$ Ma. El Cántaro está compuesto por derrames de lava de composición andesítica, al que siguieron domos de composición dacítica (Luhr y Carmichael, 1990b). La actividad del volcán Cántaro finalizó hace aproximadamente 1.0 Ma.

Posteriormente, la actividad volcánica migró $\sim 15 \mathrm{~km}$ al sur, para formar el volcán ancestral Nevado de Colima, el cual tuvo una historia eruptiva bastante compleja descrita en dos fases eruptivas por Mooser (1961), en cuatro por Robin et al. (1987) y en seis periodos eruptivos por Cortés et al. (2005). Según estos últimos autores, varios de estos periodos eruptivos estuvieron influenciados por la falla Tamazula (Garduño-Monroy et al., 1998) y tres de ellos están asociados a depósitos de avalanchas de escombros los cuales se resumen a continuación:

1) Durante el primer periodo eruptivo hace aproximadamente $0.53 \mathrm{Ma}$, se formó un edifico volcánico que tenía unos $25 \mathrm{~km}$ de diámetro (Robin et al., 1987). Este estratovolcán está compuesto por derrames de lavas andesíticas, flujos piroclásticos y depósitos de caída aérea, que alcanzaron un volumen total superior a $300 \mathrm{~km}^{3}$.

2) Formación de un segundo edificio volcánico, con dimensiones menores al anterior, compuesto por derrames de lava, flujos piroclásticos y depósitos de pómez de caída de composición andesítica de edad desconocida.

3) Construcción de un tercer edificio volcánico constituido por depósitos de flujos de lava, flujos piroclásticos y material de caída de composición andesítica. Este edifico está asociado a una caldera semicircular de $\geq 4 \mathrm{~km}$ de diámetro abierta hacia el SE, producida por el colapso del edificio volcánico, el cual generó la primera avalancha de escombros expuesta al NE del poblado El Platanar.

4) La actividad continuó con la construcción de un nuevo edificio volcánico, con una emisión de flujos de lava andesíticos de hasta $17 \mathrm{~km}$ de largo, flujos piroclásticos y material de caída área. Algunas de las lavas de este edificio tienen edades de 0.35 Ma (Robin y Boudal, 1987). La actividad de este edificio volcánico culminó con el colapso lateral de su flanco hacia el SE, lo que originó una segunda avalancha de escombros, cuyos depósitos afloran hasta 25 km al SE del cráter en los cauces de la barranca Beltrán y río Tuxpan-Naranjo. La edad precisa de este colapso se desconoce todavía.

5) La actividad reinició al interior de la caldera anterior mediante el emplazamiento de espesos flujos de lava y depósitos de flujos piroclásticos expuestos en la barranca Atenquique; estos depósitos construyeron un quinto edificio volcánico. Este periodo finalizó con un evento explosivo, que originó flujos de bloques y cenizas que viajaron hasta $17 \mathrm{~km}$ al ESE del volcán en la zona de Atenquique y dejó una caldera semicircular abierta hacia el ENE en la cima del volcán. Estos depósitos sobreyacen discordantemente a lahares y depósitos fluviales de la Formación Atenquique (Mooser, 1961) que Robin y Boudal (1987) fecharon entre 0.38 y $0.26 \mathrm{Ma}$. Esta caldera fue asociada por otros autores al colapso gravitacional del Nevado de Colima ocurrido hace 18500 años antes del presente (AP), que generó una tercera avalancha de escombros (Robin et al., 1987; Stoopes y Sheridan, 1992; Capra-Pedol, 2000; Capra y Macías, 2002). Es probable que la fuente de este colapso se encuentre en una parte de esta caldera, sin embargo, la edad del colapso es aparentemente más joven. Independientemente del origen de dicho colapso, esta avalancha de escombros despertó gran interés entre la comunidad vulcanológica. Inicialmente se consideró que ésta había viajado a lo largo de los valles de los ríos Tuxpan-Naranjo y Salado, hasta alcanzar la costa del Pacífico, a una distancia de $120 \mathrm{~km}$ de la cima del volcán (Stoopes y Sheridan 1992), siendo una de las más grandes en el mundo. Sin embargo, CapraPedol (2000) y Capra y Macías (2002) concluyeron que este evento inició como un colapso gravitacional, que produjo una avalancha de escombros y viajó $25 \mathrm{~km}$ hasta el cauce del río Naranjo. El depósito formó una represa que bloqueó el drenaje y dio lugar a la formación de un lago temporal. Pocos días después, la represa cedió originando un flujo de escombros, que viajó a lo largo de los ríos Tuxpan-Naranjo hasta el Océano Pacífico.

6) A este periodo siguió un lapso de quietud volcánica del Nevado de Colima, que permitió la formación de suelos seguida de eventos explosivos, con la generación de flujos de ceniza y pómez extensos de color amarillo (Yellow ash de Robin y Boudal, 1987). Uno de estos depósitos fue fechado en 17960 años AP al NW del poblado de Quesería, cuya edad es muy cercana a la avalancha más joven del Nevado, por lo que representan eventos asociados o muy cercanos en el tiempo. Asimismo, tuvieron lugar una serie de erupciones plinianas entre 8000 y 2000 años AP, las cuales emplazaron depósitos de caída y oleadas piroclásticas en el interior de la caldera (Navarro-Ochoa y Luhr, 2000; Luhr y Navarro-Ochoa, 2002). La actividad eruptiva del Nevado de Colima finalizó con derrames andesíticos contenidos dentro de la caldera y el emplazamiento del domo El Picacho, que representa la cima actual del volcán.

\subsubsection{Volcán Paleofuego}

Al mismo tiempo que las últimas etapas de actividad del Nevado de Colima se construyó el cono ancestral del 
volcán de Colima, conocido como Paleofuego (Robin y Boudal, 1987), a unos $5 \mathrm{~km}$ al sur (Figura 4). Este edificio volcánico está representado por una caldera de $5 \mathrm{~km}$ de diámetro abierta hacia el sur; la proyección de sus paredes indica que este volcán debió de haber alcanzado unos 4100 m de elevación (Luhr y Preestegard, 1988). Las paredes de la caldera del Paleofuego en su flanco norte están compuestas por derrames de lava andesíticos alternados con depósitos de flujos de bloques y ceniza, que en conjunto presentan un espesor mayor de $300 \mathrm{~m}$ (Cortés et al., 2005). Estos flujos de lava se extienden $17.5 \mathrm{~km}$ al SW y $31 \mathrm{~km}$ al SE. Una secuencia compuesta por un flujo piroclástico, lahares y capas lacustres, fue fechada en 38400 años AP por Komorowski et al. (1993) quienes la asociaron al volcán Paleofuego. Por lo tanto, esta edad representa la mínima del inicio de la actividad de este volcán.

Waitz (1906) fue el primero en mencionar la caldera del Paleofuego, quien la describió como un maar; Demant (1979) asoció su formación a una serie de erupciones cíclicas de escoria y ceniza; Robin et al. (1987) y Luhr y
Preestegard (1988) la interpretaron como una estructura debida al colapso del volcán tipo Santa Elena. Estos últimos autores estimaron un área de $1550 \mathrm{~km}^{2}$ para el depósito de avalancha ubicado al sur del volcán y fecharon material carbonizado en su base en $4280 \pm 110$ años AP. Sin embargo, Robin et al. (1987) le asignaron una edad superior a la anterior de $9370 \pm 400$ años AP y la interpretaron como una unidad compuesta por varios depósitos. Este depósito fue mapeado detalladamente por Komorowski et al. (1997), quienes afirmaron que este depósito representaba la avalancha de escombros más reciente del volcán, la cual viajó alrededor de $30 \mathrm{~km}$ hacia el sur, cubrió una superficie $\sim 1200 \mathrm{~km}^{2}$ y tuvo lugar hace 2500 años AP. Cortés et al. (2005) reportaron que en realidad el volcán Paleofuego de Colima había colapsado al menos en cinco ocasiones y que estos depósitos cubrían un área de $5000 \mathrm{~km}^{2}$ (Figura 4). A continuación se resumen estos eventos:

El depósito de avalancha más antiguo (CVP3; Cortés et al., 2005) aflora $40 \mathrm{~km}$ al sur del actual volcán de Colima, alrededor de Coquimatlán. Este depósito forma una serie

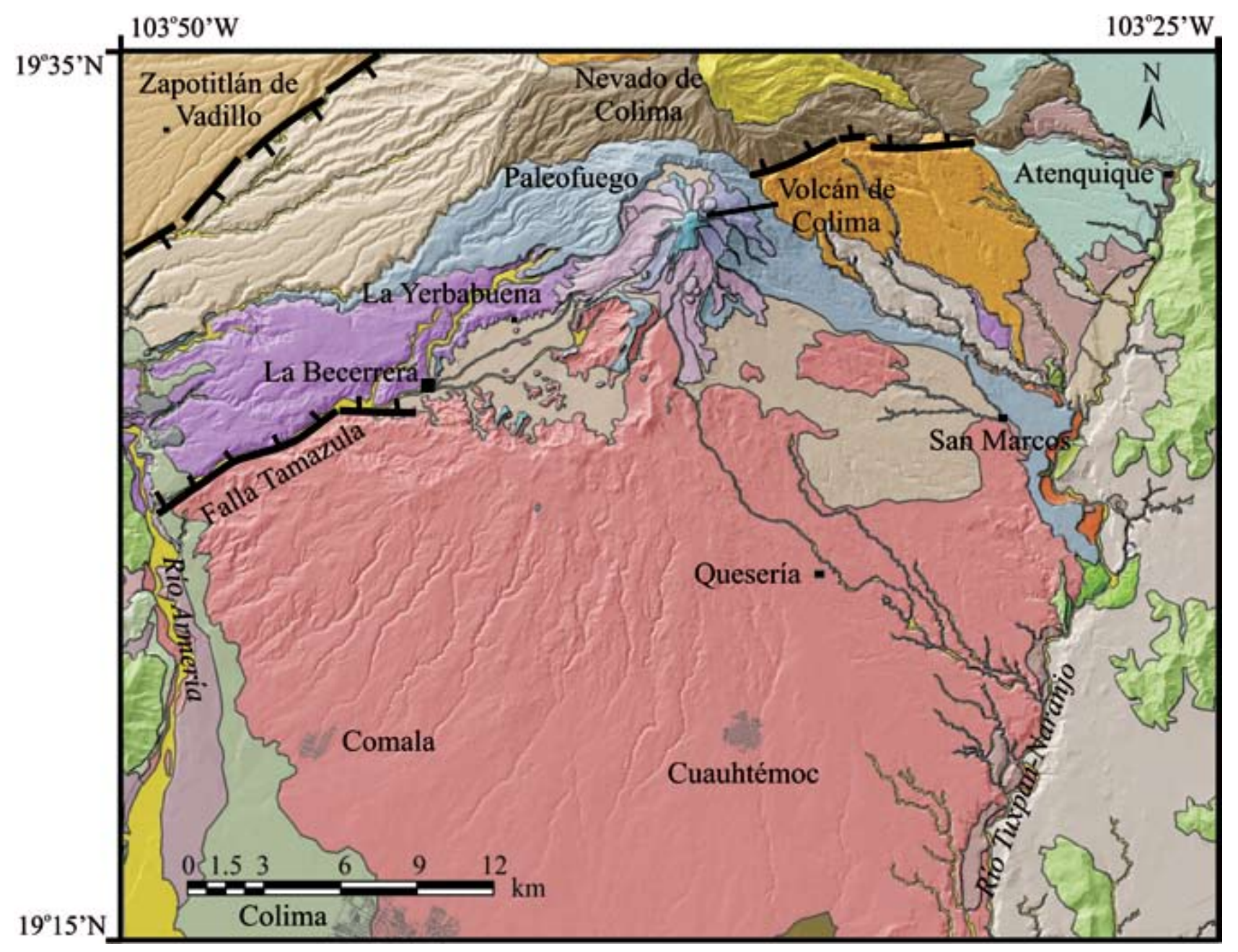

Figura 4. Mapa geológico simplificado de la porción meridional del complejo volcánico de Colima (tomado de Cortés et al., 2005) sobrepuesto a un modelo digital de terreno. Por simplicidad se señala únicamente la geología del volcán de Colima y una porción del volcán Nevado de Colima. 


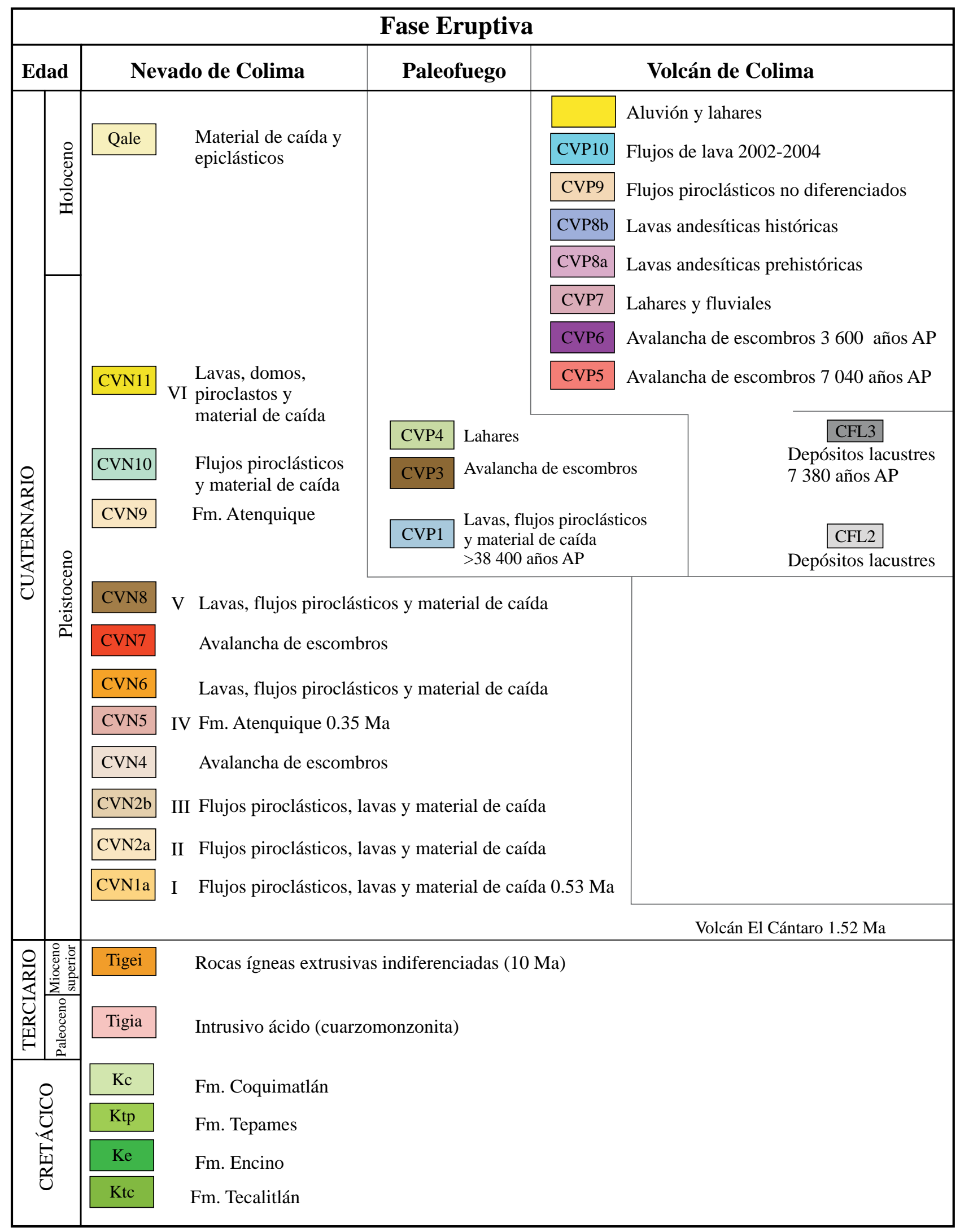


de montículos pequeños alargados en dirección del flujo y cubre una superficie $\sim 445.5 \mathrm{~km}^{2}$, con un espesor promedio de $20 \mathrm{~m}$ y un volumen de $8.9 \mathrm{~km}^{3}$. La avalancha está cubierta por una secuencia fluvial y de lahares que está dividida por un paleosuelo fechado en $16650 \pm 135$ años AP.

El segundo depósito de avalancha (CVP4) aflora en las inmediaciones del poblado de Mazatán al oeste del volcán y sobre las calizas de Cerro Grande. Esta avalancha seguramente represó el río Armería, dado que está cubierta por una secuencia de depósitos lacustres, que fueron fechados en 6390 y 7380 años AP por Komorowski et al. (1997).

El tercer depósito de avalancha (CVP5) cubre una superficie hacia el sur de $\sim 586 \mathrm{~km}^{2}$ y tiene un volumen $\sim 30$ $\mathrm{km}^{3}$. De 0 a $15 \mathrm{~km}$ del volcán, la avalancha está constituida por una topografía abrupta de montículos (facies de bloques), con depresiones cerradas en donde se formaron varios lagos (El Jabalí, Carrizalillos, etc.). A una distancia de entre 15 y $30 \mathrm{~km}$ del volcán, la avalancha tiene una topografía suave con lomeríos (facies de matriz). La facies de bloques consiste de bloques de lava de color rojo y gris con fracturamiento en rompecabezas y escasa o nula matriz. La facies de matriz consiste de bloques angulosos de andesita de hasta $2 \mathrm{~m}$, sostenidos por una matriz de ceniza fina semiconsolidada. El material orgánico encontrado al interior de este depósito fue fechado en $6990 \pm 130$ años AP (Cortés-Cortés y Navarro-Ochoa, 1992).

El cuarto depósito de avalancha de escombros (CVP6) se extiende hacia el SW del volcán hasta $25 \mathrm{~km}$ de la cima del volcán actual de Colima y cubre una superficie aproximada de $40 \mathrm{~km}^{2}$. Cortés-Cortés (2002) definió un depósito de avalancha que consiste en megabloques asimilados de diferentes depósitos volcánicos y fluvio-lacustres, fechado en 3600 años AP (Komorowski et al., 1997). El quinto depósito corresponde al evento más joven fechado en 2500 años AP descrito anteriormente.

\subsubsection{Volcán de Colima}

Después del último colapso del volcán Paleofuego ocurrido hace aproximadamente 2500 años AP, la actividad volcánica migró hacia el sur y se instauró dentro de la caldera del Paleofuego. Esta actividad ha dado origen al actual volcán de Colima, el cual tiene un volumen aproximado de $10 \mathrm{~km}^{3}$ y ha crecido a razón de $0.002 \mathrm{~km}^{3} /$ año (Luhr y Carmichael, 1990a, 1990b).

Este estratovolcán está compuesto por una alternancia de derrames andesíticos, depósitos de flujos piroclásticos y de caída. Una de las características del volcán de Colima ha sido la generación de flujos piroclásticos que han alcanzado hasta $15 \mathrm{~km}$ del cráter; los más notables son aquellos formados durante la erupción de 1913.

Durante los últimos 400 años, el volcán de Colima ha presentado alrededor de 43 erupciones que lo colocan como el volcán más activo de Norteamérica (De-la Cruz-Reyna, 1993; Saucedo et al., 2004b). Como consecuencia de su constante actividad, el volcán de Colima cuenta con el registro histórico más completo de los volcanes mexicanos.
Los trabajos más detallados sobre la actividad histórica del Colima son aquellos publicados por Medina-Martínez (1983), De-la Cruz-Reyna (1993), Saucedo y Macías (1999) y Bretón-G. et al. (2002), en ellos se mencionan erupciones ocurridas en los siglos XVI y XVII (Tello, 1651), el 13 de diciembre de 1606 (Arreola 1915), el 15 de abril de 1611 (Bárcena, 1887), en 1690 (De-la Cruz-Reyna, 1993), en 1771 (Bárcena, 1887) y un gran número de menciones de eventos menores. Sin embargo, el registro más detallado de las erupciones comienza con la erupción ocurrida el 15 de febrero de 1818 (Sartorius, 1869), la cual destruyó un domo de lava (Dollfus y Monserrat, 1867) y arrojó escoria y ceniza hasta las ciudades de Guadalajara, Zacatecas, Guanajuato, San Luis Potosí y México (Bárcena, 1887; Arreola, 1915). Después de la erupción quedó un cráter abierto mayor a $500 \mathrm{~m}$ de diámetro y con forma de embudo, con paredes que variaban de 50 a $230 \mathrm{~m}$.

El 12 de junio de 1869 inició la formación del domo adventicio "El Volcancito", misma que concluyó en 1872 (Sartorius, 1869; Bárcena, 1887). Orozco et al. (1869) reportaron que "El Volcancito" estaba localizado a una altura de $3500 \mathrm{~m}$ y que había alcanzado una altura total de 300 metros a partir de su base ubicada a $3200 \mathrm{~m}$. La etapa comprendida entre los años 1893 y 1903 es especialmente importante en el estudio del volcán Colima, ya que tanto el padre Arreola, en Colima, Col. como su colega Castellanos, en Zapotlán, Jal. (hoy Ciudad Guzmán), instalaron observatorios para vigilarlo. A partir de esta fecha se hicieron observaciones sistemáticas que continuaron hasta 1906, mismas que mensualmente eran publicadas en el Boletín del Observatorio Meteorológico Central de México (Arreola, 1915).

La erupción explosiva mejor documentada del volcán de Colima fue la ocurrida en 1913. Antes de la erupción la cima del volcán tenía un cráter cubierto por un domo de lava. La erupción comenzó el 17 de enero de 1913 (OrtizSantos, 1944) con una serie de explosiones que generaron densas nubes de vapor y ceniza. El 20 de enero la erupción continuó con la formación de una columna pliniana que alcanzó $21 \mathrm{~km}$ de altura (Saucedo-Girón, 1997). Esta columna provocó una lluvia de ceniza, que en Zapotlán, Jal. alcanzó $15 \mathrm{~cm}$ de espesor y en la Barca, Jal., alrededor de $4 \mathrm{~cm}$ según el periódico El Imparcial publicado el $21 \mathrm{de}$ enero de 1913. Ésta llegó hasta Saltillo, Coah., a más de $700 \mathrm{~km}$ del volcán. El volumen total de la erupción de 1913 fue estimado en $0.9 \mathrm{~km}^{3}$ (Saucedo-Girón, 1997). Durante la erupción también se produjeron flujos piroclásticos, los cuales fluyeron $15 \mathrm{~km}$ por el flanco sur del volcán, dejando depósitos de ceniza y rocas de $40 \mathrm{~m}$ de espesor (Waitz, 1915). Como resultado de esta explosión, la morfología de la cima del volcán cambió drásticamente, el edificio perdió $100 \mathrm{~m}$ de altura y se formó un cráter con un diámetro cercano a $400 \mathrm{~m}$ y profundidad desconocida.

Para 1931, la profundidad del cráter oscilaba entre 50 y 100 m (Waitz, 1935; Arreola 1915); para 1958, el cráter estaba casi completamente ocupado por un tapón de lava en 
bloques (Mooser, 1961) que, entre 1961 y 1962, comenzó a derramarse por la ladera norte del volcán de Colima formando una lengua de lava que llegó hasta la base norte del volcán, en el sitio denominado El Playón. En 1975-1976 comenzó la generación de varios flujos de lava acompañados por primera vez de flujos piroclásticos, los cuales fueron documentados por Thorpe et al. (1977). Esta clase de actividad consistió en la intrusión de un cuerpo de magma que empujó el domo o tapón central y eventualmente generó derrames andesíticos como el de 1982 (Luhr y Carmichael, 1990b) y/o flujos piroclásticos producidos por el colapso gravitacional de las partes externas del domo, como el de 1991 (Rodríguez-Elizarrarás et al., 1991), también de la parte frontal de los flujos de lava, como en 1998 (Saucedo et al., 2002), y de manera más violenta, durante los primeros meses del año 2005.

\section{Volcán Nevado de Toluca}

El volcán Nevado de Toluca $\left(99^{\circ} 45^{\prime} \mathrm{W} ; 1^{\circ} 09^{\prime} \mathrm{N}\right)$ está ubicado a $23 \mathrm{~km}$ en dirección suroeste de la ciudad de Toluca (Figura 5). Con una elevación de 4680 metros sobre el nivel del mar, representa la cuarta cima más alta del país. El Nevado de Toluca también es conocido como "Xinantécatl" (hombre desnudo, en lengua náhuatl), aunque recientemente García-Martínez (2000) concluyó que el nombre náhuatl apropiado para el volcán es "Chicnauhtécatl" que significa "nueve colinas". El edificio volcánico se encuentra emplazado en un basamento de rocas volcanosedimentarias metamorfizadas de edad JurásicoCretácico (Bonet, 1971; Bloomfield et al., 1977; Campa et al., 1974; Demant, 1981), ignimbritras de composición riolítica del Eoceno y derrames andesíticos del Mioceno (García-Palomo et al., 2002) (Figura 6).

El Nevado de Toluca (NT) es un volcán de tipo compuesto de edad Pleistoceno tardío-Holoceno constituido por andesitas y dacítas calcialcalinas (Bloomfield y Valastro, 1974; Cantagrel et al., 1981; García-Palomo et al., 2002). El Nevado de Toluca está emplazado en dos cráteres antiguos en forma de anfiteatro (flancos SE y NE), los cuales están relacionados con el colapso parcial del edificio dado que se han encontrado depósitos de avalanchas de escombros en sus alrededores. El flanco norte del NT tiene una elevación

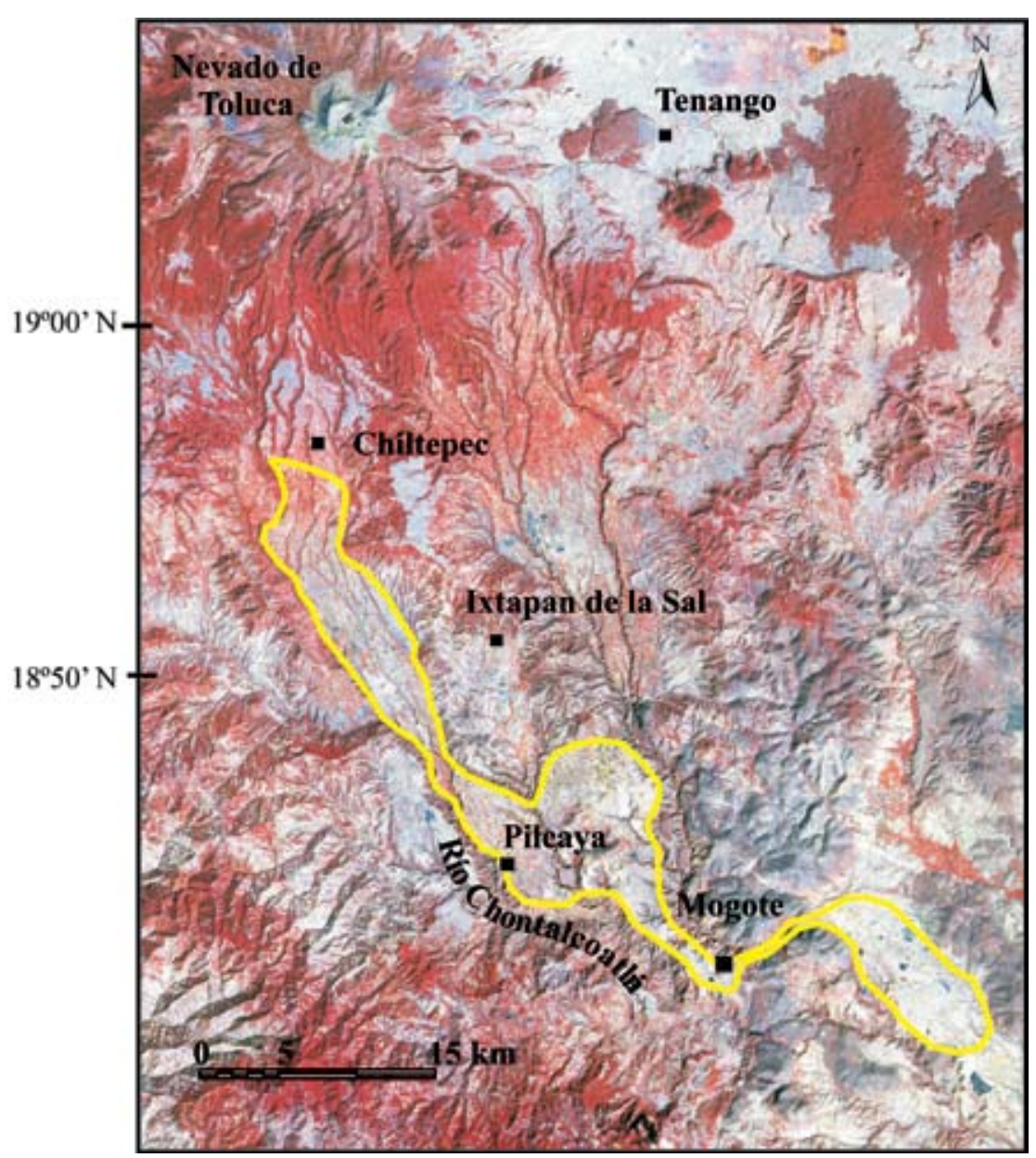

Figura 5. Imagen de satélite tipo LANDSAT que muestra el alcance máximo del depósito de flujos de escombros Pilcaya y el lahar El Mogote de manera conjunta según Capra y Macías (2002). El volcán Nevado de Toluca se ubica a $21 \mathrm{~km}$ al SW de la ciudad de Toluca que no aparece en esta imagen. 

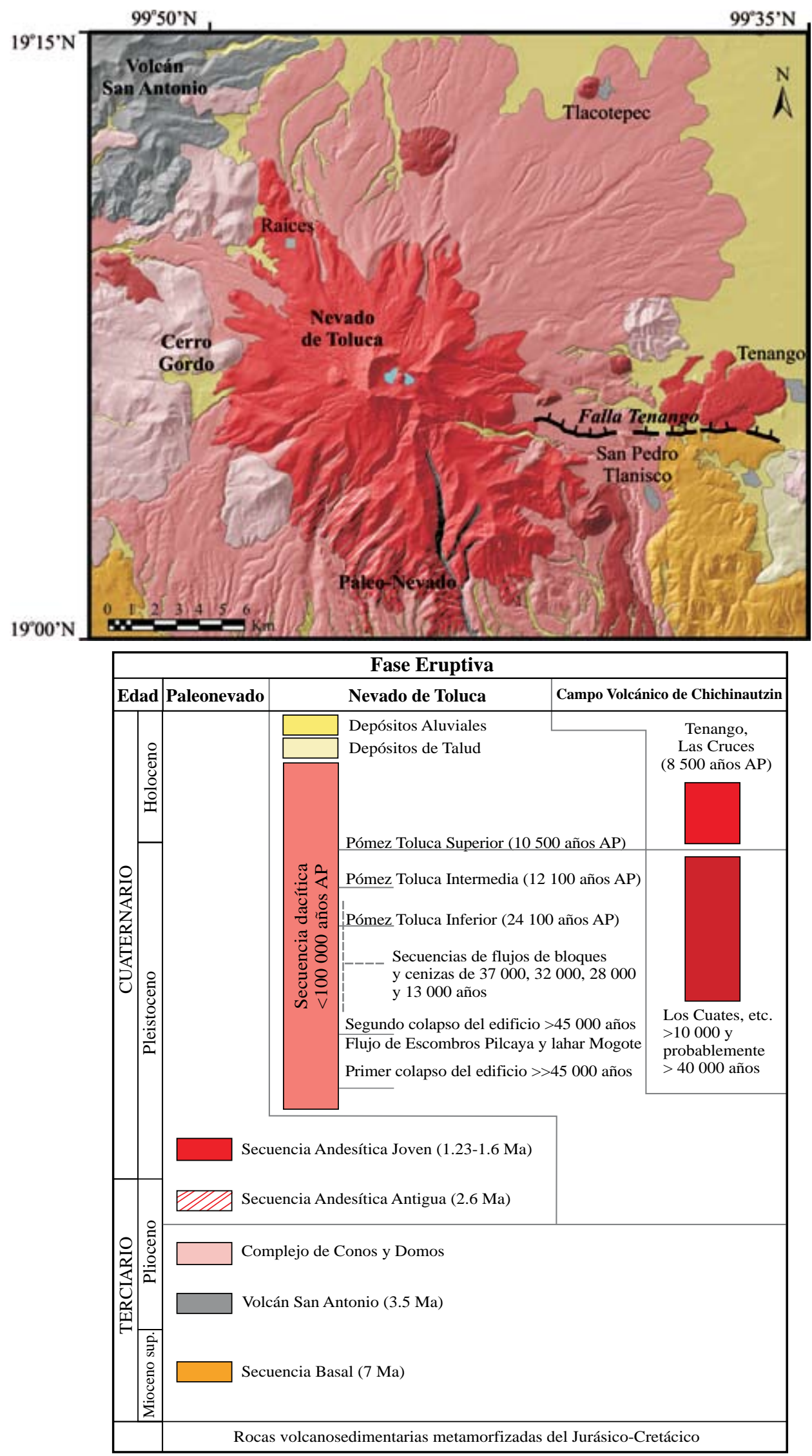

Figura 6. Mapa geológico simplificado del volcán Nevado de Toluca tomado de García-Palomo et al. (2002). En este mapa aparece la Secuencia Basal, el volcán San Antonio, las diferentes fases de formación del Nevado de Toluca y la porción occidental del campo volcánico de Chichinautzin. 
relativa con respecto a la cuenca del río Lerma de 2015 $\mathrm{m}$ y en su flanco sur de $2900 \mathrm{~m}$, considerando el poblado de Ixtapan de la Sal (Figura 5). El cráter del Nevado de Toluca está truncado (Figura 7a), tiene una forma elíptica con un diámetro de $2 \times 1.5 \mathrm{~km}$, con su eje mayor orientado en dirección E-W y una apertura en forma de herradura hacia el este. En el interior del cráter existen dos lagos llamados el Sol y la Luna, con una elevación de $4200 \mathrm{~m}$, separados por un domo dacítico central conocido como "El Ombligo" (Figura 7b). El agua de estos lagos tiene una composición alcalina (Armienta et al., 2000). Navajas de obsidiana y restos de cerámica prehispánica aparecen esparcidas en la superficie de El Ombligo y en las profundidades de los lagos, lugares en donde se realizaban ceremonias religiosas por los antiguos pobladores (matlazincas) y posteriormente por los aztecas (Quezada-Ramírez, 1972). Otro aspecto importante del cráter del NT y sus flancos son los vestigios de actividad glacial (depósitos de morrenas y glaciares rocosos) ocurrida durante el Pleistoceno tardío y el Holoceno (Heine, 1988; Aceves-Quezada, 1996; Vázquez-Selem y Heine, 2004).

\subsection{Estudios previos}

En los primeros estudios geológicos efectuados en el volcán Nevado de Toluca, se describió su morfología general y aspectos petrográficos (Ordoñez, 1902; Hovey, 1907; Flores, 1906; Waitz, 1909). Sin embargo, no fue hasta los años setenta cuando se realizaron los primeros estudios sobre la geología del Nevado de Toluca y su evolución vulcanológica (Bloomfield y Valastro, 1974; Bloomfield y Valastro, 1977; Bloomfield et al., 1977; Whitford y Bloomfield, 1977). Estos autores describieron dos erupciones de tipo pliniano que produjeron los famosos depósitos conocidos como la Pómez Toluca Inferior y la Pómez Toluca Superior, y que fecharon con el método de radiocarbono en 24000 y 11600 años AP. Asimismo, en estos estudios se estableció parte de su historia eruptiva reciente y el carácter calcialcalino de sus productos.

Posteriormente, Cantagrel et al. (1981) dividieron la evolución del NT en dos etapas principales. La más antigua compuesta por una serie de lavas andesíticas que conforman el edificio antiguo con edades obtenidas con el método de $\mathrm{K}$-Ar de $1.60 \pm 0.12$ y $1.23 \pm 0.15 \mathrm{Ma}$. La más joven consistía en una secuencia compleja de depósitos volcaniclásticos, sin diferenciar, que circundan el volcán. Estos depósitos en el flanco sur alcanzan espesores mayores de $100 \mathrm{~m}$, con una edad de 100000 años. Según estos autores, la actividad entre ambas etapas fue esencialmente volcaniclástica.

Después de estos estudios, el NT permaneció casi sin ser estudiado hasta la década de los noventa, cuando se iniciaron una serie de estudios encaminados a descifrar su ambiente estructural (García-Palomo et al., 2000), su geología e historia eruptiva (Macías et al., 1997a; García-Palomo et al., 2002), los depósitos producidos por erupciones de tipo pliniano (Arce et al., 2003; Arce et al., 2005b; Capra et al., 2006), los colapsos del edificio volcánico (Capra y Macías 2000), los aspectos geomorfológicos del volcán (Norini et al., 2004), los paleosuelos preservados entre los depósitos piroclásticos y su significado paleoambiental (Sedov et al., 2001; Sedov et al., 2003; Solleiro-Rebolledo et al., 2004) y estudios paleoambientales realizados en la cuenca del Alto Lerma (Metcalfe et al., 1991; Newton y Metcalfe, 1999; Caballero et al., 2001; Caballero et al., 2002; Lozano-García et al., 2005).

\subsection{Evolución del Nevado de Toluca}

Los resultados del estudio estructural (García-Palomo et al., 2000) indican que el NT se emplazó en la intersección de tres sistemas de fallas con orientaciones NW-SE, NE-SW y E-W; esta geometría estructural ha favorecido la formación de abanicos piroclásticos adyacentes con
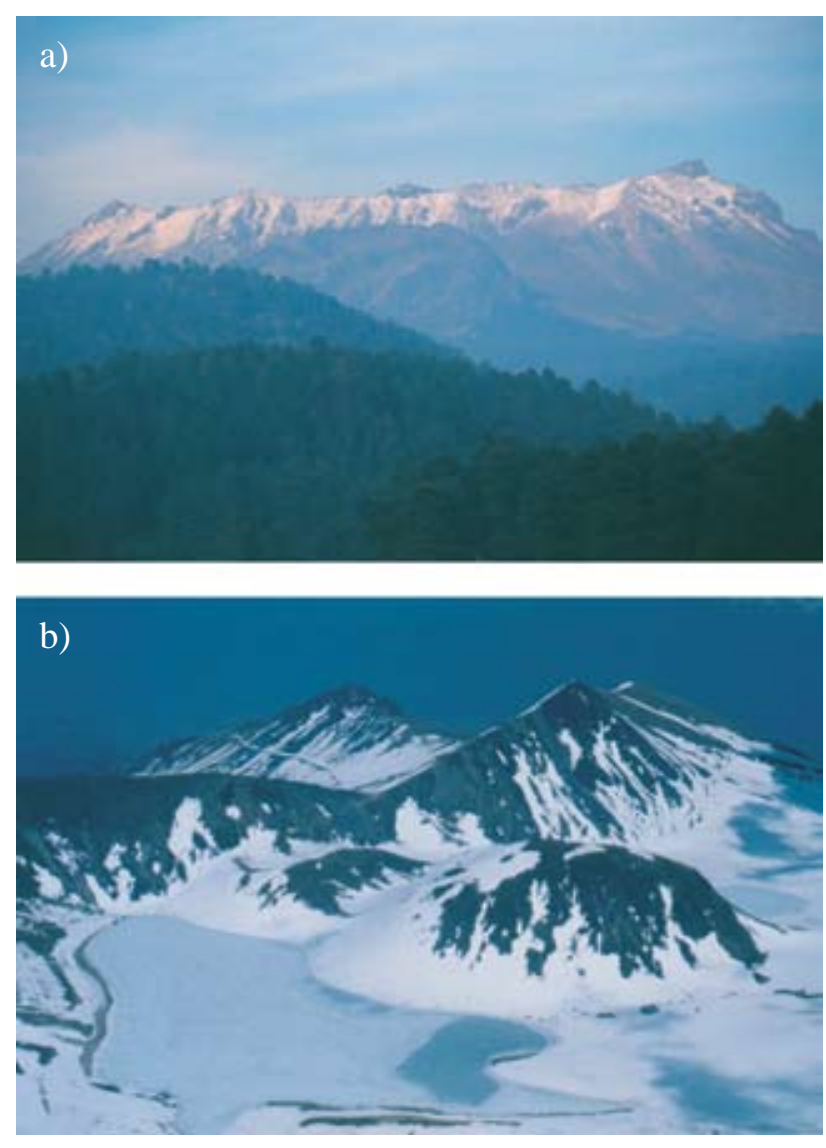

Figura 7. a) Vista del flanco occidental del volcán Nevado de Toluca que muestra su cráter truncado cuya elevación máxima está representada por el Pico del Fraile. Fotografía tomada en la carretera Toluca-Valle de Bravo por Jorge Neyra el 19 de mayo de 2001. b) Vista hacia el sureste del interior del cráter del Nevado de Toluca cubierto de nieve en enero de 1992. Aquí se aprecia el domo dacítico El Ombligo y el lago del Sol congelado que se encuentra a una elevación de $4230 \mathrm{~m}$. Al fondo se aprecia el cráter abierto hacia el este. Fotografía de Jorge Neyra. 
morfología suave en el flanco norte del volcán y el relleno de estructuras tipo graben en su flanco sur (García-Palomo, 1998; García-Palomo et al., 2002). La actividad volcánica en la región inició hace 1.6-1.3 Ma, con la formación de un aparato volcánico denominado Paleonevado, el cual estaba ubicado al S-SE del edifico actual (Cantagrel et al., 1981), aunque estudios recientes indican que esta actividad inició hace 2.6 Ma (Norini et al., 2004). El Paleonevado fue construido mediante el emplazamiento de lavas de composición andesítica hasta hace 1.2 Ma (García-Palomo et al., 2002; Norini et al., 2004). Entre 1.2 Ma y 0.1 Ma, el Paleonevado estuvo sujeto a una intensa actividad erosiva (Cantagrel $e t$ al., 1981) representada por lahares y sedimentos fluviales (Macías et al., 1997a; Capra y Macías, 2000) (Figura 8). La formación del edifico moderno del NT se inició hace aproximadamente $0.1 \mathrm{Ma}$ con la emisión de productos dacíticos que han dado lugar a actividad de tipo explosivo (Macías et al., 1997a; García-Palomo et al., 2002). Durante el Pleistoceno tardío, el flanco sur del edifico moderno del Nevado de Toluca colapsó en dos ocasiones, originando avalanchas de escombros que se han transformado en flujos de escombros con la distancia (Scott et al., 2001). Las cicatrices producidas por dichos colapsos han desaparecido debido tanto a la actividad volcánica subsiguiente como a la actividad glaciar.

El colapso más antiguo está representado por una avalancha de escombros (A1; Macías et al., 1997a), de color café claro, parcialmente litificada, con bloques con estructura de rompecabezas inmersos en una matriz de arena gruesa, y un espesor aproximado de $10 \mathrm{~m}$. Este depósito está distribuido en la región sur del Nevado de Toluca, hasta distancias mínimas de $35 \mathrm{~km}$ (Figura 5). Al colapso le siguió el emplazamiento de lahares y sedimentos fluviales y lacustres en pequeñas depresiones, durante un periodo de cientos a miles de años, aún sin determinar con precisión. Todavía durante el Pleistoceno tardío ocurrió un nuevo colapso del flanco sur del NT, el cual fue favorecido por la intensa alteración hidrotermal del edifico volcánico. $\mathrm{Su}$ origen y trayectoria fueron reconstruidos por Capra y Macías (2000). Este evento generó una avalancha de es-

\begin{tabular}{|c|c|c|c|}
\hline Espesor & $\begin{array}{l}\text { Edad } \\
(\mathbf{A P})\end{array}$ & Depósito & Descripción \\
\hline $1.5 \mathrm{~m}$ & $\sim 3.3 \mathrm{ka}$ & & Oleada piroclástica gris con estratificación cruzada y flujos de ceniza con carbón diseminado. \\
\hline $100 \mathrm{~m}$ & $8.5 \mathrm{ka}$ & & Derrame andesítico de lava (Tenango) del Campo Volcánico de Chichinautzin. \\
\hline $20 \mathrm{~m}$ & PTS & & Pómez Toluca Superior compuesto por tres miembros de caída intercalados con flujos piroclásticos y oleadas. \\
\hline $20 \mathrm{~m}$ & PTI $\sim 12.1 \mathrm{ka}$ & D & $\begin{array}{l}\text { Pómez Toluca Intermedia compuesta por tres depósitos de caída, oleadas piroclásticas y dos espesos flujos } \\
\text { piroclásticos de pómez. }\end{array}$ \\
\hline $5 \mathrm{~m}$ & FBC $\sim 14 \mathrm{ka}$ & & $\begin{array}{l}\text { Flujo de bloques y ceniza (FBC) de color gris masivo y oleadas piroclásticas con lapilli acrecional. El depósito } \\
\text { contiene bloques dacíticos juveniles. }\end{array}$ \\
\hline $3 \mathrm{~m}$ & PTI $24.5 \mathrm{ka}$ & & $\begin{array}{l}\text { Pómez Toluca Inferior compuesta por un depósito de caída gradado inversamente rico en pómez de color amarilla } \\
\text { y fragmentos de esquistos, cubierta por oleadas piroclásticas. }\end{array}$ \\
\hline $10 \mathrm{~m}$ & FBC $\sim 26.5 \mathrm{ka}$ & & FBC gris observado en pocos afloramientos. \\
\hline $10 \mathrm{~m}$ & FBC $\sim 28 \mathrm{ka}$ & +8 & $\begin{array}{l}\text { FBC gris masivo compuesto por al menos } 3 \text { unidades de flujo y oleadas piroclásticas. Los flujos están } \\
\text { compuestos por bloques dacíticos juveniles, pómez y líticos rojos alterados. }\end{array}$ \\
\hline $5 \mathrm{~m}$ & FBC $\sim 32 \mathrm{ka}$ & & $\begin{array}{l}\text { Flujo de ceniza compuesto por al menos tres unidades de flujo con carbón diseminado y oleadas piroclásticas } \\
\text { intercaladas. }\end{array}$ \\
\hline $10 \mathrm{~m}$ & FBC $\sim 37 \mathrm{ka}$ & & $\begin{array}{l}\text { FBC gris constituido por tres unidades masivas y escasas oleadas piroclásticas. Consiste de bloques juveniles de } \\
\text { dacita, líticos alterados rojos y pómez escasa. }\end{array}$ \\
\hline $3.5 \mathrm{~m}$ & $\sim 36-39 \mathrm{ka}$ & & $\begin{array}{l}\text { Depósito de caída de color ocre compuesto por tres capas interestratificadas con oleadas piroclásticas y cubiertas } \\
\text { por un flujo piroclástico masivo rico en pómez rosa y carbón. }\end{array}$ \\
\hline$\sim 4 \mathrm{~m}$ & $\sim 42 \mathrm{ka}$ & & $\begin{array}{l}\text { Flujo piroclástico de pómez compuesto por varias unidades de flujo. Los clastos incluyen pómez subredondeada } \\
\text { dacítica y escasos fragmentos andesíticos en una matriz de ceniza. }\end{array}$ \\
\hline $40 \mathrm{~m}$ & $\Gamma D$ & & $\begin{array}{l}\text { Flujo de detritos heterolitológico cohesivo (Pilcaya) compuesto por clastos de dacita y clastos exóticos del } \\
\text { basamento (basalto, caliza, areniscas) en una matriz endurecida. }\end{array}$ \\
\hline $15 \mathrm{~m}$ & DAD1 1 & & Avalancha de escombros compuesta por clastos de dacita en una matriz arenosa. \\
\hline $200 \mathrm{~m}$ & $\begin{array}{l}\text { Secuencia } \\
\text { Antigua }\end{array}$ & e & Secuencia interestratificada de capas de flujos de escombros, lahares, fluviales y lacustres escasos. \\
\hline $150 \mathrm{~m}$ & $1.2-1.6 \mathrm{Ma}$ & 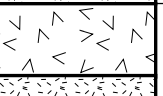 & Derrames de flujos de lava primitivos de composición andesítica-dacítica del Paleonevado. \\
\hline $100 \mathrm{~m}$ & $2.6 \pm 0.2 \mathrm{Ma}$ & & Derrames de lava porfiríticos de color gris. \\
\hline
\end{tabular}

Figura 8. Columna estratigráfica simplificada de los depósitos piroclásticos del Nevado de Toluca tomada de Macías et al. (1997) y García-Palomo et al. (2002). Los depósitos FDP y DAD1 representan los depósitos de dos antiguos colapsos ocurridos hacia el sur del volcán sobre los cuales descansan los depósitos piroclásticos dacíticos del Nevado de Toluca. 
combros (A2, Macías et al., 1997a), que inmediatamente se transformó en un flujo de escombros denominado "Pilcaya Debris Flow", el cual viajó hasta $55 \mathrm{~km}$ desde la cima. Este depósito es masivo, de color café claro con bloques dacíticos (algunos con estructura de rompecabezas) inmersos en una matriz de arena gruesa. El depósito Pilcaya descansa sobre un paleosuelo café claro y es sobreyacido por un depósito de lahar "El Mogote", originado a partir del flujo de escombros Pilcaya. Por su posición estratigráfica se le asigna una edad tentativa $>40000$ años.

La actividad del NT durante el Pleistoceno tardío prosiguió con explosiones de gran magnitud que produjeron flujos piroclásticos de pómez de color rosa y color blanco, en todas direcciones alrededor del volcán. Uno de estos depósitos contiene material carbonizado con una edad de 42000 años. Estos depósitos generalmente están expuestos en la base de varias barrancas alrededor del NT y son cubiertos por depósitos de flujos de bloques y ceniza fechados en 37000 años. El NT ha tenido una actividad muy intensa durante los últimos 50000 años, por una parte con erupciones que han causado la destrucción total o el colapso parcial de domos dacíticos y por otra, con la generación de columnas plinianas que han depositado secuencias espesas de caída.

\subsection{Destrucción parcial o total de domos}

Los depósitos de flujos de bloques y ceniza producidos por las erupciones asociadas a la destrucción de domos fueron reconocidos como "old lahar assemblages" (Bloomfield y Valastro, 1974, 1977) о "nueés ardentes" (Cantagrel et al., 1981). Bloomfield y Valastro (1977) estimaron la edad de estos depósitos en 28000 años AP, con base en la edad de ${ }^{14} \mathrm{C}$ de un paleosuelo que cubre el depósito. Sin embargo, Macías et al. (1997a) identificaron dos depósitos de flujos de bloques y cenizas, el depósito antiguo lo fecharon en $37000 \pm 1125$ años y lo correlacionaron con el depósito denominado "gray lahar" (Heine, 1988) fechado en $35600+2600 /-1800$ años y que está subyacido por un paleosuelo fechado en 38000 años (Cantagrel et al., 1981). El flujo de bloques y cenizas joven fue fechado en $28140+865 /-780$ y $28925+625 /-580$ años; estas fechas se correlacionan con la edad de $27580 \pm 650$ años, fechada en una grava fluvial encima del depósito por Bloomfield y Valastro (1977). Estudios posteriores mostraron que existen al menos cinco depósitos de flujos piroclásticos de bloques y ceniza con edades de 37, 32, 28, 26 y 14 ka (GarcíaPalomo et al., 2002). El depósito de 14 ka, también aparece en el registro estratigráfico del lago de Chiconahuapan (Newton y Metcalfe, 1999; Caballero et al., 2001; 2002). Los cinco depósitos de flujos de bloques y cenizas tienen una distribución amplia alrededor del Nevado de Toluca y alcanzan distancias mínimas de $25 \mathrm{~km}$ con espesores aún considerables. Los depósitos más extensos son aquellos de 37, 28 y 14 ka AP (Figura 9). Éstos son de color gris, masivos de hasta $30 \mathrm{~m}$ de espesor con conductos de desgasificación y leña carbonizada; generalmente consisten de varias unidades de flujo. Estos flujos están compuestos por líticos juveniles con pocos líticos con alteración hidrotermal, escasa pómez y obsidiana. Los líticos juveniles de estos depósitos tienen una composición química uniforme, con un rango en la concentración de sílice que va de 65 a $67 \%$ en peso.

\subsection{Erupciones plinianas}

Los primeros estudios sobre la estratigrafía del NT fueron dedicados precisamente a dos erupciones plinianas muy bien registradas en los flancos del NT y en la cuenca del Lerma. Estos depósitos fueron denominados por Bloomfield y Valastro (1974, 1977) como: Pómez Toluca Inferior (PTI) de 24500 años AP y Pómez Toluca Superior (PTS) de $\sim 11600$ años AP. Estas erupciones fueron fechadas mediante paleosuelos y material carbonizado encontrado por debajo de los depósitos, pero nunca con material encontrado dentro. Sin embargo, estudios detallados recientes indican que la edad de estas erupciones es ligeramente más joven, 21 700 años AP para la PTI (Capra et al., 2006) y 10500 años AP para la PTS (Arce-Saldaña, 2003; Arce et al., 2003). Posteriormente, se reconocieron los depósitos de una erupción fechada en $~ 12100$ años denominada inicialmente como "White Pumice Flow" por Macías et al. (1997a) y que fue estudiada con más detalle (Cervantes-de la Cruz, 2001; Arce et al. 2005b) y designada como Pómez Toluca Intermedia. Además, GarcíaPalomo et al. (2002) reconocieron otro depósito de caída de tipo pliniano que fue nombrado Pómez Ocre, fechado en >36 000-37 000 años AP. De estos cinco eventos eruptivos producidos en el cráter del NT, cuatro han sido estudiados con detenimiento y se resumen a continuación:

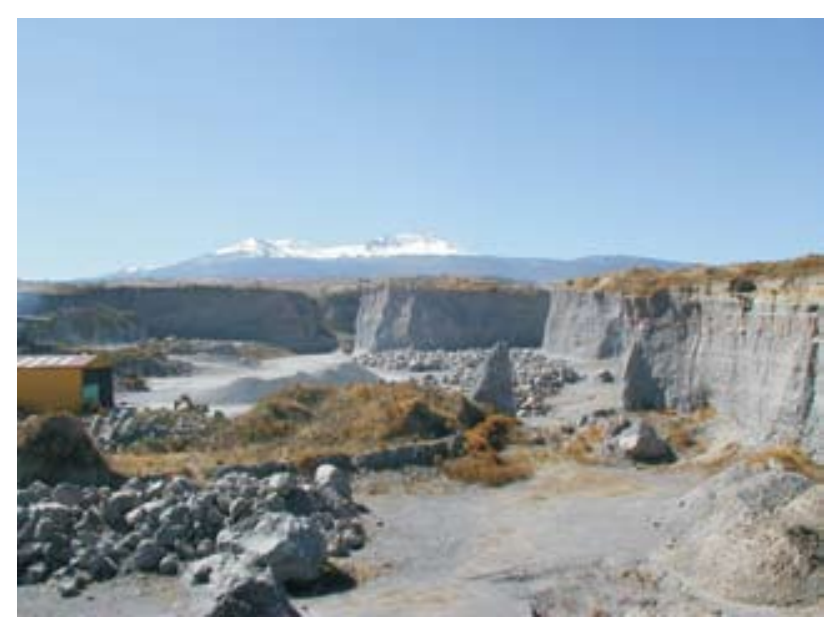

Figura 9. Cantera El Refugio localizada a $15 \mathrm{~km}$ al NE del cráter del Nevado de Toluca en donde están expuestos los flujos de bloques y cenizas (FBC) de la erupción ocurrida hace 37000 años. 
La Pómez Toluca Inferior ( 21 700 años) fue originada a partir de una columna pliniana que alcanzó $24 \mathrm{~km}$ de altura, para después ser dispersada hacia el NE. La erupción fue seguida por varios pulsos subplinianos y explosiones hidromagmáticas que produjeron un volumen total de 2.3 $\mathrm{km}^{3}\left(0.8 \mathrm{~km}^{3}\right.$ de DRE, Roca Densa Equivalente por sus siglas en inglés). Esta erupción es muy particular en la historia eruptiva del NT por dos razones: en primer lugar incorporó fragmentos de esquistos del basamento, y en segundo la pómez tiene una composición química que varía de andesita $55 \%$ a dacita $65 \%$ en peso de $\mathrm{SiO}_{2}$. Las pómez andesíticas representan el magma más básico emitido por el NT durante los últimos 50000 años (Capra et al., 2006).

La Pómez Toluca Intermedia ( 12 100 años) generó inicialmente una columna pliniana de $20 \mathrm{~km}$ de altura, cuya pluma eruptiva fue transportada por los vientos dominantes hacia el NE. La columna fue interrumpida por explosiones hidromagmáticas que favorecieron el establecimiento de una columna subpliniana (18-19 km de altura), que se desvaneció con el tiempo. La secuencia estratigráfica de la Pómez Toluca Intermedia indica que las fases finales de la erupción formaron columnas eruptivas que fueron interrumpidas por explosiones hidromagmáticas que generaron oleadas piroclásticas y finalmente el colapso de la columna con la formación de flujos piroclásticos ricos en pómez, por los cuales Macías et al. (1997a) habían denominado a este depósito como "White Pumice Flow". La erupción Pómez Toluca Intermedia generó $1.8 \mathrm{~km}^{3}$ (DRE) de magma dacítico con una composición química homogénea (63.54$65.06 \%$ en peso de $\mathrm{SiO}_{2}$ ). Su asociación mineralógica está representada por fenocristales de plagioclasa $>$ ortopiroxen $\mathrm{o}>$ hornblenda \pm ilmenita y titanomagnetita y xenocristales de biotita, todo embebido en una matriz de composición riolítica (70-71\% en peso de $\mathrm{SiO}_{2}$ ). Los xenocristales de biotita se encontraron en reacción con la matriza riolítica; algunos de estos cristales fueron fechados con el método ${ }^{40} \mathrm{Ar} /{ }^{39} \mathrm{Ar}$, arrojando una edad superior a los $0.8 \mathrm{Ma}$, lo que indica que fueron asimilados de la cámara magmática o del substrato rocoso (Arce et al., 2005a).

Pómez Toluca Superior ( 10500 años) fue una erupción compleja que tuvo cuatro columnas plinianas PC0, PC1, PC2 y PC3, que alcanzaron alturas de 25, 39, 42, y 28 $\mathrm{km}$ por encima del cráter, respectivamente, y que fueron dispersadas por los vientos dominantes en dirección $\mathrm{NE}$ (Figura 10). Las últimas tres columnas eruptivas fueron interrumpidas por explosiones hidromagmáticas en el cráter, que causaron la generación de oleadas piroclásticas y el colapso de las columnas con la formación de flujos piroclásticos de pómez. Las caídas $\mathrm{PC} 1$ y PC2, cubrieron un área mínima de $2000 \mathrm{~km}^{2}$, superficie actualmente ocupada por las ciudades de Toluca y México con un volumen de $14 \mathrm{~km}^{3}$ ( $\sim 6 \mathrm{~km}^{3}$ DRE). En la cuenca de México, la PTS fue descrita inicialmente como la pómez tripartita (Mooser, 1967). La composición química del magma de esta erupción fue muy homogénea, dado que varió de 63 a $66 \%$ en peso de sílice (Arce et al., 2003).

\subsection{Profundidad de la cámara magmática}

La composición química homogénea del magma emitido y la similitud mineralógica encontrada en los productos juveniles de las erupciones de 14000 años (flujo de bloques y cenizas), de 12100 años (Pómez Toluca Intermedia) y de 10500 años (PTS), indican que el magma arrojado por el NT podía provenir de una sola cámara magmática, rellenada con un magma de composición dacítica (Arce et al., 2005b). Con esta premisa, estos autores determinaron la composición química de los minerales en las pómez de las tres erupciones que efectivamente resultó ser muy similar y que consiste en plagioclasa $\left(\mathrm{An}_{30-59}\right)>$ ortopiroxeno $\left(\mathrm{En}_{56-59}\right)>$ hornblenda (edenita-hornblenda principalmente) $>>$ óxidos de Fe$\mathrm{Ti}+$ escaso apatito (en ortopiroxeno)+biotita, embebidos en una matriz riolítica (72-76 $\mathrm{SiO}_{2} \%$ en peso). Con la presencia de los óxidos de hierro y titanio (ilmenita y titanomagnetita), se determinaron temperaturas de equilibrio de los magmas antes de las erupciones, las cuales oscilaron en torno a $850{ }^{\circ} \mathrm{C}$ y fugacidades de oxígeno igual a -11 . Con esta información se realizaron estudios de petrología experimental con muestras naturales que definieron los campos de estabilidad de los minerales y, por ende, las condiciones de equilibrio de estos magmas antes de la erupción (presión y temperatura). De esta forma, se

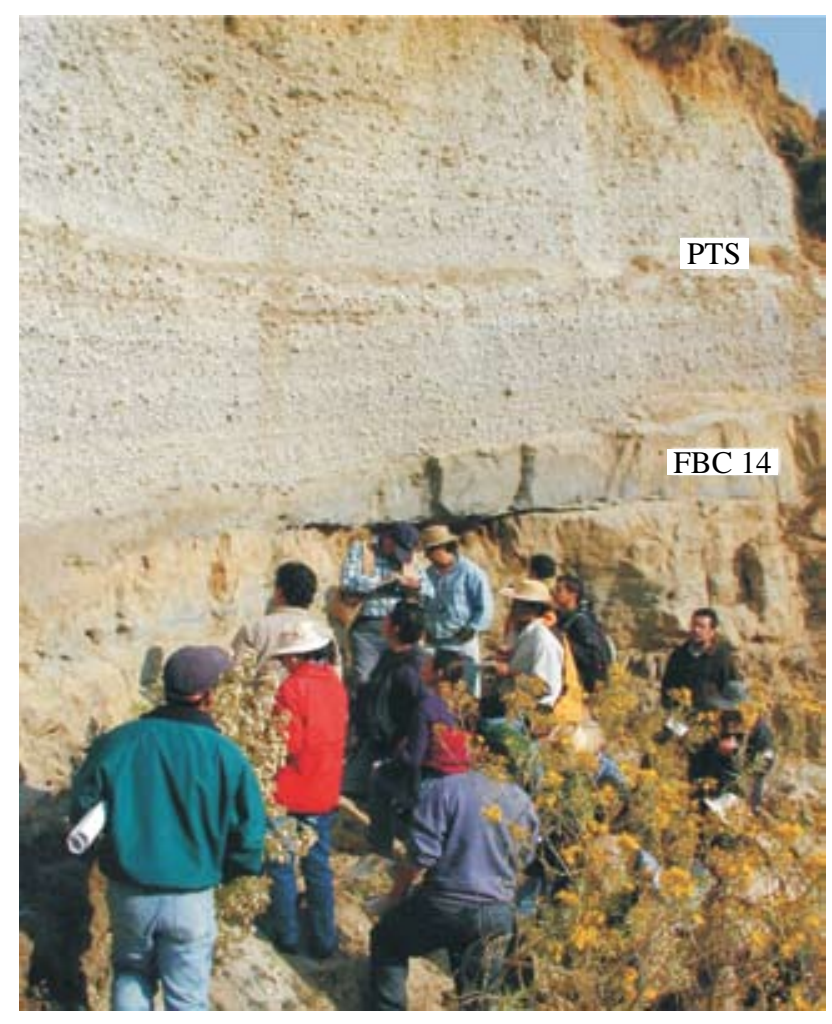

Figura 10. Afloramiento ubicado a $15 \mathrm{~km}$ al noreste del cráter del Nevado de Toluca en donde están expuestos los flujos de bloques y cenizas (FBC en la Figura 8) de la erupción ocurrida hace 14000 años y la caída de la Pómez Toluca Superior (PTS) 
sabe que durante el periodo eruptivo de 14 a $10.5 \mathrm{ka}$ años existía una sola cámara magmática, la cual se encontraba ubicada a $\sim 6 \mathrm{~km}$ de profundidad por debajo del cráter del NT (Figura 11).

La historia holocénica del NT se limita a: 1) la extrusión del domo dacítico El Ombligo, en el cráter del volcán. Las estrías de pulimento glaciar en las rocas del domo indican que éste tiene una edad mínima de $9100 \pm 500$ años AP, la cual fue determinada con el método de ${ }^{36} \mathrm{Cl}$ (Arce et al., 2003). Por lo tanto, es muy probable que este domo haya sido emitido al finalizar la erupción de la PTS o poco tiempo después. 2) La última erupción del NT tuvo lugar hace $\sim 3300{ }^{14} \mathrm{C}$ años $\mathrm{AP}$, en alguna parte del cráter central (Macías et al., 1997a), la cual emitió un flujo piroclástico y una oleada piroclástica que fueron emplazadas en el flanco NE del volcán. Esta erupción holocénica ubica al NT como un volcán activo en estado de quietud. 3) Una serie de lahares de color amarillo, que cubren a toda la secuencia volcánica del NT.

\section{Volcán Popocatépetl}

El volcán Popocatépetl se sitúa a unos $65 \mathrm{~km}$ al sudeste de la Ciudad de México y a unos $45 \mathrm{~km}$ al oeste de la ciudad de Puebla (Figuras 1 y 12). Se estima que en un radio de $40 \mathrm{~km}$ alrededor del volcán habitan 1 millón de personas. El volcán forma el extremo sur de la Sierra Nevada compuesta por los volcanes Tláloc, Telapón, Teyotl, Iztaccíhuatl y Popocatépetl. Popocatépetl significa en lengua náhuatl "la Montaña que humea"; esto alude al hecho de que durante la época prehispánica, los aztecas lo observaron en diversas ocasiones en actividad como en 1363, 1509, 1512, y 1519-1528; esta última ocurrió durante y después de la conquista, por lo que incluye descripciones de Bernal Díaz

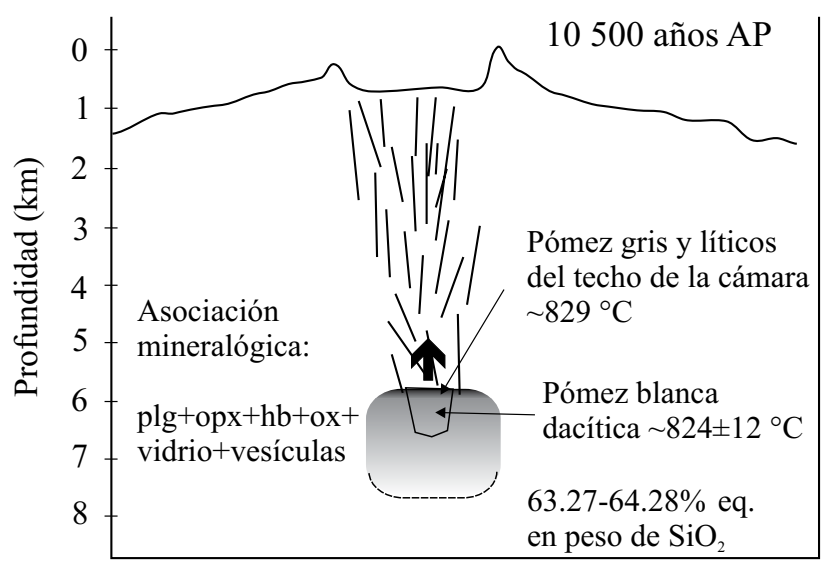

Figura 11. Esquema que muestra la posición de la cámara magmática del Nevado de Toluca hace 10500 años antes de la erupción que emitió a la Pómez Toluca Superior. El magma dacítico de la PTS se encontraba a una temperatura aproximada de $860{ }^{\circ} \mathrm{C}$ y estaba estacionado a unos 6 $\mathrm{km}$ por debajo del cráter.

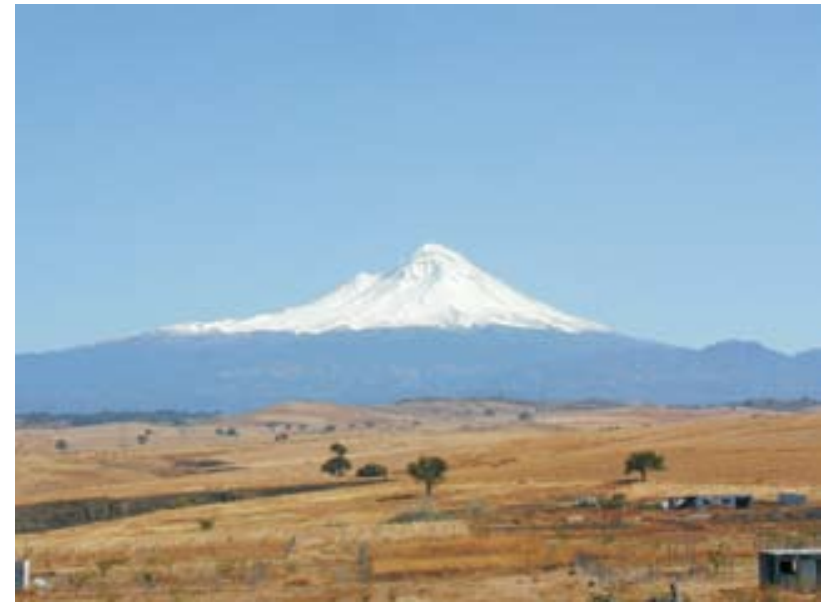

Figura 12. Vista panorámica del flanco sur del volcán Popocatépetl cubierto de nieve hasta una altura aproximada de $4000 \mathrm{~m}$ (línea de árboles). Esta imagen muestra las planicies del estado de Puebla con una topografía ondulada de montículos de uno de los depósitos de avalancha.

y Gomarra (De la Cruz-Reyna et al., 1995). Durante la Colonia existen numerosas menciones de eventos menores del Popocatépetl, como en 1530, 1539, 1540, 1548, 15621570, 1571, 1592, 1642, 1663, 1664, 1665, 1697, у 1720. Durante el siglo XIX, varios científicos visitaron el volcán entre otros von Humboldt en 1804 (Humboldt, 1862) y los geólogos Del Río en 1842, Del Castillo en 1870 y Sánchez en 1856, quienes realizaron descripciones generales de su morfología.

Desde 1895, Aguilera y Ordóñez (1895) identificaron al Popocatépetl como un estratovolcán con un cráter truncado, compuesto por una alternancia de depósitos piroclásticos y lavas de composición andesítica de hiperstena y hornblenda. En 1896, estos mismos autores, señalaron que existían siete fumarolas principales en el cráter del Popocatépetl con temperaturas inferiores a $100{ }^{\circ} \mathrm{C}$ y un lago, de color azul verdoso, formado por agua de los deshielos y con una temperatura variable entre 28 y $52{ }^{\circ} \mathrm{C}$. Weitzberg (1922) estudió de manera detallada el glaciar del Popocatépetl (Ventisquero). En 1906, el fondo del cráter lucía como un embudo con paredes verticales con un lago en el fondo.

El Popocatépetl despertó nuevamente en febrero de 1919. En marzo-abril de ese mismo año, varios lugareños observaron que en el fondo del cráter había un montón de piedras que parecía una "cazuela volteada" (Atl, 1939). El 11 de octubre de 1920, Waitz visitó el cráter y describió que en el fondo había un "tapón" de lava. El 15 de noviembre de 1921, Camacho y Friedlaender fotografiaron el interior del cráter y observaron una cúpula de lava (domo de lava), en torno a la cual surgían emanaciones de gas y algunas explosiones esporádicas del domo (Friedlaender, 1921; Camacho, 1925). En enero de 1922, el mismo Camacho observó que en el lugar del domo central, existía un cráter. Atl (1939) documentó detalladamente la erupción y la evolución del cráter; este autor sugiere que la erupción concluyó 
en 1927. El Popocatépetl se mantuvo tranquilo durante 67 años para reactivarse el 21 de diciembre de 1994.

\subsection{Estudios previos}

Los únicos estudios geológicos realizados antes de su reactivación en 1994, fueron los de Heine y Heide-Weise (1973), Miehlich (1984), Robin (1984), Carrasco-Núñez (1985) y Boudal y Robin (1989), así como algunos estudios petrológicos (Boudal 1985; Boudal y Robin 1987; Kolisnik, 1990). En estos trabajos se define al Popocatépetl como un estratovolcán y se presenta la estratigrafía de sus depósitos más recientes, con la ayuda de fechamientos de ${ }^{14} \mathrm{C}$.

La evolución geológica del Popocatépetl se puede resumir en las siguientes etapas:

1) El primer edificio formado fue el volcán Nexpayantla (Mooser et al., 1958) o volcán primitivo (Robin, 1984), mediante la emisión de una serie de derrames andesíticos y dacíticos. Una erupción ocurrida hace 200000 años produjo el colapso de una parte de este volcán y la formación de una caldera. Al interior de esta caldera inició la construcción de un nuevo volcán conocido como El Fraile, a través del emplazamiento de derrames andesíticos y dacíticos. Este último volcán colapsó hace 50000 y 30000 años AP, según Boudal y Robin (1989), debido a una erupción tipo Bezymiany, la cual destruyó la parte meridional del volcán. Estos autores estimaron un volumen excesivo para este depósito de $28 \mathrm{~km}^{3}$. La erupción generó una avalancha de escombros, que se emplazó hacia el S-SW del cráter y fue seguida por la formación de una erupción pliniana, que depositó una pómez de caída de color blanco hacia el sur del volcán y flujos piroclásticos. Después de este evento, inició la formación del cono moderno conocido como Popocatépetl. La mayor parte de los estudios geológicos realizados durante la última década han sido impulsados por la reactivación del Popocatépetl (Siebe et al., 1995a, 1995c, 1996a, 1996b, 1997; Espinasa-Pereña y Martín-del Pozzo, 2006). Los trabajos sobre la estratigrafía y distribución de los depósitos del Popocatépetl han arrojado datos sorprendentes, los cuales son resumidos a continuación:

\subsection{Destrucción del cono antiguo del Popocatépetl}

Hace aproximadamente 23000 años, una erupción lateral de magnitud superior a la ocurrida el 18 de mayo de 1980 en el volcán Santa Elena (Estados Unidos), produjo el colapso hacia el sur del antiguo cono del Popocatépetl (Figura 13). La explosión generó una avalancha de escombros que alcanzó distancias hasta de $70 \mathrm{~km}$ de la cima. La descompresión del sistema magmático, debido al colapso, produjo una explosión lateral dirigida (blast) que emplazó una oleada piroclástica y permitió la formación de una columna pliniana (Figura 14). Esta columna depositó una gruesa capa de caída de pómez, ampliamente distribuida en los flancos meridionales del volcán. La columna colapsó por gravedad y depositó un flujo de ceniza. Material carbonizado en un paleosuelo debajo del depósito de avalancha arrojó una edad de $23445 \pm 210$ años; mientras que ramas carbonizadas inmersas en el depósito de flujo de ceniza arrojaron una edad de $22875+915 /-820$ años, por lo que la edad de este evento es estimada en 23000 años. Robin y Boudal (1987) supusieron la existencia de este depósito de avalancha expuesto hasta $30 \mathrm{~km}$ de la cima, cubriendo una superficie de $300 \mathrm{~km}^{2}$ con un volumen de $28 \mathrm{~km}^{3} \mathrm{y}$ una edad menor a 50000 años. Sin embargo, hasta este momento se ha reportado la existencia de al menos cuatro depósitos de avalancha alrededor del Popocatépetl y no sólo uno, como fue propuesto por estos autores. El más antiguo proviene del colapso de la porción sur del volcán Iztaccíhuatl y los tres más jóvenes del colapso del paleoPopocatépetl (Siebe et al. 1995b; García-Tenorio, 2002). El depósito más joven (23 000 años) es el referido por Robin et al. (1987), este depósito de avalancha alcanzó distancias mínimas de $70 \mathrm{~km}$ y cubre un área aproximada de $900 \mathrm{~km}^{2}$. Si se le asigna un espesor promedio de $15 \mathrm{~m}$, se obtiene un volumen mínimo de $9 \mathrm{~km}^{3}$.

\subsection{Construcción del cono actual}

El cono actual del Popocatépetl ha sido construido durante los últimos 23000 años, tiene una elevación sobre el nivel del mar de $5472 \mathrm{~m}$ y una elevación relativa respecto a sus faldas de $3000 \mathrm{~m}$. Está edificado por una serie de depósitos piroclásticos y coladas de lava de composición andesítica-dacítica, cuyos fragmentos juveniles están compuestos por fenocristales de plagioclasa, hiperstena, augita, olivino y escasa hornblenda, en una matriz vítrea microcristalina.

Durante los últimos 20000 años, la actividad explosiva del Popocatépetl ha sido caracterizada por cuatro eventos mayores, con producción de pómez de caída y flujos de ceniza (14 000, 5 000, 2150 y 1100 años AP) y cuatro menos expuestos, ocurridos hace $11000,9000,7000$ y 1 800 años AP (Siebe et al., 1997; Siebe y Macías, 2004). La historia geológica del Popocatépetl para los últimos 20000 años se puede sintetizar de la siguiente forma:

4. Erupción freatopliniana $\sim 14000$ años (Pómez con Andesita o Tutti Fruti)

Un evento de gran magnitud, que generó una serie de flujos piroclásticos y oleadas (surges) en zonas proximales, culminó con la formación de una columna pliniana, la cual fue dispersada por los vientos estratosféricos hacia el noroeste en dirección de la Ciudad de México (Siebe et al., 1995b, 1997). Este horizonte de caída contiene pómez dacítica de color anaranjado, fragmentos de granodiorita gris, limolitas metamorfizadas, skarns y otros fragmentos del basamento. Posiblemente este evento se originó en un cráter lateral, situado en la actual barranca de Nexpayantla. Este depósito de caída fue descrito en la cuenca de la Ciudad 


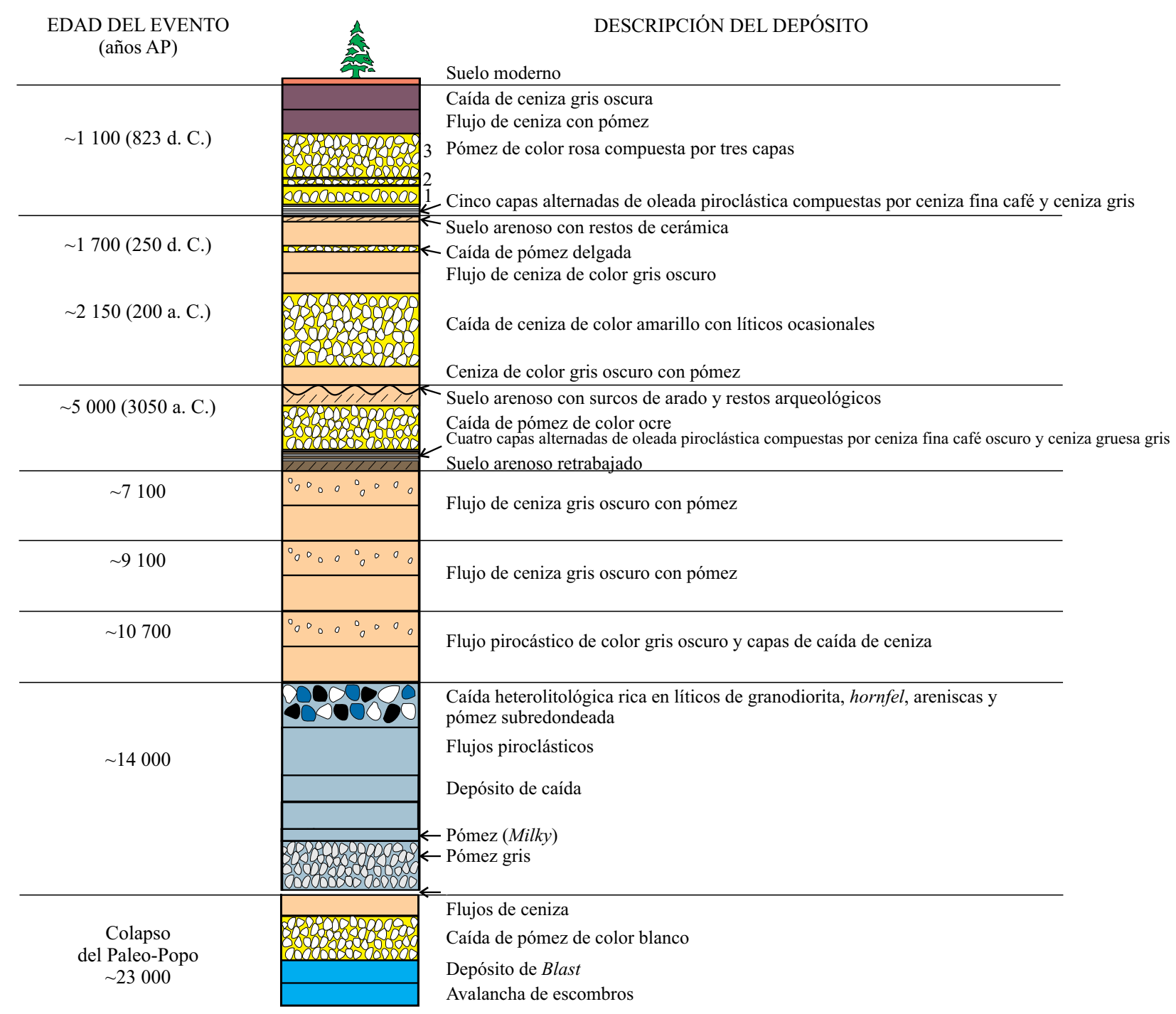

Figura 13. Columna estratigráfica simplificada del volcán Popocatépetl que muestra los depósitos emplazados a partir del último colapso del cono ocurrido hace 23000 años (Siebe et al., 1995; Siebe y Macías, 2004).

de México como "Pómez con andesita" por Mooser (1967), con un espesor de $5 \mathrm{~cm}$. Este depósito está ampliamente distribuido en los alrededores del volcán y por lo regular no contiene material carbonizado. El único fechamiento de material orgánico, encontrado en la base de este depósito, dio una edad aproximada de 14000 años. Esto implica que durante esta erupción el Popocatépetl estaba cubierto por un glaciar y en sus faldas existía poca vegetación.

\subsection{Erupciones plinianas recientes}

Se han identificado tres eventos plinianos principales, los cuales ocurrieron hace aproximadamente 5000,2150 y 1100 años AP (Figura 15). Los eventos ocurridos hace 5000 y 1100 años tuvieron una evolución muy similar; iniciaron con erupciones hidromagmáticas bastante violentas que dispersaron nubes turbulentas húmedas tipo surge a distancias mínimas de $20 \mathrm{~km}$ Estos eventos abrieron el conducto volcánico y permitieron que el magma fuera emitido a grandes velocidades para formar una columna pliniana que alcanzó alturas mínimas de $25 \mathrm{~km}$ (Siebe et al., 1996a, 1996b), para después ser transportada por los vientos estratosféricos en dirección N-NE-E. En los tres casos, las columnas plinianas se colapsaron debido al agotamiento del material juvenil en la cámara magmática. El colapso de las columnas eruptivas produjo flujos piroclásticos incandescentes de cenizas que se emplazaron alrededor del volcán y fueron capaces de carbonizar el material encontrado a su paso. Estas erupciones bloquearon la red hidrográfica del Popocatépetl y del Iztaccíhuatl, por lo que lluvias torrenciales durante y después de la erupción generaron lahares, que se depositaron en las planicies cercanas (cuenca de Puebla). 


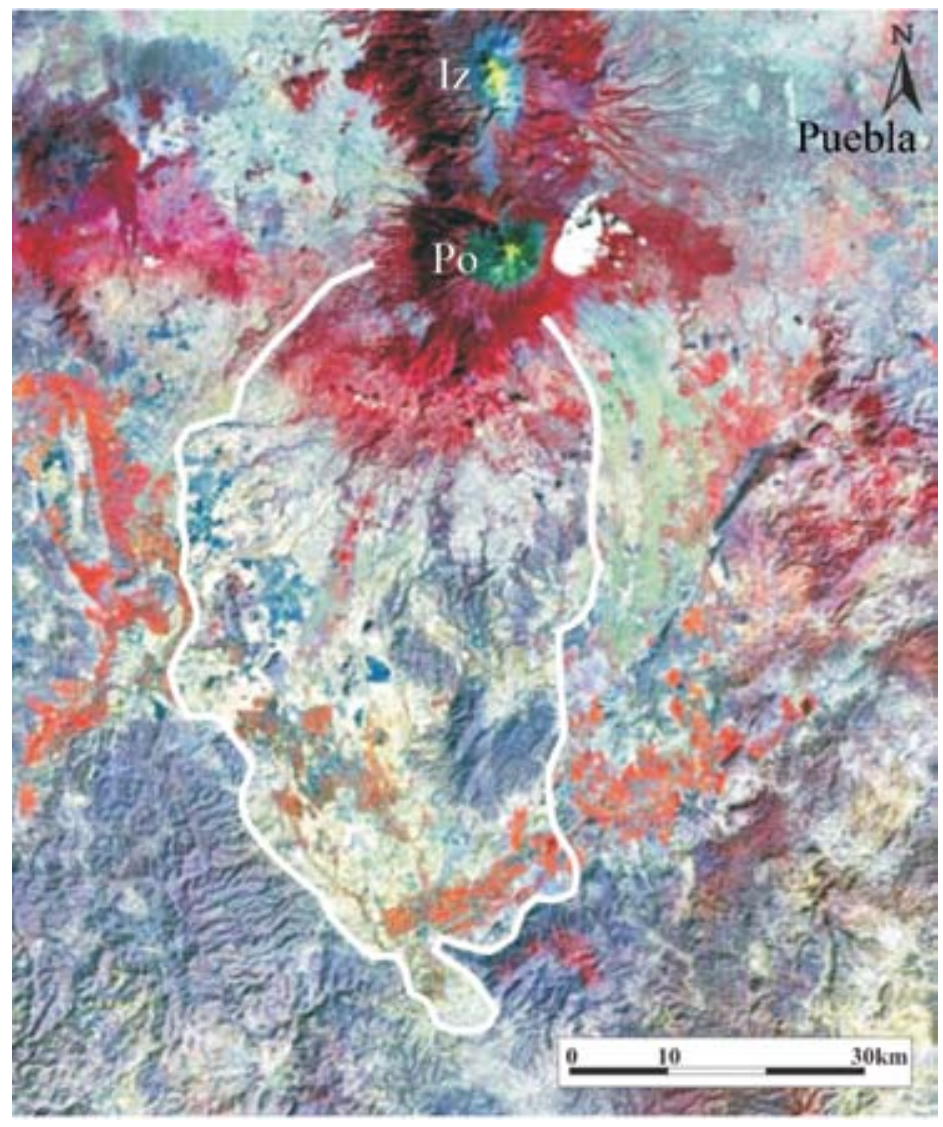

Figura 14. Imagen de satélite tipo LANDSAT que muestra a los volcanes Iztaccíhuatl (Iz) y Popocatépetl (Po) junto con la distribución de las avalanchas de escombros según Siebe et al. (1995b) (tomado de Capra et al., 2001).

Contemporáneamente a las erupciones explosivas o en etapas intermedias, el Popocatépetl ha producido actividad de tipo efusivo: flujos de lava originados en el conducto central, los cuales constituyen la morfología del cráter actual, y flujos de lava fisurales de composición andesítica (Schaaf et al., 2005; Espinasa-Pereña y Martín-del Pozzo, 2006) como aquellos que estuvieron asociados a la erupción acontecida hace 2150 años, localizados cerca de San Nicolás de Los Ranchos.

\subsection{Efectos de las erupciones}

Las erupciones plinianas del Popocatépetl desde tiempos prehispánicos han afectado los asentamientos humanos alrededor del volcán, ya sea directamente con la generación de flujos incandescentes y el emplazamiento de gruesos espesores de material caliente de pómez y ceniza, o indirectamente con la generación de lahares, que inundaron extensas áreas situadas en la cuenca de Puebla (Siebe et al., 1996a, 1996b). Las últimas tres erupciones plinianas del Popocatépetl coinciden con eventos importantes de la historia de Mesoamérica: La erupción ocurrida hace 5000 años (3195-2830 a. C.) coincide con la fecha 3114 a. C. del inicio del Calendario Mesoamericano, la erupción que ocurrió hace 2150 años (800-215 a. C.) coincide con la transición Pre-Clásico al Clásico de la arqueología mexicana y la última, ocurrida hace 1100 años (675-1095 d. C. probablemente $823 \mathrm{~d}$. C.), también coincide con la transición de los periodos Clásico al Post-Clásico (Figura 16).

La erupción pliniana ocurrida hace 2150 años depositó un horizonte de caída, rico en pómez en el flanco noreste del volcán, sepultando hasta con $1 \mathrm{~m}$ de espesor asentamientos prehispánicos que se encontraban en esta región (Seele, 1973). Estos asentamientos se conocen como Tetimpa (Plunket y Uruñuela, 1999, 2000, 2005).

El evento pliniano ocurrido hace 1100 años fue muy similar al anterior, ya que afectó directamente a poblaciones prehispánicas. Sin embargo, el hecho más sorprendente fue el hallazgo de depósitos de lahar, circundando importantes sitios arqueológicos de edad Clásica (Cholula, Cacaxtla y Xochitécatl). Los depósitos de lahar están compuestos por los mismos componentes de los depósitos piroclásticos en partes más cercanas al volcán y contienen abundantes fragmentos de cerámica, esquirlas de obsidiana y leña carbonizada, cuyas edades concuerdan con el último evento pliniano del Popocatépetl (675-1 095 d. C.) en una fecha aproximada de 823 d. C. El abandono del centro ceremo- 


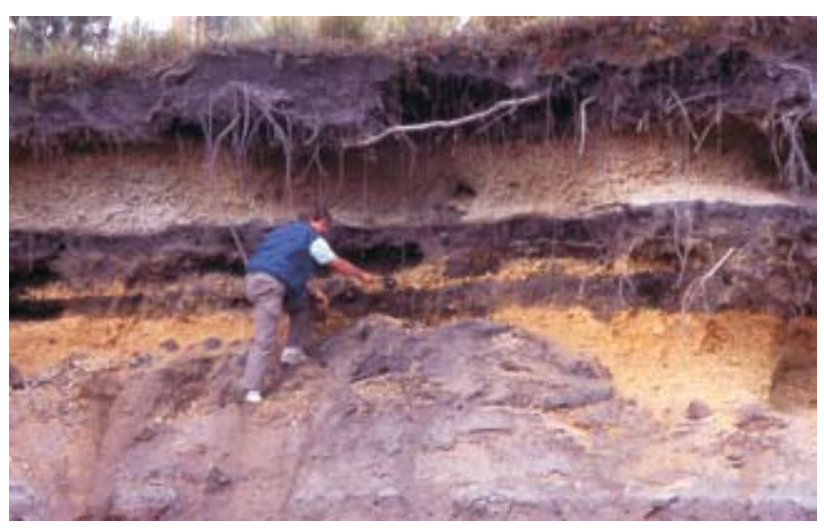

Figure 15. Fotografía que muestra los depósitos de las últimas tres erupciones plinianas del volcán Popocatépetl ocurridas hace 5 000, 2150 y 1100 años la cuales están separadas por paleosuelos. C. Siebe señala el depósito de la erupción ocurrida hace 2150 años.

nial de Cholula se cree que ocurrió alrededor de $800 \mathrm{~d}$. C. (Suárez-Cruz y Martínez-Arreaga, 1993), lo que coincide con el rango de edades obtenidas por Siebe et al. (1996a, 1996b).

\subsection{La erupción de 1994-2006}

Después de un periodo de 67 años de quietud, el Popocatépetl despertó de su letargo el día 21 de diciembre de 1994 con la emisión de columnas de ceniza, vapor de agua y gases que se elevaban hasta alturas de 2 a $3 \mathrm{~km}$ Estas emisiones provenían de pequeñas bocas eruptivas alineadas, que se localizaban en la parte este del interior del cráter. Esta serie de eventos continuaron esporádicamente hasta fines de marzo de 1995, cuando se registró un decremento en las emanaciones de ceniza. A pesar de haber tenido fluctuaciones en la actividad sísmica y emisión de gases, el volcán permaneció tranquilo sin la emisión de columnas de ceniza hasta inicios de marzo de 1996, cuando nuevas emanaciones tuvieron lugar. Finalmente, apareció una colada de lava muy viscosa, a partir de una fractura situada en el interior del cráter, el día 29 de marzo. El 10 de junio de 1996, el domo alcanzó espesores mínimos de $50 \mathrm{~m}$ y cubrió completamente el cráter interno formado en la década de 1920. Explosiones pequeñas lanzaron material del tamaño de lapilli en los flancos del volcán y algunas poblaciones aledañas. Estas explosiones cobraron la vida de 5 alpinistas que se encontraban en el borde del cráter el día 30 de abril. Esta explosión lanzó material juvenil del domo (diámetros de $1-2 \mathrm{~cm}$ ) a varios poblados (Xalitzintla, San Nicolás de los Ranchos, etc.) localizados en su flanco noreste a unos $12 \mathrm{~km}$ de distancia. Entre abril de 1996 y junio de 1997 se habían emplazado tres domos de lava. El 30 de junio de 1997 ocurrió una explosión precedida por una serie de sismos volcanotectónicos. La erupción formó una columna eruptiva de $8 \mathrm{~km}$ de altura y los vientos dis-

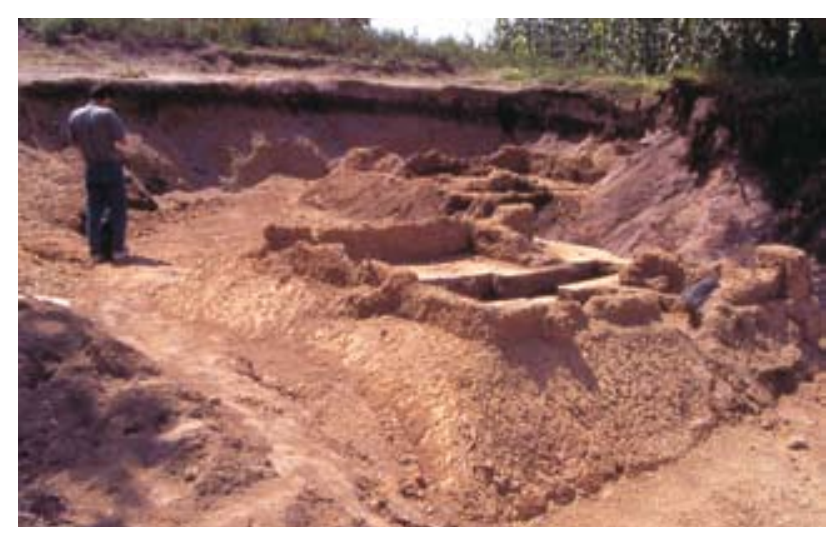

Figura 16. Sitio con restos de viviendas de la comunidad denominada Tetimpa por arqueólogas de la Universidad de las Américas. Al fondo se aprecia el depósito de caída de pómez de 2150 años del volcán Popocatépetl. Este depósito sepultó con al menos $1 \mathrm{~m}$ de pómez a la comunidad de Tetimpa.

persaron la nube hacia la Ciudad de México, provocando una lluvia de ceniza y el cierre del aeropuerto internacional. Esta erupción tuvo una intensidad de 2 a 3 en la escala de IEV (Índice de Explosividad Volcánica). Un día después, se originaron lahares que llegaron a $12 \mathrm{~km}$ hasta el poblado de Santiago Xalitzintla. De julio de 1997 a noviembre del 2000 se emplazaron cuatro domos, los cuales fueron destruidos por sendas explosiones que lanzaron proyectiles hasta $5 \mathrm{~km}$ del cráter. Del 12 al 16 de diciembre del 2000, la actividad del Popocatépetl se incrementó notoriamente, por lo que cerca de 40000 habitantes fueron evacuados. Para estas fechas, el cráter del Popocatépetl se había llenado casi completamente, por lo que la erupción ocurrida el 18 de diciembre, fue observada por los medios y el público en general. La explosión vulcaniana lanzó proyectiles a más de $5 \mathrm{~km}$, produciendo incendios en el bosque. Desde abril de 1996 al presente, se ha producido la emisión de más de 20 domos en el interior del cráter del Popocatépetl, los cuales han sido posteriormente destruidos por explosiones vulcanianas, proceso que ha sido controlado por la temperatura y la viscosidad del magma. Una de las últimas erupciones más importantes fue la ocurrida el 21 de enero de 2001, dado que produjo un flujo piroclástico rico en escoria, que erosionó el glaciar y viajó 5-6 km desde la cima hasta llegar al bosque. A partir de estos flujos se originaron lahares que viajaron alrededor de $15 \mathrm{~km}$ hacia el poblado de Xalitzintla (Capra et al., 2004). Después de 11 años de actividad, el cráter del Popocatépetl está casi completamente lleno, por lo que esta erupción ha rebasado la magnitud de la ocurrida de 1919 a 1927 (Macías y Siebe, 2005) (Figura 17).

\section{Volcán Citlaltepetl o Pico de Orizaba}

El volcán Citlaltépetl $\left(19^{\circ} 01^{\prime} \mathrm{N}, 97^{\circ} 16^{\prime} \mathrm{W} ; 5675 \mathrm{~m}\right)$ representa la cima más alta del país (Figura 18a). El Pico de Orizaba o Citlaltépetl que significa "Montaña de la 


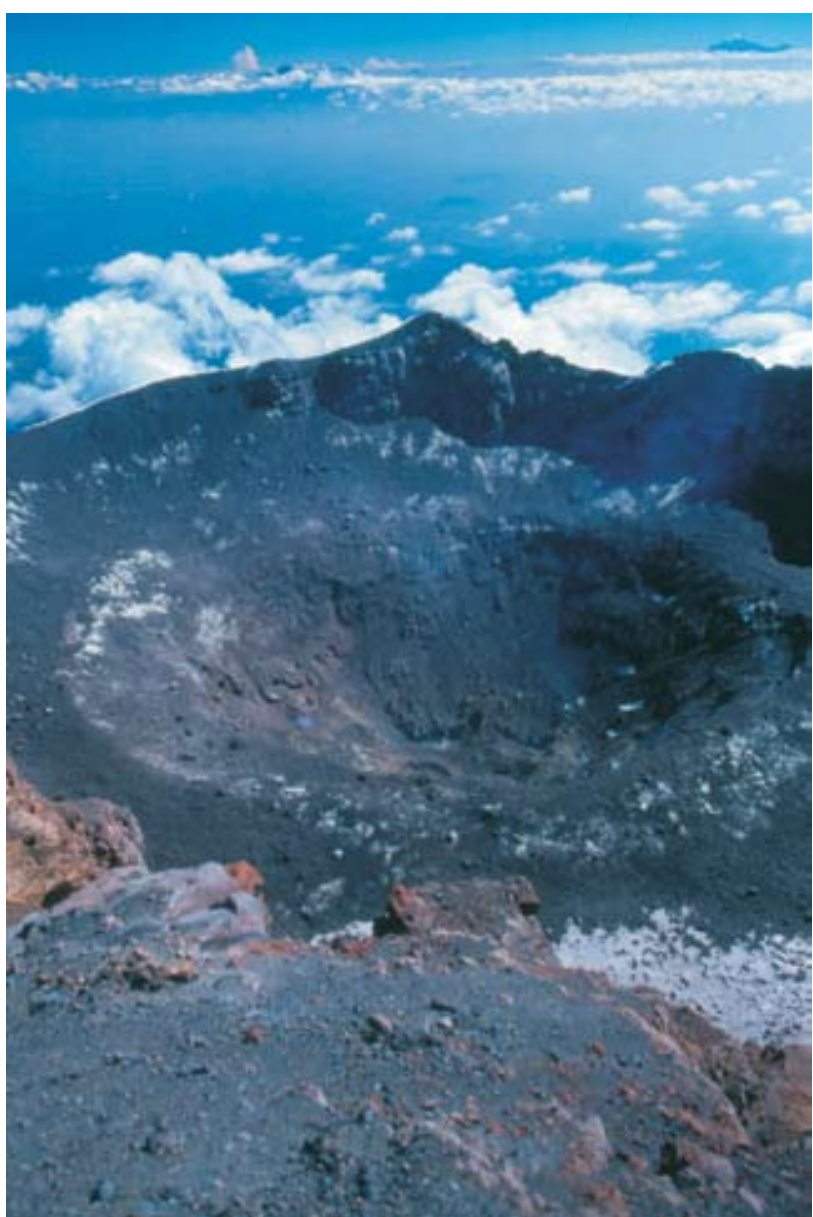

Figura 17. Detalle del interior del cráter del volcán Popocatépetl visto hacia el este. La fotografía fue tomada el 24 de octubre de 2004. Se aprecia el cráter interno de unos $340 \mathrm{~m}$ de diámetro sin la presencia de domo. Al fondo a la derecha se observa el volcán Pico de Orizaba. Fotografía de Jorge Neyra.

Estrella" en lengua náhuatl, está ubicado en la porción oriental de la Faja Volcánica Transmexicana (Figura 1). Su cima sirve como punto limítrofe entre los estados de Veracruz y Puebla. Existen reportes de actividad histórica del Pico de Orizaba; la última actividad importante ocurrió en el año de 1687 (Mooser, et al., 1958), aunque hay reportes de erupciones menores en tiempos más recientes (De-la Cruz y Carrasco-Núñez, 2002). Existen escasas señales de actividad moderna como exhalaciones débiles de $\mathrm{SO}_{2}$ y depósitos de azufre en las paredes del cráter (Waitz, 1910-1911), por lo que se considera como un volcán activo en estado de quietud. El edifico actual tiene un cráter central con forma ovalada con un diámetro de $500 \times 400 \mathrm{~m}$ y paredes verticales de $300 \mathrm{~m}$ de profundidad (Figura 18b). Su parte norte está cubierta por un glaciar (Heine, 1988). El cono tiene una forma simétrica con pendientes pronunciadas que alcanzan $\operatorname{los} 40^{\circ}$ (Figura 18a). El volcán tiene un desnivel con respecto a la cuenca de Serdán-Oriental al occidental de 2900 m y de 4300 con respecto a la Planicie Costera del Golfo al oriente (Carrasco-Núñez, 2000).

\subsection{Estudios previos}

Las primeras observaciones geológicas generales del Pico de Orizaba fueron realizadas durante una excursión geológica (Waitz, 1910-1911). Sin embargo, no es sino hasta mediados del siglo XX cuando el Pico es considerado como uno de nuestros volcanes activos por Mooser et al. (1958). Los primeros estudios geológicos de carácter regional fueron realizados por Yañez-García y García-Durán (1982) y Negendank et al. (1985). Robin y Cantagrel (1982) presentaron el primer trabajo sobre la estratigrafía y evolución del Pico de Orizaba, al cual le siguieron estudios más detallados (Hoskuldsson, 1992; Carrasco-Núñez, 1993). Otros estudios de carácter petrológico, también fueron realizados en la década de los ochenta (Kudo et al., 1985; Singer y Kudo, 1986; Calvin et al., 1989). Sin embargo, fue más recientemente cuando se inicia el estudio particular
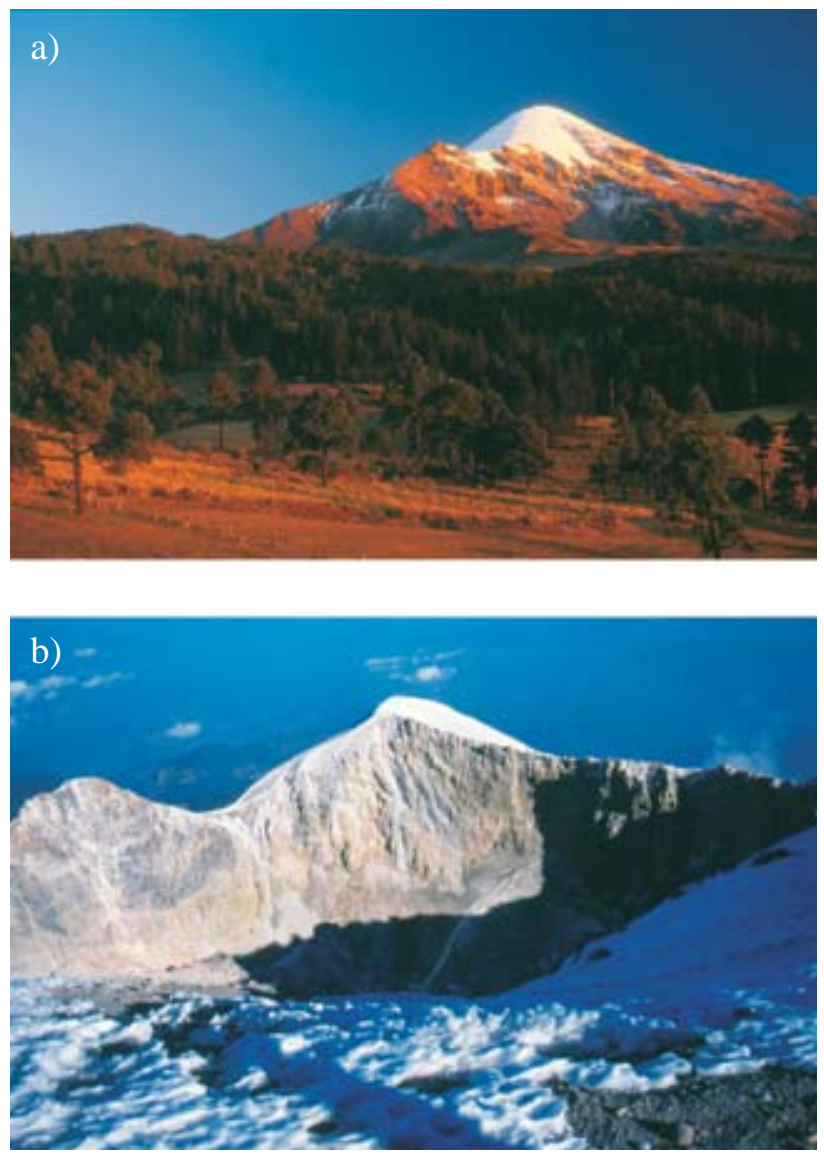

Figura 18. a) Fotografía del flanco occidental del volcán Pico de Orizaba visto desde Tlalchichuca. Fotografía tomada el 4 de febrero de 2004 por Jorge Neyra. b) Vista del interior del cráter del Pico de Orizaba visto hacia el E-NE desde la cumbre. Fotografía de Jorge Neyra tomada el 8 de noviembre de 1998. 
de la actividad eruptiva del Pico de Orizaba (Cantagrel et al., 1984; Hoskuldsson et al., 1990; Hoskuldsson y Robin, 1993; Carrasco-Núñez, 1993; Carrasco-Núñez et al., 1993; Siebe et al., 1993; Carrasco-Núñez y Rose, 1995; Carrasco-Núñez, 1997; Gómez-Tuena y Carrasco-Núñez, 1999; Rossotti y Carrasco-Núñez, 2004) y se realiza el primer mapa geológico del volcán, con la descripción de sus distintas etapas de crecimiento (Carrasco-Núñez y Ban, 1994; Carrasco-Núñez, 2000). Con toda la información geológica existente, Sheridan et al. (2002) elaboraron el mapa de peligros volcánicos del Pico de Orizaba con el empleo de los programas FLOW3D (Kover, 1995) y LAHARZ (Iverson et al., 1998) y Díaz-Castellón (2003) y Zimbelman et al. (2004) evaluaron la estabilidad del edificio volcánico. Recientemente, Sheridan et al. (2004) reevaluaron la zonificación para flujos piroclásticos del Pico de Orizaba y presentaron en forma detallada la metodología empleada para elaborar el mapa de peligros.

\subsection{Historia eruptiva}

El Pico de Orizaba es un estratovolcán cuaternario, que ha sido construido sobre rocas calizas y lutitas de edad Cretácica (Yañez-García y García-Duran, 1982). La historia eruptiva del Pico de Orizaba ha sido muy compleja dado que existen indicios de diversos eventos de construcción y destrucción del edificio volcánico. Robin y Cantagrel (1982) y Hoskuldsson (1992) propusieron que el volcán había sido construido durante tres etapas diferentes. Sin embargo, con base en un estudio estratigráfico detallado Carrasco-Núñez y Ban (1994) y Carrasco-Núñez (2000) (Figura 19) concluyeron que su construcción había ocurrido en cuatro fases eruptivas. Las etapas de evolución del Pico de Orizaba fueron denominadas de la más antigua a la más reciente como el cono Torrecillas, el cono Espolón de Oro, domos silícicos periféricos y el cono Citlaltépetl (Carrasco-Núñez y Ban, 1994; Carrasco-Núñez, 2000). Estos autores presentaron además un mapa geológico de la cima del volcán.

A continuación se presenta un resumen de las etapas eruptivas:

1) El cono Torrecillas inició su formación hace 0.65 0.71 Ma (Hoskuldsson, 1992), con la emisión de lavas de andesitas basálticas de olivino denominadas Pilancón; éstas fueron seguidas por las lavas andesíticas y dacíticas Jamapa y por las lavas Torrecillas, que consisten en andesitas con dos piroxenos, brechas y dacitas de anfíbol que fueron fechadas en $0.29 \pm 0.5$ Ma (Carrasco-Núñez, 2000), culminando con andesitas con dos piroxenos. Todas estas lavas dieron origen a la formación del estratovolcán Torrecillas, con un volumen total de $270 \mathrm{~km}^{3}$ (Carrasco-

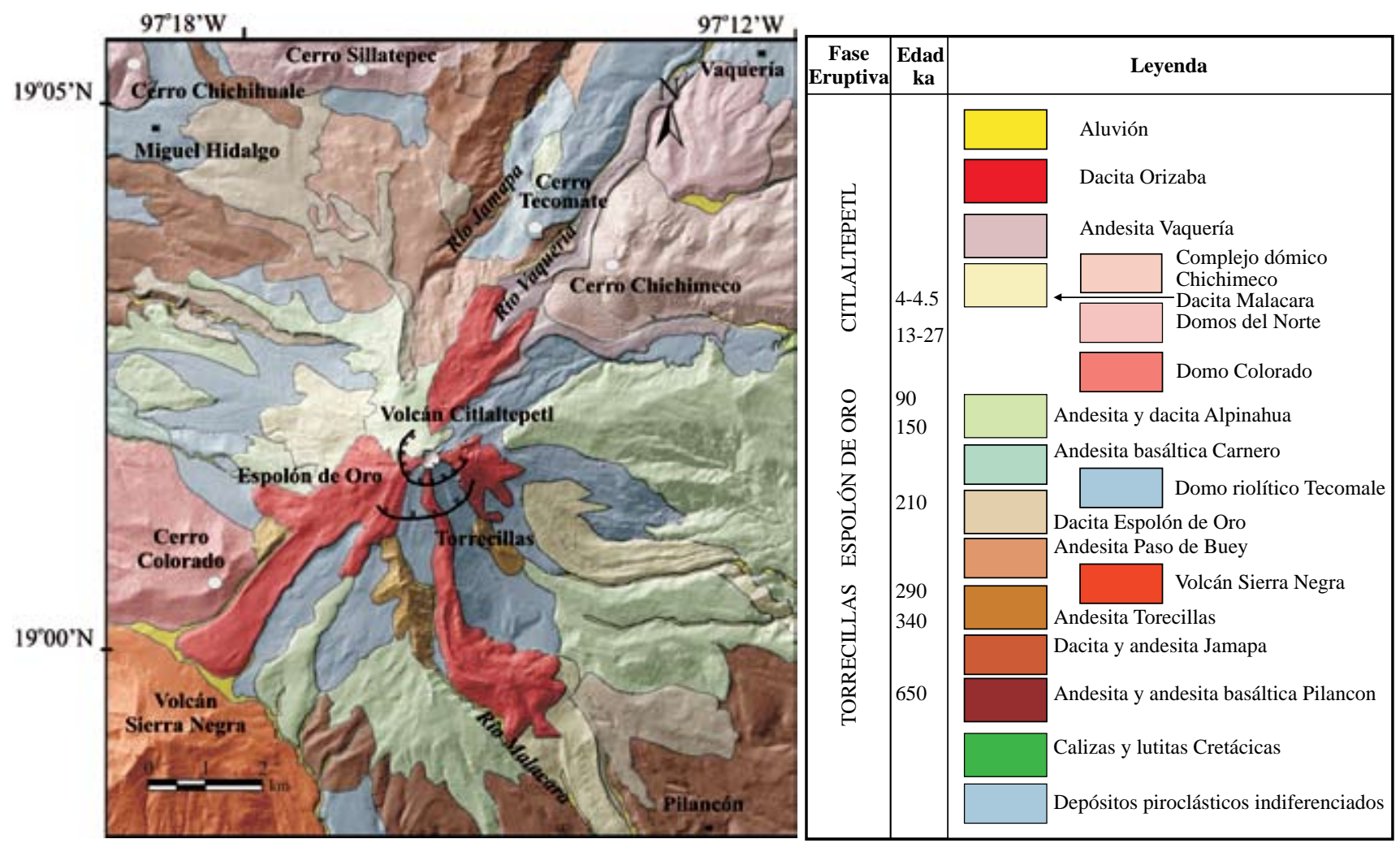

Figura 19. Mapa geológico simplificado del volcán Pico de Orizaba que muestra sus cuatro etapas principales de evolución. Tomado de CarrascoNúñez (2000). 
Núñez, 2000). La etapa constructiva de este volcán finalizó con la formación de una caldera cuyos vestigios se encuentran al sur del cráter actual (Robin y Cantagrel, 1982; Carrasco-Núñez, 1993) debida al colapso del flanco noreste del cono Torrecillas, que formó una avalancha de escombros (Hoskuldsson et al., 1990) conocida como Jamapa (Carrasco-Núñez y Gómez-Tuena, 1997) hace aproximadamente 0.25 Ma. La avalancha de escombros viajó $75 \mathrm{~km}$ hacia el este, a lo largo del río Jamapa (Carrasco-Núñez y Gómez-Tuena, 1997) (Figura 20).

2) El cono Espolón de Oro fue construido al norte del escarpe caldérico del cono Torrecillas; los remanentes de esta estructura están representados por dacitas de anfíbol fechadas en $0.21 \pm 0.04 \mathrm{Ma}$ (Carrasco-Núñez, 2000). El cono Espolón de Oro, inició su formación con la emisión de lavas andesíticas con plagioclasa y anfíbol, denominadas Paso de Buey; éstas fueron seguidas por la emisión de lavas dacitas de anfíbol conocidas como Espolón de Oro, a las cuales se asocian flujos de bloques y cenizas. La formación del volcán continuó en su flanco oeste con la emisión lateral de lavas andesítico basálticas de olivino, el Carnero. Entre 0.15 y $0.09 \mathrm{Ma}$, fue emitida en la parte norte del volcán, una secuencia piroclástica alternada con lavas andesíticas denominada Alpinahua. Dicha secuencia finaliza con lavas andesíticas afaníticas intercaladas con brechas y una ignimbrita soldada con fiammes. Hasta esta fase, se estima que el cono Espolón de Oro tenía un volumen aproximado de rocas de $50 \mathrm{~km}^{3}$ (Carrasco-Núñez, 1997). Esta etapa terminó con el colapso del cono Espolón de Oro que ocurrió hace aproximadamente 16500 años AP (Carrasco-Núñez et al., 2005). Este colapso originó una avalancha de escombros, que se transformó en un lahar cohesivo (10-16\% de arcilla) el cual viajó $85 \mathrm{~km}$ desde el origen, cubrió un área de 143 $\mathrm{km}^{2}$ y tuvo un volumen de $1.8 \mathrm{~km}^{3}$ (Carrasco-Núñez et al., 1993). Estos autores denominaron Tetelzingo al evento y concluyeron que no había sido debido a la intrusión de un nuevo magma (tipo Santa Elena), sino que se originó por la alteración de las rocas del edifico volcánico, promovida por una intensa alteración hidrotermal y la presencia de un glaciar.

3) Domos periféricos. Los domos Tecomate al NE y Colorado al SW (Figura 20) fueron emplazados durante la construcción del cono Espolón de Oro. El domo Tecomate consiste en lavas riolíticas de obsidiana, mientras que el domo Colorado está formado por lavas dacíticas y flujos piroclásticos asociados. A estos domos siguió el emplazamiento de los domos dacíticos Sillatepec y Chichihuale, al NW del cráter, con flujos piroclásticos asociados. Finalmente, ocurrió la emisión del complejo de domos Chichimeco, que consiste en domos y lavas andesíticas de anfíbol, que son cubiertas por un flujo piroclástico de escoria fechado en 8 630 \pm 90 años AP (Carrasco-Núñez, 1993), por lo que estos domos tienen una edad anterior.

4) El cono Citlaltépetl, inicio su formación hace aproximadamente 16500 años AP, dentro de los remanentes caldéricos del cono Espolón de Oro. Su actividad comenzó con la emisión de lavas dacíticas de hornblenda denominadas Malacara, las cuales fluyeron por $13 \mathrm{~km}$ en el flanco sureste del cráter. A estas lavas siguieron las lavas andesíticas denominadas Vaquería, que fluyeron hacia el flanco noreste del cráter. La construcción del cono actual concluyó con la emisión hacia el SW y NE de espesas lavas dacíticas

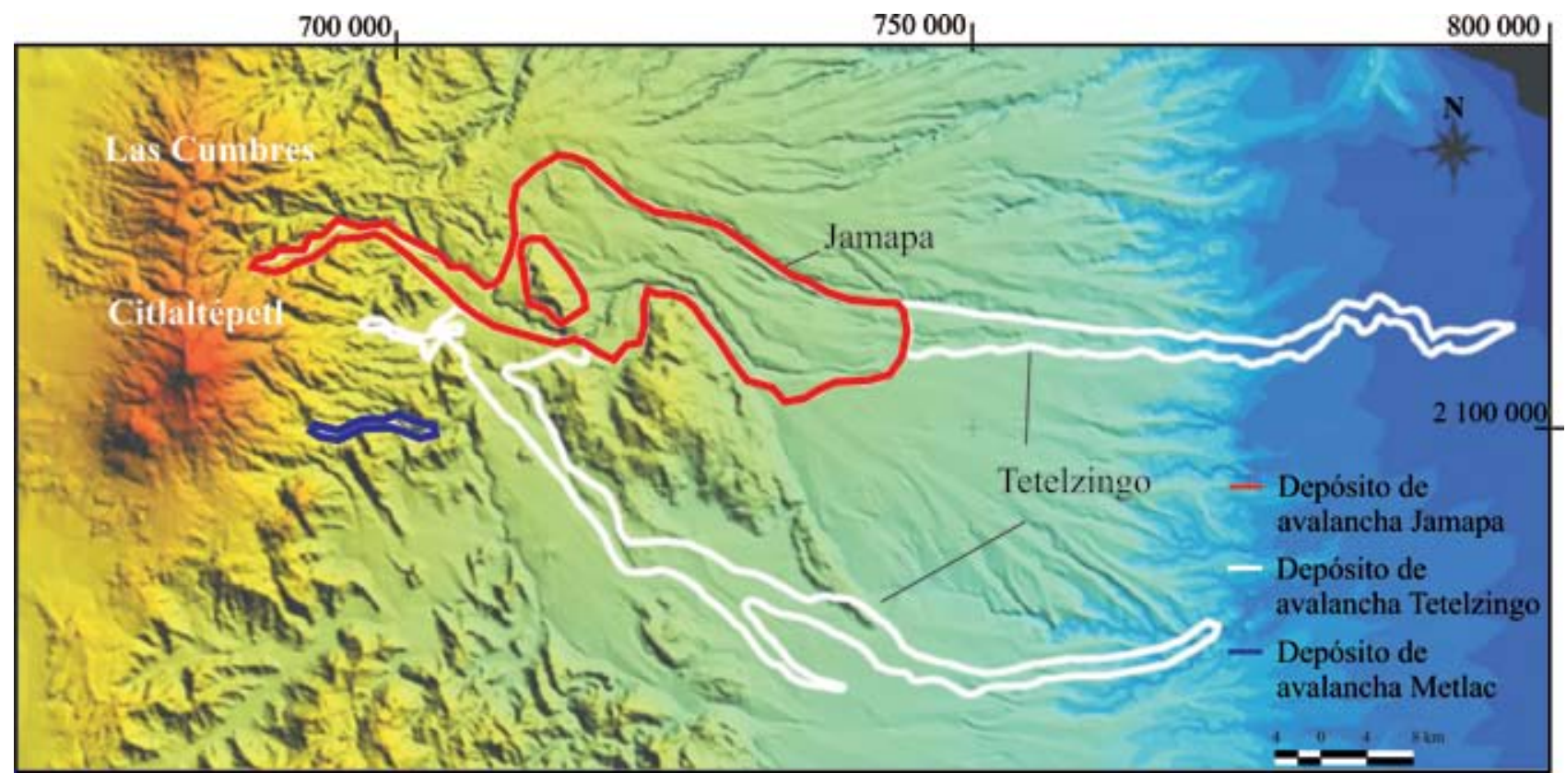

Figura 20. Modelo digital de terreno que muestra la distribución de los diferentes depósitos de avalanchas de escombros producidos por el volcán Citlaltépetl (Carrasco-Núñez et al., en prensa). Base topográfica obtenida de GEMA con coordenadas UTM. 
denominadas Orizaba. El cono actual del Citlaltépetl tiene un volumen de $25 \mathrm{~km}^{3}$ (Carrasco-Núñez, 1997). Este autor describió la morfología, longitud y características reológicas de las lavas de la cima del Citlaltépetl. En este mismo estudio, el autor señaló la ubicación de las lavas producidas por las erupciones de 1537, 1545, 1566 y 1613, siguiendo las notas históricas recopiladas por Crausaz (1994).

La formación del cono Citlaltépetl no está únicamente ligada a la ocurrencia de erupciones efusivas, descritas anteriormente, sino también a la ocurrencia de erupciones explosivas (Siebe et al., 1993; Hoskuldsson y Robin, 1993; Carrasco-Núñez y Rose, 1995; Rossotti y Carrasco-Núñez, 2004). El registro estratigráfico indica que existen tres eventos explosivos mayores, que han sido bien documentados: 1) una erupción que produjo flujos de pómez en el sector oriental del volcán, hace aproximadamente 13000 años, 2) la secuencia eruptiva Citlaltépetl, compuesta por diversas caídas de pómez y flujos piroclásticos ocurrida entre 8500 y 9000 años (Carrasco-Núñez y Rose, 1995) y 3 ) una serie de flujos de bloques y cenizas, expuestos en el flanco oeste y sureste ocurrida hace 4100 años (Siebe et al., 1993; Carrasco-Núñez, 1999). Existen depósitos de flujos de ceniza, escoria, y de bloques y ceniza, que han sido fechados para ocho eventos eruptivos distintos, oscilan de entre 8170 y 1730 años AP y seis depósitos de caída que fluctúan entre 10600 y 690 años AP (De-la Cruz-Reyna y Carrasco-Núñez, 2002). De estos eventos eruptivos, sólo las erupciones ocurridas hace $8500-9000$ y 4100 años AP han dejado un registro geológico y estratigráfico fehaciente en torno al volcán. Por su importancia, estas dos erupciones se resumen a continuación:

\subsection{Ignimbrita-Pómez Citlaltépetl (8 500-9 000 AP)}

Esta secuencia representa el evento explosivo más importante durante el Holoceno. Dicha secuencia fue originalmente descrita en dos miembros compuestos por flujos piroclásticos, separados por una capa de caída de pómez (Carrasco-Núñez y Rose, 1995). Estos autores precisaron que el miembro inferior, estaba compuesto por al menos cuatro unidades de flujo piroclástico, un lahar y un paleosuelo poco desarrollado. Los flujos piroclásticos del miembro inferior contenían material carbonizado con una edad promedio de $8795 \pm 57$ años AP (seis fechamientos). Por su parte, el miembro superior estaba compuesto por un depósito de caída a la base y una unidad de flujo y material carbonizado, con una edad promedio de $8573 \pm 79$ años AP (diez fechamientos). Con esta estratigrafía, los autores concluyeron que la secuencia había sido originada a partir del cráter central del cono Citlaltépetl, por una serie de erupciones ocurridas entre 8500 y 9000 años AP.

Los flujos piroclásticos originados por estas erupciones se emplazaron en todas direcciones alrededor del volcán hasta una distancia de $30 \mathrm{~km}$; dichos flujos fueron designados como Ignimbrita Citlaltépetl por Carrasco-Núñez y
Rose (1995), quienes calcularon un volumen total de 0.26 $\mathrm{km}^{3}$. Los depósitos están compuestos por escoria andesítica con cantidades menores de pómez y líticos, en una matriz de limo. De acuerdo con las características texturales del depósito y a la composición química de sus componentes, Carrasco-Núñez y Rose (1995) propusieron que los flujos fueron originados mediante un mecanismo de boiling over en el cráter, a partir de una mezcla de dos magmas de composición andesítica (58-59\% en peso de $\mathrm{SiO}_{2}$ ) y dacítica (62-63\% en peso de $\mathrm{SiO}_{2}$ ). Posteriormente, Gómez-Tuena y Carrasco-Núñez (1999) estudiaron detalladamente la unidad de flujo piroclástico inferior de la Ignimbrita Citlaltépetl. Con base en su distribución y en el estudio de las características texturales, sedimentológicas y de componentes, los autores propusieron que esta ignimbrita se emplazó en áreas cercanas al cráter, mediante un mecanismo de acreción gradual y en sitios distantes a través de un mecanismo de emplazamiento en masa.

En dos estudios recientes sobre los depósitos de caída del Holoceno del volcán Citlaltépetl (Rossotti y CarrascoNúñez, 2004; Rossotti, 2005), se describieron al menos 10 capas de caída de ceniza fina a pómez del tamaño de lapilli, intercaladas con 4 flujos piroclásticos y tres horizontes parcialmente humificados. Los autores denominaron a esta secuencia Pómez Citlaltépetl, debido a que seis edades radiométricas de estos depósitos caen en el periodo de 8500 a 9000 años AP, propuesto por Carrasco-Núñez y Rose (1995) para la Ignimbrita Citlaltépetl. Con base en estas nuevas columnas estratigráficas, fechamientos radiométricos y correlación con trabajos previos, estos autores determinaron que la secuencia Ignimbrita-Pómez Citlaltépetl fue originada durante cuatro fases eruptivas ocurridas hace $\sim 9000-8900, \sim 8900-8800, \sim 8800-8700 \mathrm{y}$ $\sim 8700-8500$ años AP. Esto quiere decir que en un periodo de 500 años, el volcán Citlaltépetl estuvo muy activo con la generación de al menos cuatro erupciones, que emplazaron depósitos de caída preferencialmente hacia el NE y flujos piroclásticos, ambos hasta $30 \mathrm{~km}$ del cráter.

\subsection{Destrucción de un domo central (4 100 AP)}

Este evento estuvo caracterizado por la destrucción de un domo central, que generó flujos de bloques y cenizas formando un abanico cerca de la población de Avalos al oeste del cráter (Siebe et al., 1993). Los flujos viajaron $\sim 16 \mathrm{~km}$, por lo que tienen un $\mathrm{H} / \mathrm{L}$ de 0.186 . Estos autores calcularon un volumen de $0.048 \mathrm{~km}^{3}$ para los depósitos de flujos de bloques y ceniza y los fecharon en $4040 \pm 80$ y 4060 \pm 120 años AP. Posteriormente, Carrasco-Núñez (1999) describió otra secuencia de flujos de bloques y cenizas, los cuales forman terrazas prominentes al sureste del cráter. Estos flujos viajaron $\sim 28 \mathrm{~km}$ desde el cráter, y tienen un $\mathrm{H} / \mathrm{L}$ de 0.153 . Este autor determinó un volumen aproximado de $0.162 \mathrm{~km}^{3}$ para esta secuencia y la fechó en $4130 \pm 70$ años AP. Debido a la similitud entre los depósitos, 
la proximidad de las edades y la composición química homogénea de los líticos juveniles (dacita 62.7-63.95\% en peso $\mathrm{SiO}_{2}$ ), el mismo autor propuso que ambos depósitos, habían sido emplazados por el mismo evento eruptivo hace aproximadamente 4100 años, con un volumen mínimo de $0.27 \mathrm{~km}^{3}$.

\section{Volcán El Chichón}

El volcán Chichón (17²1 ’N; W9341'W; 1100 msnm) se localiza en la porción noroeste del estado de Chiapas, a unos $60 \mathrm{~km}$ de la ciudad de Pichucalco. El Chichón es el volcán activo y más joven del arco volcánico Chiapaneco (Damon y Montesinos, 1978). Este arco volcánico tiene una edad que va del Plioceno al Reciente y se ubica entre la Faja Volcánica Transmexicana y el arco volcánico de Centroamérica (Figura 1). El Chichón está construido sobre evaporitas y calizas del Jurásico-Cretácico Temprano, calizas dolomíticas del Cretácico Temprano a medio, y calizas, areniscas y lutitas del Terciario (Canul y Rocha, 1981; Canul-Dzul et al., 1983; Duffield et al., 1984) (Figura 21). Estas rocas están plegadas en dirección NW-SE, con lo que dan lugar a una serie de estructuras que son el anticlinal Catedral y los sinclinales La Unión y Caimba (Macías et al., 1997b; García-Palomo et al., 2004). Desde un punto de vista tectónico, el Chichón se ubica dentro de las Provincia de Fallas Laterales Motagua-Polochic (Meneses-Rocha, 2001). Localmente, las rocas del basamento del Chichón están afectadas por fallas orientadas E-W con movimiento lateral izquierdo, como la falla San Juan y por fallas normales de rumbo $\mathrm{N} 45^{\circ} \mathrm{E}$, con planos buzando en dirección NW, conocidas como la zona de fallas de Chapultenango (García-Palomo et al., 2004).

El Chichón es un volcán compuesto por un cráter de $1.5 \times 2 \mathrm{~km}$ de diámetro denominado Somma, que tiene una elevación de 1150 msnm (Figura 22). Este cráter en realidad es un anillo de domos de composición traquiandesítica que tiene paredes internas subverticales y pendientes externas suaves. La elevación relativa del Somma, con respecto a la topografía circundante es de sólo $700 \mathrm{~m}$ con respecto a la parte oriental y de $900 \mathrm{~m}$ considerando la parte occidental. El cráter Somma está cortado por estructuras más jóvenes, en su parte SE por un cono de tobas denominado Guayabal, y al SW y NW por dos domos traquiandesíticos de edad desconocida (Macías, 1994). Dentro del cráter Somma se encuentra el cráter reactivado durante la erupción de 1982 (Figura 23). Este cráter tiene un diámetro de $1 \mathrm{~km}$ y paredes verticales de $140 \mathrm{~m}$. La altura máxima del cráter sobre el nivel del mar es de $1100 \mathrm{~m}$ y la altura del fondo del cráter

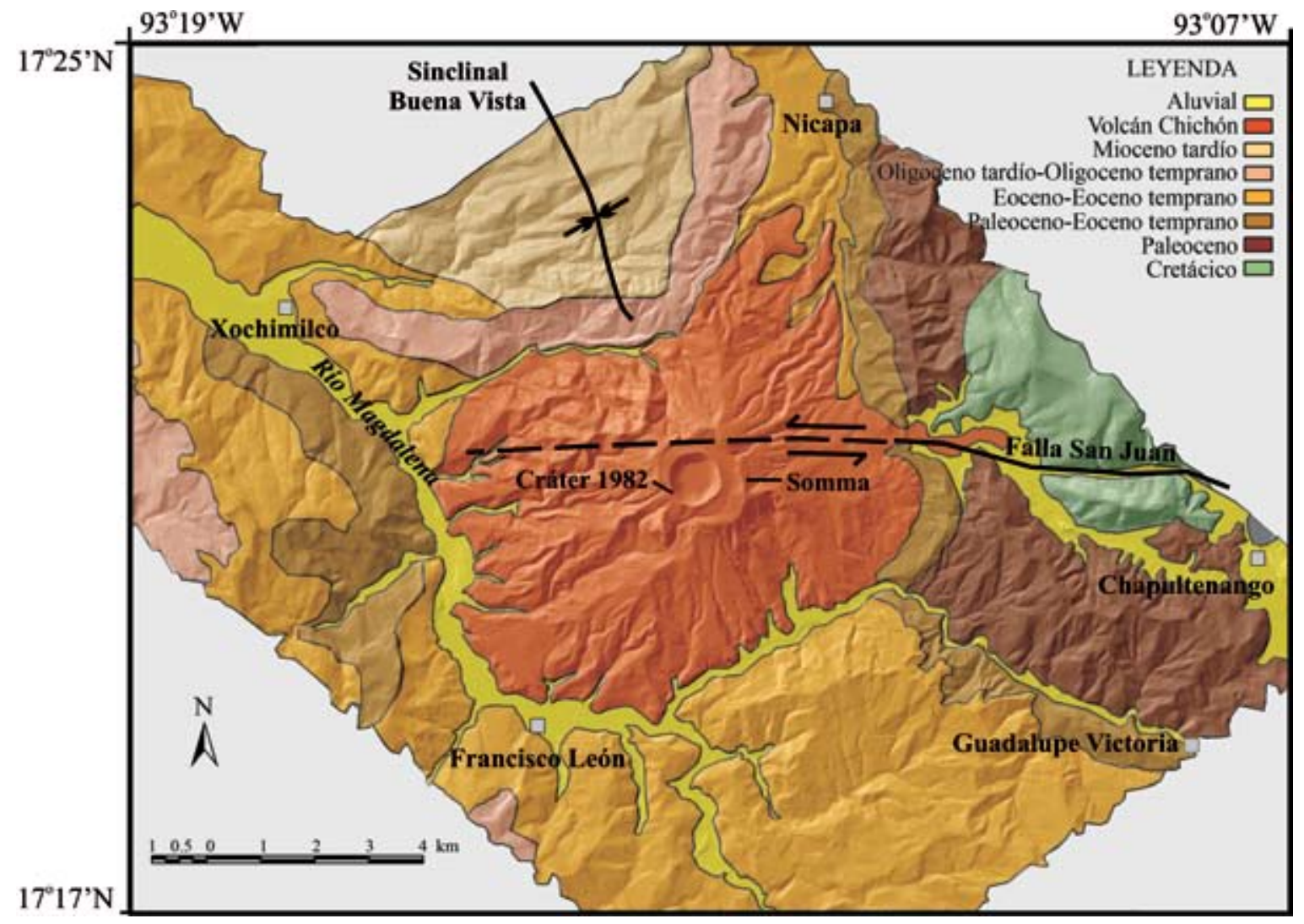

Figura 21. Mapa geológico simplificado del volcán Chichón en el que se puede apreciar que el volcán esta emplazado en el sinclinal Buena Vista (tomado de García-Palomo et al., 2004). 


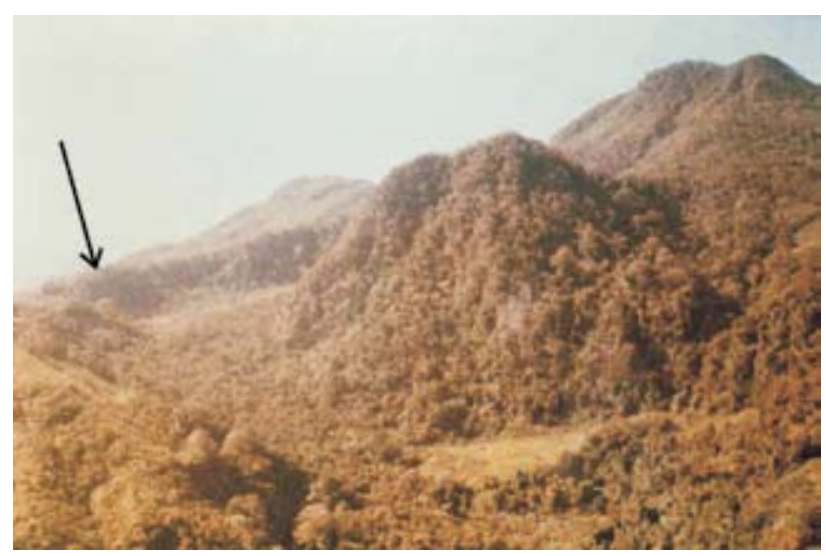

Figura 22. Fotografía hacia el oeste del volcán Chichón con su domo central al centro de la fotografía y el cráter Somma a la izquierda (flecha) antes de la erupción de 1982. Fotografía cortesía de René Canul.

es de $860 \mathrm{~m}$. El cráter contiene un lago generalmente de color azul turquesa, que regularmente tiene una temperatura de $32{ }^{\circ} \mathrm{C}$ (Armienta et al., 2000), pozas de lodo hirviendo y fumarolas con temperaturas variables cercanas a los $100^{\circ} \mathrm{C}$ (Taran et al., 1998; Tassi et al., 2003), que contienen compuesto orgánicos (Capaccioni et al., 2004) y las cuales son alimentadas por un sistema hidrotermal activo (Rouwet et al., 2004) (Figura 24).

\subsection{Estudios previos}

El volcán Chichón se dio a conocer a la comunidad geológica del país en 1930 cuando un grupo de pobladores de la región notificaron a las autoridades locales, que en el cerro conocido como la Unión o Chichonal se escuchaban retumbos y se movía la tierra. Como consecuencia de estas declaraciones, el Instituto Geológico encomendó al geólogo Müllerried el estudio de estos fenómenos. Müllerried (1933), reportó que el Chichón consistía en un cráter y un domo central, entre los cuales existía un pequeño lago y varias fumarolas con temperaturas cercanas a $\operatorname{los} 90^{\circ} \mathrm{C}$, por lo que concluyó que el Chichón era un volcán activo. Esta mención permitió que se considerara al Chichón, en el catálogo de los volcanes activos del mundo (Mooser $e t$ al., 1958). El volcán no volvió a ser estudiado sino hasta la década de los setenta, cuando la Comisión Federal de Electricidad (CFE) inició un estudio de prospección geotérmica en el área (González-Salazar, 1973, Molina-Berbeyer, 1974). En 1978, en un trabajo de prospección minera del estado de Chiapas, Damon y Montesinos (1978), llegaron hasta el Chichón, fecharon la pared E del cráter Somma en $0.209 \pm 0.019 \mathrm{Ma}$ (método K-Ar), y también lo consideraron como un volcán activo. A principios de los ochentas, la CFE continúo con sus estudios de prospección del volcán (Canul y Rocha, 1981; Templos, 1981). En particular, el estudio geológico estuvo encaminado a conocer la historia eruptiva del volcán. En este trabajo Canul y Rocha (1981) reconocieron erupciones antiguas sin llegar a fecharlas y concluyeron que el volcán se encontraba en actividad al sentir y escuchar explosiones. Desafortunadamente, este trabajo fue poco divulgado y sólo quedó como un reporte interno de la CFE, en donde los autores pronosticaban que el Chichón, podría entrar en erupción en los próximos años.

\subsection{La erupción de 1982}

Antes de la erupción, el Chichón estaba compuesto por el cráter Somma y un domo central con una altura sobre el nivel del mar de $1235 \mathrm{~m}$ (Figura 22). A este domo central se le conocía como el Chichón o Chichonal. La erupción de 1982, tomó por sorpresa a la población y a la comunidad científica del país, a pesar de los constantes avisos de reactivación que el volcán había dado. La erupción, en realidad, fue precedida por actividad fumarólica y temblores; estos últimos quedaron registrados en los instrumentos de la red sísmica de la presa hidroeléctrica de Chicoasén, perteneciente a la CFE (Espíndola et al., 2002). Jiménez et

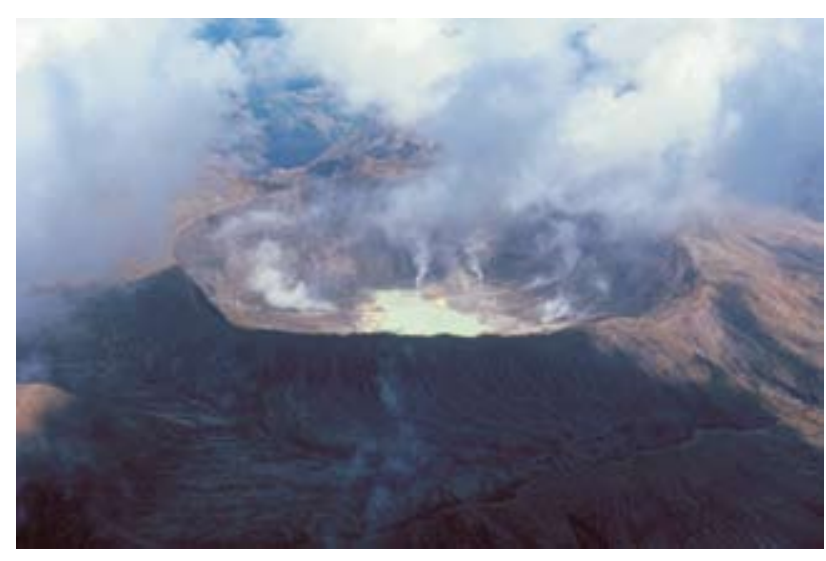

Figura 23. Vista aérea del volcán Chichón tomada después de la erupción de 1982. Se aprecian los bordes del cráter formado por la erupción de 1982 y en su interior el lago color turquesa, fumarolas y sublimados de azufre. Fotografía de Reynaldo Mota.

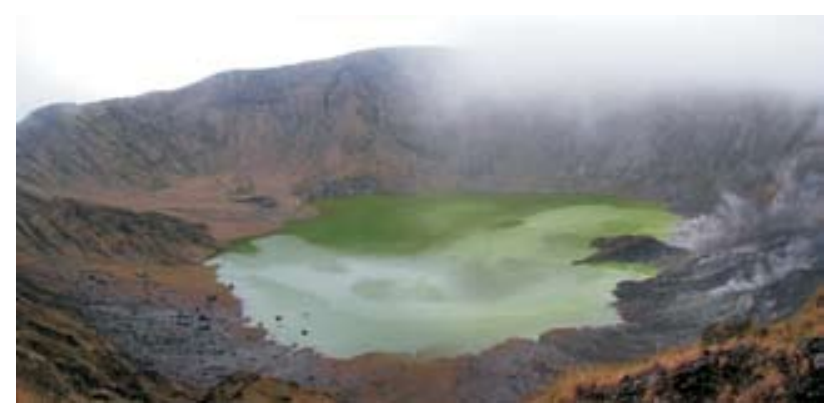

Figura 24. Vista panorámica hacia el noroeste del interior del cráter del volcán Chichón tomada en mayo del 2004. En la parte derecha de la imagen se observa actividad fumarólica. 
al. (1998) concluyeron que la actividad sísmica comenzó a finales de 1980, incrementándose en 1981 y a finales de marzo de 1982. La noche del 28 de marzo, la actividad sísmica se convirtió en tremor de amplitud cambiante, el cual fue seguido por una hora de calma absoluta. Una hora después comenzó la primera erupción, que se registró como un tremor de gran amplitud. La erupción del 28 de marzo de origen magmático produjo un cráter de 150 a 180 $\mathrm{m}$, destruyó cerca de una cuarta parte del domo central y originó una columna pliniana con una altura estimada de 27 km (Medina-Martínez, 1982; Sigurdsson et al., 1984; Carey y Sigurdsson, 1986). Dicha columna fue dispersada hacia el NE del volcán, depositando la capa de caída A. Este evento provocó gran desconcierto entre los pobladores, que salieron huyendo hacia ciudades más cercanas como Pichucalco, Villahermosa y Tuxtla Gutiérrez. Un día después, el área fue acordonada por el ejército para aplicar el plan de emergencia DNIII (SEDENA, 1983), durante el cual se desalojó a todos los pobladores de la región de mayor peligro. El volcán permaneció en relativa calma durante una semana, a pesar de que se registraron diversas explosiones y actividad sísmica constante. Al finalizar esa semana, las autoridades permitieron el regreso a sus hogares de gran parte de la población, sobre todo en el poblado de Francisco León, al suroeste del cráter en donde inclusive permaneció un convoy del ejército y un geólogo. Desafortunadamente, esa misma noche del 3 de abril ocurrió la explosión más violenta de la erupción de 1982 (Yokohama et al., 1992). El magma entró en contacto con agua, probablemente del sistema hidrotermal, produciendo una explosión hidromagmática violenta que destruyó completamente el domo central y generó oleadas piroclásticas húmedas (S1), las cuales viajaron hasta $8 \mathrm{~km}$ del cráter, arrasando con todo lo que encontraban a su paso, incluidas las vidas de más de 2000 personas y la destrucción de 9 poblados (Sigurdsson et al., 1984; Sigurdsson et al., 1987; Macías et al., 1997a; Scolamacchia y Macías, 2005) (Figura 25). Las oleadas fueron casi inmediatamente seguidas por flujos piroclásticos espesos (F1) que terminaron por rellenar el terreno y por la formación de una segunda columna pliniana que alcanzó $32 \mathrm{~km}$ de altura, depositando la capa rica en líticos B (Carey y Sigurdsson, 1986). Horas después, la columna pliniana colapsó formando flujos piroclásticos de pómez (F2) y otros eventos menores que no alcanzaron más allá de $2 \mathrm{~km}$ del cráter (UI). Cuatro horas más tarde, ya en la madrugada del 4 de abril, el volcán reinició su actividad con otra explosión que formó una tercera columna pliniana (C), que alcanzó $29 \mathrm{~km}$ de altura y fue dispersada nuevamente hacia el NE. Explosiones hidromagmáticas originaron oleadas piroclásticas (S3) que llegaron hasta $4 \mathrm{~km}$ del cráter. Las oleadas contenían vapor de agua que favoreció la aglutación de ceniza volcánica (Varekamp et al., 1984) formando agregados de ceniza (Scolamacchia et al., 2005).

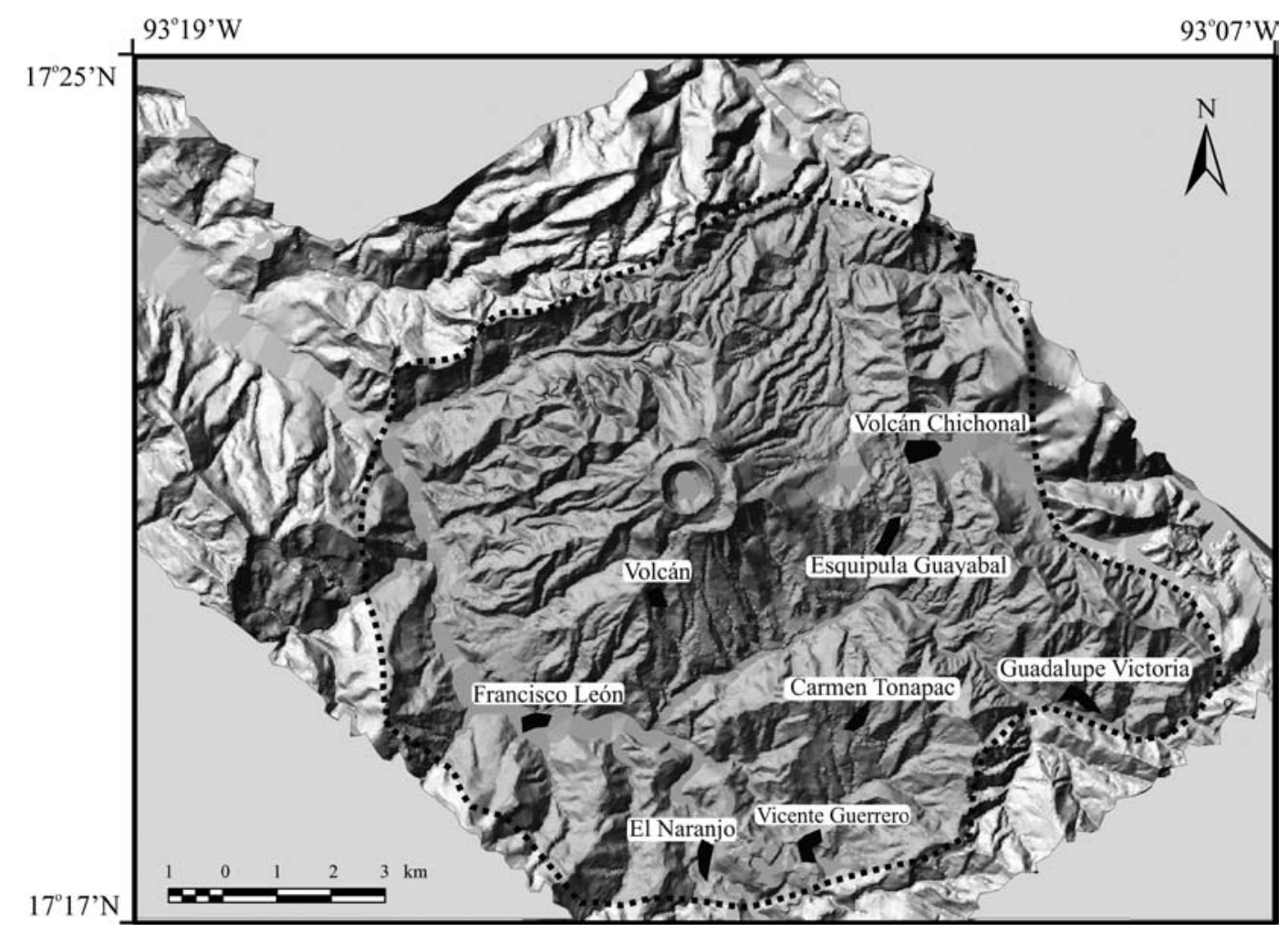

Figura 25. El área punteada muestra la distribución de flujos y oleadas piroclásticas de la erupción de 1982 de acuerdo a Scolamacchia y Macías (2005). Los pueblos en color negro fueron destruidos por la erupción. 
En el sitio en donde se encontraba el domo central yacía un cráter de $1 \mathrm{~km}$ de diámetro con cuatro cráteres internos y sus respectivos lagos. Las paredes verticales del cráter expusieron una secuencia estratigráfica que claramente sugiere que este cráter, había sido tapado por la formación de domos anteriores y reactivado por erupciones explosivas posteriores.

Después del 4 de abril, la actividad del Chichón disminuyó drásticamente aunque se reportaron explosiones pequeñas desde abril hasta septiembre de 1982. La emisión repentina de cerca de $1.5 \mathrm{~km}^{3}$ (roca densa equivalente) modificó completamente la topografía del volcán, pero sobre todo, bloqueó la red hidrológica preexistente formada por el cauce de los ríos Susnubac-Magdalena y Platanar (RivaPalacio Chiang, 1983; SEAN, 1982). Los flujos piroclásticos emitidos durante la segunda fase pliniana bloquearon el río Magdalena, formando una represa de 25 a $75 \mathrm{~m}$ de espesor (Macías et al., 2004a). El agua del río Susnubac y la lluvia precipitada durante los meses de abril-mayo comenzó a acumularse dando lugar a la formación de un lago (Figura 26). El material piroclástico recién depositado tenía una temperatura cercana a los $300^{\circ} \mathrm{C}$, por lo que el agua del lago estaba casi al punto de ebullición. Para fines de abril el lago tenía $4 \mathrm{~km}$ de largo y 300-400 $\mathrm{m}$ de ancho, con un volumen de $26 \times 10^{6} \mathrm{~m}^{3}$ de agua caliente, que para inicios de mayo se había incrementado hasta $40 \times 10^{6} \mathrm{~m}^{3}$ (Medina-Martínez, 1982). Los últimos días de mayo, el ejército había evacuado a 1288 habitantes aguas abajo de la represa (Baéz-Jorge et al., 1985). El día 26 de mayo a la 1:30 am, la represa colapsó debido a que el nivel del agua la superó y comenzó a erosionarla. La ruptura de la represa descargó dos flujos de escombros calientes, que se transformaron rápidamente en flujos hiperconcentrados (Macías et al., 2004a). A $10 \mathrm{~km}$ de distancia, los flujos tenían $82^{\circ} \mathrm{C}$; ahí inundaron el pueblo de Ostuacán así como sembradíos de café y cacao. El flujo continuó su viaje a lo largo del cauce del río Magdalena hasta alcanzar el río Grijalva. Ya en el río Grijalva viajó otros $7 \mathrm{~km}$ hasta la presa hidroeléctrica Penitas de la CFE, entonces en construcción. El agua que tenía todavía una temperatura de $50^{\circ} \mathrm{C}$, elevó $7 \mathrm{~m}$ el nivel del río causando la muerte de un trabajador, quemó a otros tres trabajadores y dañó maquinaria.

La erupción de 1982 devastó la vegetación selvática de las laderas del volcán, arrasando un área cercana a los $100 \mathrm{~km}^{2}$; en sitios distantes como Ostuacán y Pichucalco causó el derrumbe de los techos de lámina de las iglesias. La erupción expulsó 7 millones de toneladas de $\mathrm{SO}_{2}$ en la estratósfera, las cuales dieron lugar a la formación de aerosoles (Krueger, 1983; Matson, 1984). Estos aerosoles crearon una nube de material fino que circundó en varias ocasiones el planeta, produciendo un impacto en el clima global, al reducir la temperatura del planeta en $0.5^{\circ} \mathrm{C}$. Así mismo, los productos juveniles de la erupción contenían anhidrita, mineral que no había sido reportado en rocas volcánicas (Luhr et al., 1984; Rye et al., 1984). Todos estos ingredientes, atrajeron la atención de un gran número de

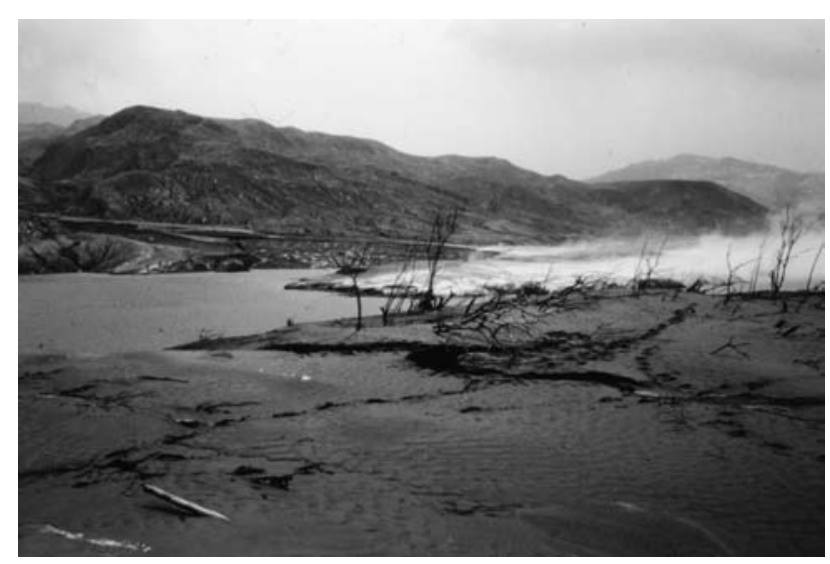

Figura 26. Vista del lago temporal formado entre abril y mayo de 1982. El agua del lago estaba en contacto con los depósitos piroclásticos por lo que estaba casi a punto de ebullición. Fotografía de Servando de la Cruz.

especialistas hacia nuestro país, quienes realizaron estudios del lago cratérico (Casadevall et al., 1984), depósitos piroclásticos (Tilling et al., 1984; Sigurdsson et al., 1984; Rose et al., 1984; Sigurdsson et al., 1987), de la dispersión de las nubes eruptivas (Varekamp et al., 1984; Carey y Sigurdsson, 1986), contenido de azufre en el magma (Devine et al., 1984; Carroll y Rutherford, 1987) y petrología de los magmas (Luhr et al., 1984).

\subsection{Erupciones holocénicas}

Como se mencionó anteriormente, la erupción arrasó con la cobertura vegetal y expuso a la luz parte del registro estratigráfico antiguo del volcán Chichón, el cual había estado en parte, cubierto por la vegetación. Los primeros estudios estratigráficos realizados después de la erupción de 1982, revelaron la existencia de depósitos con material carbonizado producidos por erupciones antiguas ocurridas hace 550, 1250 y 1650 años AP (Rose et al., 1984; Tilling et al., 1984). Tilling y colaboradores encontraron que los depósitos de la erupción ocurrida hace 1250 años, contenían fragmentos de cerámica de tipo Maya de una población que había ocupado las faldas del volcán. Posteriormente, Macías (1994) reportó otras dos erupciones fechadas en 900 y 1400 años. En el primer estudio sistemático de la historia eruptiva del volcán, Espíndola et al. (2000) encontraron que el Chichón había presentado al menos 11 erupciones explosivas, durante los últimos 8000 años ocurridas hace 550, 900,1 250, 1 400,1 700, 1 800, 2000 , 2400,3 100, 3700 y 7500 años AP (Figura 27). Este hecho ubica al Chichón, como uno de los volcanes más activos del mundo durante el Holoceno (Espíndola et al., 2000). Las erupciones ocurridas hace 550, 1250 y 1450 fueron más grandes que la erupción de 1982, que tuvo un Índice de Explosividad Volcánica IEV=4 (Newhall y Self, 1982). De hecho, la erupción pliniana ocurrida hace 550 años, 


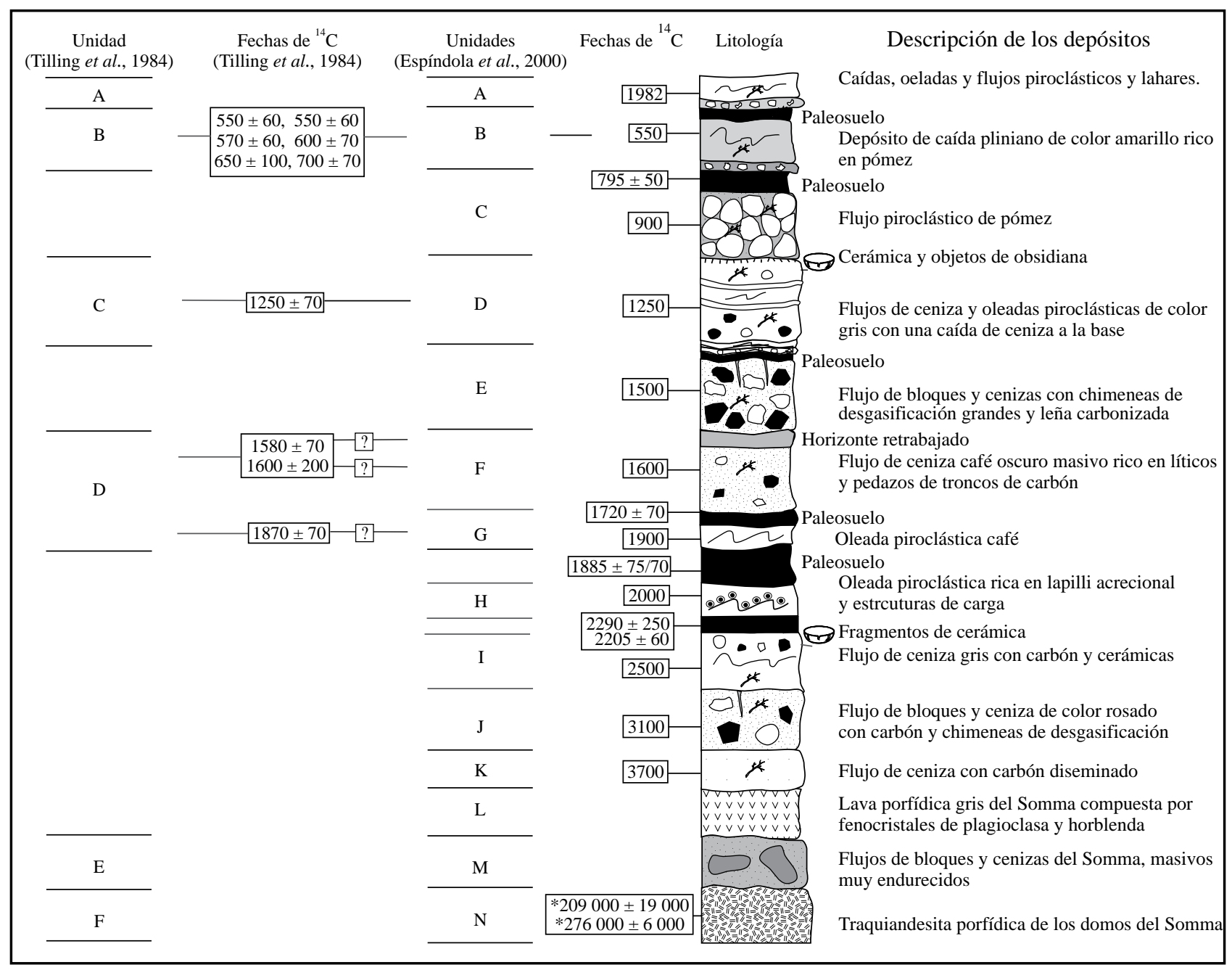

Figura 27. Columna estratigráfica simplificada del volcán Chichón que muestra los depositos formados durante el Holoceno (tomada de Espíndola et al., 2000).

produjo 1.4 km³ de material y generó un depósito de caída, que tiene un espesor con un orden de magnitud mayor al de las caídas A, B, y C de la erupción de 1982 (Macías et al., 2003). Sorprendentemente, los depósitos de flujo piroclástico de la erupción de hace 2400 años, también contenían fragmentos de cerámica casera, lo que claramente indicaba que el volcán había sido habitado durante los últimos 2500 años y que ha tenido un impacto directo y frecuente en comunidades prehispánicas. Sus erupciones pudieron haber tenido impacto en las tierras bajas de los Mayas, en donde la ceniza volcánica fue utilizada por los pobladores para cocer y elaborar sus cerámicas (Ford y Rose, 1995). La composición química del vidrio y cristales de estas cerámicas, apunta a que el Chichón y otros volcanes de Guatemala, pudieron haber hecho erupción durante este periodo, produciendo lluvia de cenizas en estas regiones desprovistas de rocas volcánicas.

El periodo de reposo entre todas estas erupciones ha variado de 100 a 600 años, la erupción de 1982 tuvo lugar después de un periodo de reposo de 550 años (Tilling et al., 1984; Espíndola et al., 2000). En el futuro no podemos descartar que ocurra una erupción en las condiciones actuales, esto es, con un cráter abierto ocupado por un lago. Una erupción en estas condiciones podría generar oleadas piroclásticas, como aquéllas registradas en las erupciones de hace 2000 y 2400 años.

\subsection{Composición química de los magmas}

Los magma expulsados por El Chichón durante los últimos 8000 años, tienen una composición traquiandesítica (Duffield et al., 1984; Rose et al., 1984; McGee et al., 1987; Espíndola et al., 2000; Macías et al., 2003). La mineralogía predominante es plagioclasa $>$ anfíbol $>$ augita, con magnetita, esfena, pirrotita, biotita y apatita como minerales accesorios (Luhr et al., 1984; Duffield et al., 1984; Espíndola et al., 2000). Tanto la composición química 
como la mineralógica son muy similares a la de los volcanes del arco volcánico Chiapaneco (Capaul, 1987). Las traquiandesitas ricas en azufre $\left(\mathrm{SO}_{2}\right)$, expulsadas durante la erupción de 1982, eran muy ricas en cristales ( $\sim 53$ vol. \%), incluyendo un $\sim 2$ vol. \% de anhidrita (Luhr et al., 1984). No se conocen erupciones previas del Chichón con un contenido alto de azufre, debido a que la anhidrita se lixivia rápidamente (Luhr et al., 1984). Mediante el uso de varios geotermómetros, se ha estimado que las traquiandesitas de la erupción de 1982 estuvieron sujetas a temperaturas entre 750 y $880{ }^{\circ} \mathrm{C}$ antes de la erupción (Luhr et al., 1984) y a profundidades cercanas a $\operatorname{los} \sim 6 \mathrm{~km}$ ( 2 kilobares, Luhr, 1990). Sin embargo, los estudios sísmicos indican que la cámara magmática durante la erupción de 1982, se encontraba entre 7 y $13 \mathrm{~km}$ por debajo del volcán debido a que a esta profundidad se presentó un gap sísmico (Jiménez et $a l ., 1998)$ lo cual podría indicar una reservorio magmático más profundo en el basamento sedimentario y evaporítico de edad Cretácica de la región, donde la asimilación pudo contribuir al enriquecimiento de azufre del magma (Rye et al., 1984). Antes de la erupción ocurrida hace 550 años, el magma tenía una temperatura de $820-830{ }^{\circ} \mathrm{C}$ y estaba saturado en agua (5-6\% en peso de $\left.\mathrm{H}_{2} \mathrm{O}\right)$, a profundidades de $\sim 6-7.5 \mathrm{~km}$ (2-2.5 kilobares) por debajo de la cima del volcán (Macías et al., 2003). Esto indica que el reservorio magmático del Chichón, ha cambiado ligeramente su posición por debajo del volcán, durante las ultimas dos grandes erupciones.

La composición constante de los productos expulsados sugiere que el sistema magmático se ha mantenido relati- vamente estable. Sin embargo, la presencia de inclusiones máficas (traquibasaltos y traquiandesitas-basálticas) en las traquiandesitas del Chichón y la variación isotópica en los perfiles de fenocristales de plagioclasas, indican que el sistema magmático ha sufrido recargas de magma en forma repetida (Espíndola et al., 2000; Tepley et al., 2000; Davidson et al., 2000; Macías et al., 2003) (Figura 28).

\section{Volcán Tacaná}

El volcán Tacaná $\left(15^{\circ} 08^{\prime} \mathrm{N}, 92^{\circ} 09^{\prime} \mathrm{W} ; 4060 \mathrm{~m}\right)$ toma su nombre del poblado de Tacaná del municipio de San Marcos, Guatemala (Figura 1). El Tacaná representa uno de los límites internacionales entre la República de Guatemala y México; es uno de los volcanes activos de nuestro país y de mayor riesgo, dado que está circundado por una población cercana a los 300000 habitantes, viviendo en un radio de $35 \mathrm{~km}$ de su cima.

\subsection{Estudios previos}

La primera mención histórica del volcán fue hecha por von Humboldt (1862), quien lo describió como el volcán Soconusco, el más noroccidental de Centroamérica. Dollfus y de Monserat (1867) lo describieron como el volcán Istak. Posteriormente, Sapper (1896; 1899) aclaró que Soconusco es sinónimo de Tacaná. En sus estudios Böse (1902, 1903, 1905) lo describió como el volcán Tacaná. Waitz (1915)

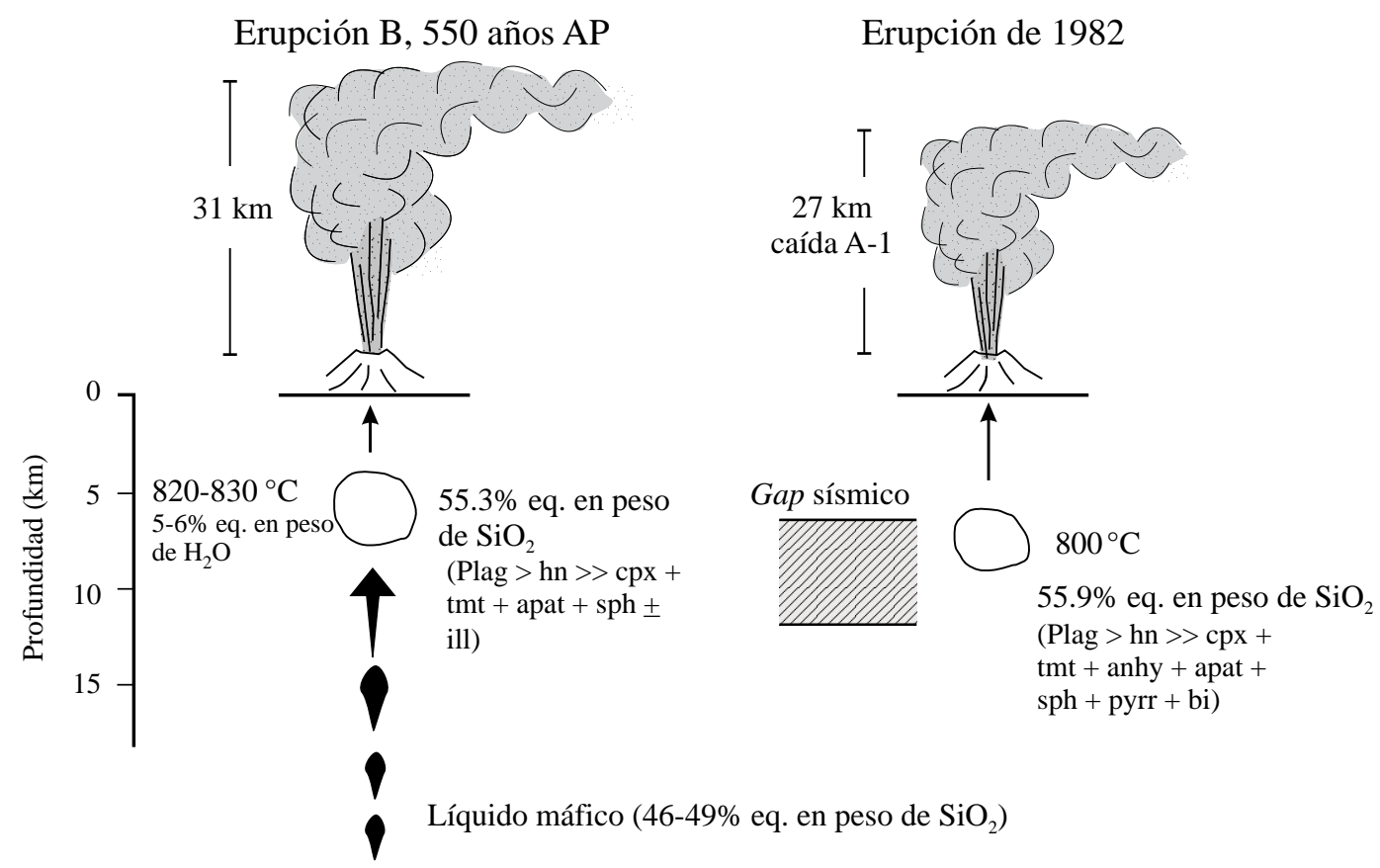

Figura 28. Esquema que muestra la posición de la cámara magmática del volcán Chichón durante sus erupciones ocurridas hace 550 años (Macías et al., 2003) y en 1982 (Jiménez et al., 1998; Luhr, 1990). 
también aclaró que Soconusco e Istak son sinónimos de Tacaná (en De Cserna et al., 1988). Sapper $(1896,1899)$ fue el primero en mencionar brevemente al volcán Tacaná. En esa misma década, Bergeat (1894) realizó la primera descripción petrográfica y clasificó a las rocas del Tacaná como andesitas de augita. Los estudios modernos en torno a este volcán iniciaron de manera casual con los temblores ocurridos el 22 de septiembre de 1902 y con la erupción de 1902 del volcán Santa María, Guatemala, ocurrida el 24 de octubre de ese mismo año. Estos eventos captaron la atención de varios geólogos, entre ellos Böse quien acudió a la región para realizar observaciones geológicas. La primera descripción detallada del Tacaná fue hecha por Böse (1902, 1903), reportando que la base del volcán se encontraba a $2200 \mathrm{msnm}$ sobre rocas graníticas. El consideró que el cerro no era realmente un cono, dado que estaba compuesto por tres escalones situados a elevaciones de 3 448, 3655 y 3872 m (cráter superior en el interior del cual está el tapón de lava). Ordóñez clasificó a las rocas colectadas por Böse $(1903,1905)$ como andesitas de hiperstena y hornblenda. El mismo Böse (1902, 1903) describió un cráter de explosión de forma elíptica de $50 \mathrm{~m}$ de diámetro y $5 \mathrm{~m}$ de profundidad, localizado al SW de la cima del volcán, sitio de donde anteriormente exhalaba ácido sulfuroso y corrientes de agua azufrosa. Sapper (1897) señaló que después de un fuerte sismo, el 12 de enero de 1855 se formaron fisuras en los flancos del Tacaná, de donde salió humo durante un tiempo breve (Mooser et al., 1958). Böse (1902, 1903) escuchó de los pobladores que en 1858 ocurrió una erupción cerca de la cima del volcán que arrojó ceniza y humo de los agujeros en forma de embudo; con menor certeza se refirió a una erupción ocurrida en 1878. Posteriormente existen las descripciones generales de Waibel (1933), quien reafirma como Böse (1902) que la roca granítica forma el basamento del Tacaná. Tanto Böse (1902, 1903) como Waibel (1933) lo consideran un volcán apagado o dormido, pero no extinto.

\subsection{La erupción de 1949}

A partir del 22 de diciembre de 1949, cuando tuvo lugar un sismo en el volcán Tacaná, los pobladores observaron columnas blancas que produjeron la caída de ceniza, cerca del poblado de Unión Juárez. Este evento atrajo la atención de los lugareños y autoridades, quienes solicitaron al Instituto de Geología estudios al respecto. En enero de 1950 acudió el geólogo Müllerried, quien realizó un recuento muy detallado de los estudios previos, de la geología de la cima y del mismo evento eruptivo (Müllerried, 1951). Mülleried observó que el cráter superior del Tacaná se encontraba $70 \mathrm{~m}$ por debajo de la cima del volcán (tercer escalón de Böse 1902) y que además se encontraba abierto hacia la porción N-NW. Al mismo tiempo, observó los otros escalones a $160 \mathrm{~m}$ por debajo de la cima, en donde se hallaba una laguna seca (cráter elíptico de Böse, 1902), y otro a $230 \mathrm{~m}$, en donde existía una laguna con agua. Según Mülleried (1951), las emanaciones de la erupción de 1949 tuvieron lugar a través de 16 bocas eruptivas localizadas en tres sitios al suroeste de la cima. Algunos de estos sitios coinciden con las descripciones de Böse (1902, 1903) sobre antiguas manifestaciones en el cráter elíptico. Las bocas eruptivas tenían diámetros variables de 2-4 m y en ocasiones se alcanzaba a ver el fondo de hasta $4 \mathrm{~m}$ de profundidad (fumarola 1); en otras fumarolas ocurrían ruidos como de locomotora (fumarola 6). De estas bocas eruptivas se levantaban columnas de humo transparente a blanco, que se observaban inclusive desde la ciudad de Tapachula. Algunas salían acompañadas de ácido sulfuroso, con la precipitación de minerales blancos a amarillos (cloruros y azufre). La erupción de 1950 propició que el Tacaná, apareciera por primera ocasión en el Catálogo de Volcanes Activos del Mundo (Mooser et al., 1958).

\subsection{La erupción de 1986}

Después de un periodo de reposo aparente de 35 años, el volcán Tacaná comenzó a dar signos de reactivación. El 19 de diciembre de 1985 se produjeron temblores locales acompañados de señales audibles, los cuales continuaron durante enero de 1986, mes en el que se instaló una red portátil de sismógrafos. El evento más importante ocurrió el 3 de febrero; en esa ocasión se produjeron daños en algunas construcciones de adobe, en la población de Ixchiguan en el Departamento de San Marcos, Guatemala, a unos $25 \mathrm{~km}$ en dirección ENE del cráter del volcán. La actividad fue incrementándose hasta el 7 de mayo, cuando se presentó un enjambre de sismos que provocó pánico entre la población. El 8 de mayo, cuando la frecuencia de los temblores sentidos era de más de 2 por minuto, una pequeña erupción freática dio lugar a un cráter de unos $8 \mathrm{~m}$ de diámetro en su lado noroeste, a $3600 \mathrm{~m}$ casi sobre la línea fronteriza, en el lado mexicano (De-la Cruz et al., 1989). De este cráter, se levantaba una columna de vapor de agua y gases de hasta $1000 \mathrm{~m}$ de altura. Posteriormente, la actividad sísmica declinó notablemente y dos días después alcanzó los niveles precedentes del mes de abril. La fumarola tenía una composición enriquecida en vapor de agua, sin componentes magmáticos (Martini et al., 1987).

Casualmente, un poco antes de la erupción de 1986, la Comisión Federal de Electricidad había iniciado una serie de estudios para evaluar el potencial geotérmico del volcán Tacaná. Los estudios que se implementaron incluyeron la geología de semidetalle del volcán (De-la Cruz y Hernández, 1985) y la evolución geoquímica de la zona geotérmica (Medina-Martínez, 1986). De estos últimos se desprende que las aguas de los manantiales del Tacaná son de tipo sulfatado ácido y que existían una serie de fumarolas localizadas entre 3200 y $3600 \mathrm{~m}$ de altura al S-SW de la cima del volcán, con temperaturas entre 82 y $94{ }^{\circ} \mathrm{C}$. Actualmente muchos manantiales alrededor del 
volcán tienen una composición rica en $\mathrm{CO}_{2}$; la composición química de todos los manantiales puede interpretarse como una mezcla entre un componente de agua profunda rica en $\mathrm{SO}_{4}-\mathrm{HCO}_{3}-\mathrm{Cl}$ y agua meteórica diluida (Rouwet et al., 2004). De esta forma, en la actualidad la emisión total de volátiles del Tacaná es de $\sim 50 \mathrm{t} / \mathrm{d}$ de $\mathrm{SO}_{2}$, que es un valor típico de desgasificación para volcanes pasivos.

Los estudios que siembran las bases geológicas del Tacaná, son los iniciados por la Comisión Federal de Electricidad (CFE) (De-la Cruz y Hernández, 1985) y por Saucedo-Girón y Esquivias (1988). En estos trabajos se plantea el primer mapa geológico del Tacaná, a escala aproximada 1:120 000, en donde afirman que el volcán está construido sobre el basamento granítico y andesitas del Terciario. Estos autores cartografiaron e identificaron tres depósitos de flujos piroclásticos que denominaron Qt1, Qt2 y Qt3, y asociaron a la formación de tres calderas pequeñas. Posteriormente, De Cserna et al. (1988) presentaron un mapa fotogeológico preliminar del Tacaná a escala 1:50 000, en donde definieron 14 unidades estratigráficas y una descripción detallada de los estudios previos. En su estudio concluyeron que el Tacaná es un estratovolcán poligenético compuesto por tres volcanes alineados en dirección NE-SW, que expusieron como los periodos eruptivos Talquian, Tacaná y El Águila. Seguramente estos tres volcanes corresponden a las tres calderas propuestas por De-la Cruz y Hernández (1985). De la misma forma, Mercado y Rose (1992) elaboraron un mapa fotogeológico del Tacaná y mapas de peligros para diferentes tipos de eventos volcánicos. En su trabajo reportan por primera vez análisis químicos de rocas que indican que el volcán está compuesto por andesitas de composición calcialcalina.

\subsection{Marco geológico}

El Tacaná se encuentra ubicado muy cerca de la zona de triple unión de las placas tectónicas de Norteamérica, Caribe y Cocos (Burkart y Self, 1985) dentro del bloque cortical de Chortis (Ortega-Gutiérrez et al., 2004) (Figura 29). Debido a su posición tectónica, no existe un basamento Paleozoico en la región como se había planteado (Mooser et al., 1958; De Cserna et al., 1988; De-la Cruz y Hernández, 1986) sino de probable edad Mesozoica. Existen dos fases de intrusión con edades de 29-35 Ma y 13-20 Ma representadas por granitos, granodioritas y tonalitas (Mugica-Mondragón, 1987; García-Palomo et al., 2006). La actividad volcánica inició hace 2 Ma con la formación de la caldera San Rafael y continuó hace 1 Ma con la creación de la caldera Chanjalé (García-Palomo et al., 2006). El Tacaná se emplazó durante los últimos 100000 años o menos dentro de la caldera San Rafael. En realidad el Tacaná es un complejo volcánico como lo mencionó De Cserna et al. (1988), que consiste en cuatro estructuras alineadas en dirección NE-SW y son los volcanes Chichuj (Talquian), Tacaná, el domo las
Ardillas y San Antonio (El Águila) (Macías et al., 2000; García-Palomo et al., 2006) (Figura 30).

\subsection{Historia eruptiva}

Los primeros fechamientos de material carbonizado en depósitos prehistóricos del volcán Tacaná fueron obtenidos por Espíndola et al. (1989). Estos autores fecharon en 42000 años $\left({ }^{14} \mathrm{C}\right)$ un depósito de flujos de bloques y ceniza en la localidad de La Trinidad. Este depósito correspondía al abanico de piroclástos Qt3, propuesto por De-la Cruz y Hernández (1985). Con base en esta edad, Espíndola y colaboradores consideraron que estos depósitos de Qt3 deberían de corresponder a algunos de los depósitos más viejos del Tacaná y que, por ende, los depósitos Qt2 y Qt1 tenían que ser más jóvenes. Nuevas observaciones de campo arrojaron una edad de 38000 años para el mismo depósito de flujo de bloques y ceniza de La Trinidad (Espíndola et al., 1996), edad muy cercana a la ya reportada por Espíndola et al. (1989); también otra edad cercana a los 30000 años en la localidad de Monte Perla, siempre sobre el abanico Qt3 en un depósito de flujo de bloques y ceniza. De esta forma, era obvio que aún dentro del abanico de piroclástos Qt3 existen varios depósitos sobrepuestos producidos por diferentes erupciones, que provenían probablemente del volcán Tacaná.

Posteriormente, Macías et al. (2000) identificaron dos erupciones ocurridas hace 10000 y 1950 años, lo que indicaba que el Tacaná había tenido al menos cuatro erupciones de gran magnitud durante los últimos 40000 años. La erupción de hace 1950 años proveniente del volcán San Antonio produjo el flujo piroclástico Mixcun que correspondía a el abanico de piroclástos Qt2 de De-la Cruz y Hernández (1985). Esta erupción causó el abandono temporal del centro ceremonial de Izapa (Macías et al., 2000) ocurrido durante el primer siglo de nuestra era (Lowe et al., 1982). Las erupciones acaecidas hace 40000,30000 y 1950 años, habían sido producidas por la destrucción parcial o total de un domo central con la generación de flujos piroclásticos de bloques y cenizas, capaces de viajar varios kilómetros y de rellenar barrancas con varios metros de espesor. Recientemente se han identificado al menos otras seis erupciones del volcán Tacaná, ocurridas hace $32000,28000,<26000,16000,7500$ y 6500 (Macías et al., 2004b; Mora et al., 2004; García-Palomo et al., 2006). Algunas de estas erupciones no habían sido consideradas en la zonificación de peligros volcánicos (Mercado y Rose, 1992; Macías et al., 2000).

Las erupciones que se presentaron hace $28000 \mathrm{y}$ 16000 años fueron producidas por la destrucción de un domo central, por lo que se suman a las erupciones descritas anteriormente de 40000 y 2000 años (volcán San Antonio). Sin embargo, la erupción de 32000 años fue un evento producido por actividad de tipo pliniana, que no había sido registrada en el volcán Tacaná, salvo una 

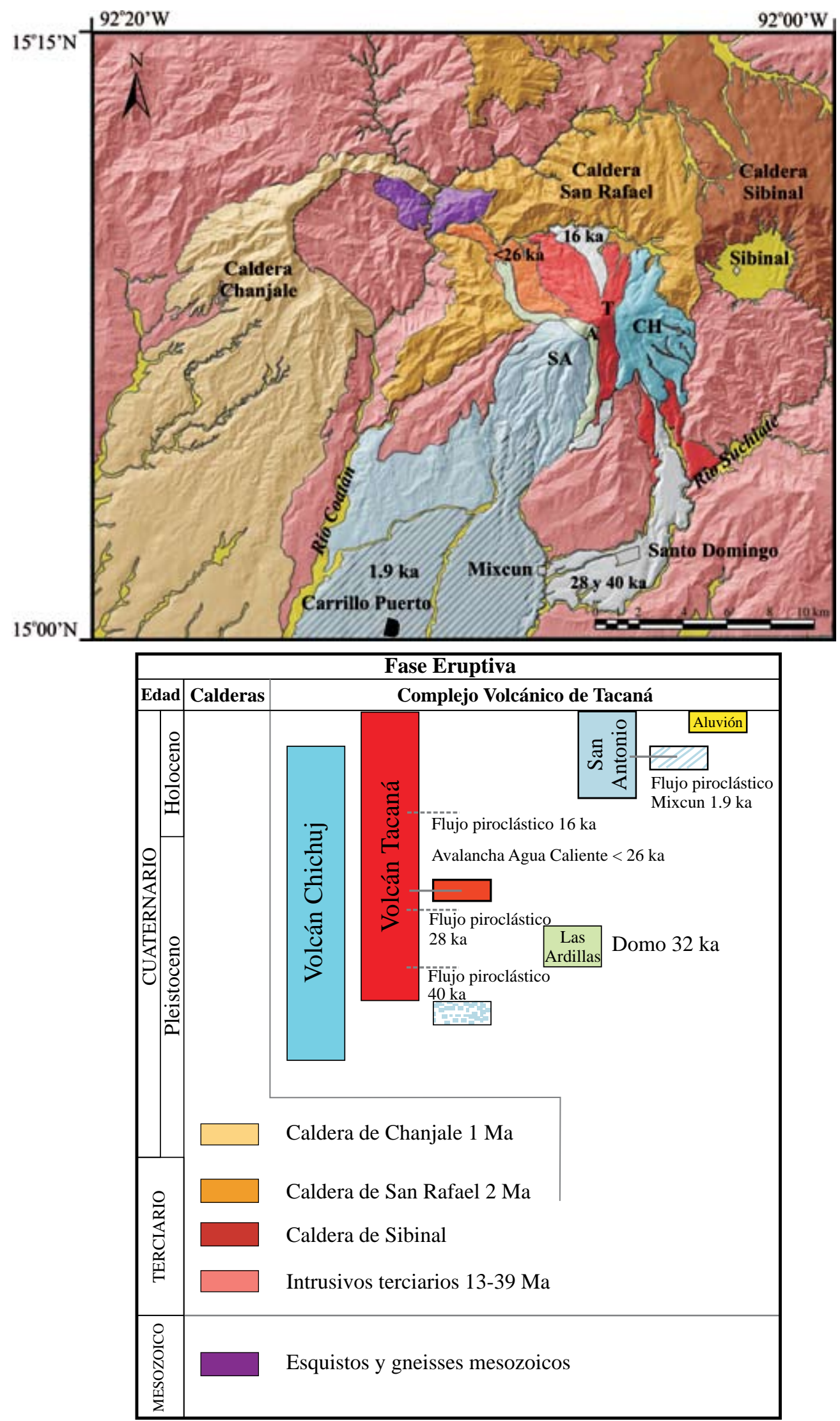

Figura 29. Mapa geológico general del complejo volcánico de Tacaná el cual se encuentra enclavado dentro de la caldera de San Rafael de 1 Ma. Se muestran algunos de los depósitos piroclásticos producidos durante los últimos 50000 años en el volcán Tacaná y el depósito de flujo piroclástico Mixcun de 1950 años. Modificado de García-Palomo et al. (2006). T: volcán Tacaná, SA: volcán San Antonio, Ch: volcán Chichuj, A: domo Las Ardillas. 


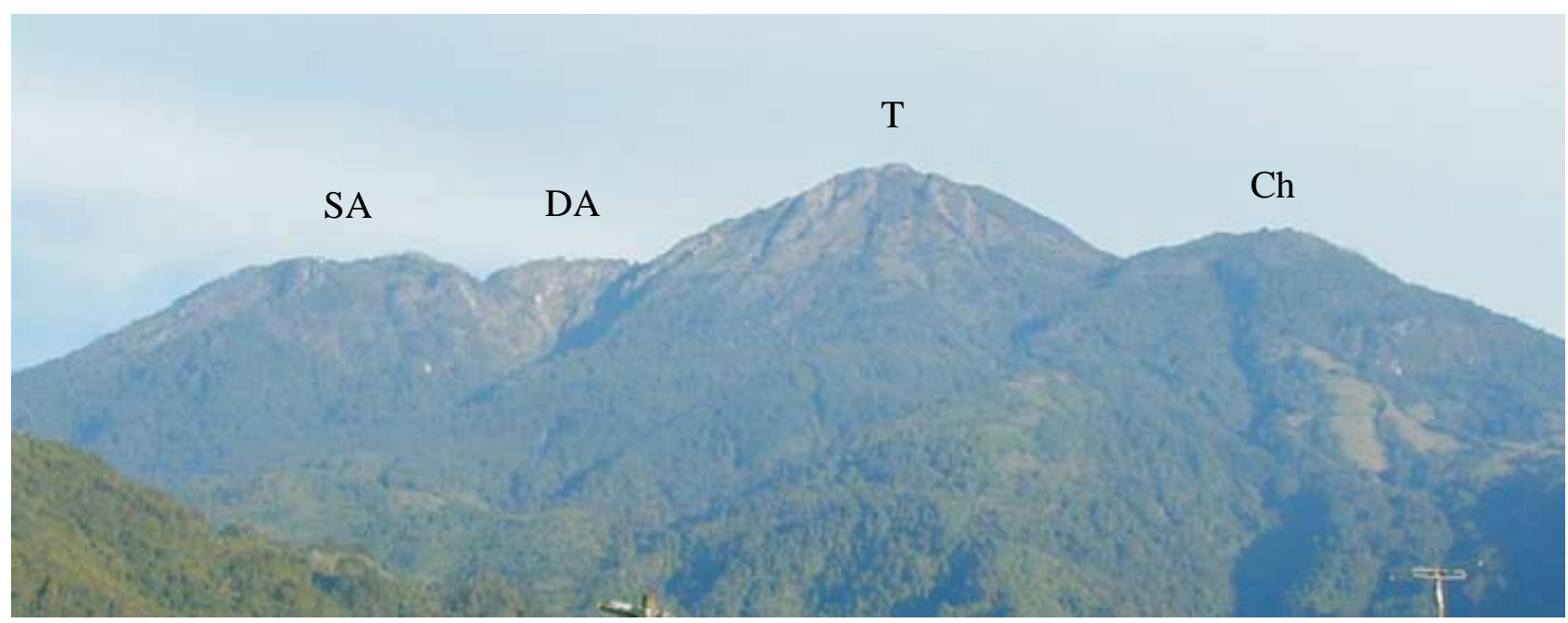

Figura 30. Panorámica del complejo volcánico de Tacaná, México-Guatemala. Vista desde el poblado de Unión Juárez hacia el NW de los edificios volcánicos de Chichuj (Ch), Tacaná (T), domo las Ardillas (DA) y San Antonio (SA).

mención muy superficial en el trabajo de Mercado y Rose (1992), en donde incluían una isopaca de $2 \mathrm{~m}$ en el pueblo de Sibinal, Guatemala. Otra erupción sobresaliente está representada por el colapso de la porción noroccidental del volcán Tacaná, que ocurrió hace menos de 26000 años. Este evento produjo una avalancha de escombros que viajó $8 \mathrm{~km}$ hasta el río Coatán, bloqueando el drenaje de los ríos San Rafael y Chocabj. El depósito tiene un H/L de 0.35, cubre un área mínima de $8 \mathrm{~km}^{2}$ y tiene un volumen mínimo de $1 \mathrm{~km}^{3}$ (Macías et al., 2004b). Las erupciones fechadas alrededor de 7500 y 6500 años han producido flujos piroclásticos de ceniza y pómez y oleadas piroclásticas, respectivamente, cuyos depósitos cubren el cono moderno del volcán Tacaná.

Todas estas erupciones han producido lahares a lo largo de los cauces de los ríos Coatán, Cahoacán y Mixcun, los cuales drenan hacia el Océano Pacífico. En el estudio de Macías et al. (2000) se reporta que el sitio prehispánico de Izapa fue abandonado alrededor del primer siglo D.C., debido a inundaciones asociadas a la erupción Peleana, ocurrida hace 1950 años en el Tacaná. Es muy impresionante observar que diversos depósitos de lahar de edad desconocida afloran en las zonas limítrofes de la ciudad de Tapachula (250 000 habitantes). La ciudad de Tapachula está asentada en los límites de dos enormes abanicos aluviales de edad Pleistoceno-Holoceno, y entre los ríos Coatán y Cahoacán. En estos ríos ocurren inundaciones anuales y en ocaciones algunas más graves como las producidas en octubre de 2005 por el huracán Stan.

Desde un punto de vista petrológico el complejo volcánico de Tacaná está compuesto principalmente por andesitas con dos piroxenos con una asociación mineralógica de plagioclasa, augita, hiperstena+óxidos de hierro y en ocasiones hornblenda. En menor proporción se tienen dacitas con la misma composición mineralógica, formando esen- cialmente lavas o domos viscosos. La composición química de los volcanes del complejo muestra algunas variaciones significativas (Mercado y Rose, 1992; Macías et al., 2000; Mora, 2001; Mora et al., 2004). De este modo el volcán Chichuj ha generado flujos de lava y domos andesíticos $\left(59-63 \% \mathrm{SiO}_{2}\right)$. El volcán Tacaná presenta flujos de lava basáltico andesíticos $\left(56-61 \% \mathrm{SiO}_{2}\right)$, flujos de lava y domos andesíticos y dacíticos $\left(61-64 \% \mathrm{SiO}_{2}\right)$, y flujos piroclásticos con líticos juveniles de composición andesítica (60-63\% $\mathrm{SiO}_{2}$ ). El volcán San Antonio ha originado flujos de lava andesíticos y domos dacíticos $\left(58-64 \% \mathrm{SiO}_{2}\right)$.

\section{Discusión y conclusiones}

En su mayoría, los grandes volcanes de México se localizan dentro de la provincia geológica conocida como la Faja Volcánica Transmexicana (FVTM), un arco volcánico continental formado por miles de estructuras volcánicas, que atraviesa nuestro país entre los paralelos $19^{\circ}$ y $20^{\circ}$ de latitud norte (Figura 1). El vulcanismo también aparece en menor grado en zonas aisladas del territorio nacional, como el campo volcánico de San Quintín y el complejo volcánico de Tres Vírgenes en Baja California, el campo volcánico de Pinacate en Sonora, las islas Revillagigedo en el Pacífico, el campo volcánico de los Tuxtlas en Veracruz, el cinturón volcánico de Chiapas y el volcán Tacaná, Chiapas, que representa el volcán activo más noroccidental del arco volcánico de Centroamérica (AVCA). Un gran número de autores concluye que la FVTM es un arco volcánico originado por la subducción de las placas de Rivera y Cocos, por debajo de la placa de Norteamérica en la trinchera Mesoamericana (Ponce et al., 1992; Singh y Pardo, 1993; Pardo y Suárez, 1993, 1995). Sin embargo, la disposición oblicua de $\sim 15^{\circ}$ con respecto a la trinchera Mesoamericana 
de la FVTM ha llevado a otros autores a proponer que su origen se debe a una zona de fractura o megacizalla (Cebull y Shurbet, 1987), una estructura parecida a un rift que está experimentando extensión activa (Sheth et al., 2000). La posición oblicua de la FVTM contrasta con el arreglo del AVCA, el cual se extiende de manera paralela a la costa desde el occidente de Panamá, hasta el borde entre México y Guatemala. En esta región el vulcanismo desaparece, se vuelve discontinuo y se aleja de la trinchera al igual que las curvas de igual profundidad de sismos (Figura 31). Así, el vulcanismo se manifiesta de manera errática formando el cinturón volcánico de Chiapas (CVC) con productos calcialcalinos, hasta el volcán activo Chichón de composición alcalino potásica, ubicado a $400 \mathrm{~km}$ de la trinchera. El vulcanismo surge de manera aislada en el campo volcánico de los Tuxtlas, con productos alcalinosódicos y calcialcalinos; este campo está ubicado a 350 $\mathrm{km}$ de la trinchera. De esta forma, Nixon (1982) propuso que el vulcanismo alcalino de los Tuxtlas y del Chichón, se debía a una tectónica extensional asociada a la triple unión entre las placas de Norteamérica, Caribe y Cocos. Sin embargo, otros autores concluyen que el vulcanismo en esta región está asociado a la subducción de la placa de Cocos, por debajo de Norteamérica (Stoiber and Carr, 1973; Thorpe, 1977; Havskov y Macías, 1983; Burbach et al., 1984; Bevis and Isacks, 1984; Luhr et al., 1984; García-Palomo et al., 2004).

Finalmente, el vulcanismo reaparece en la FVTM en el paralelo $19^{\circ}$, que ocupa la parte central de México desde las costas de Veracruz hasta las costas de Nayarit, con productos predominantemente calcialcalinos y con algunas regiones aisladas de volcanismo alcalino, como el graben de Colima y la sierra de Chichinautzin (Figura 31). Los volcanes de Colima, Nevado de Toluca, Popocatépetl y Pico de Orizaba están ubicados a lo largo de la FVTM por lo que el espesor de la corteza continental por debajo de éstos aumenta desde el volcán de Colima (20-22 km), Nevado de Toluca (40 km), Popocatépetl (47 km) hasta el Pico de Orizaba $(>50 \mathrm{~km}$ ) (Molina-Garza y Urrutia-Fucugauchi, 1993; Urrutia-Fucugauchi y Flores-Ruiz, 1996). Esto se ve reflejado en la gráfica de las relaciones isotópicas de ${ }^{87} \mathrm{Sr} /{ }^{86} \mathrm{Sr} v$ s. $\varepsilon \mathrm{Nd}$, de los volcanes (Nelson et al., 1995; Macías et al., 2003; Martínez-Serrano et al., 2004; Schaaf et al., 2004) (Figura 32). Como se puede apreciar, el volcán de Colima tiene una posición más cercana a la trinchera y las relaciones isotópicas de sus productos son más primitivas que las de los volcanes Nevado de Toluca, Popocatépetl, y Pico de Orizaba que tienen una posición más alejada a la trinchera y el espesor cortical por debajo de éstos es mayor. Debido a esto, sus magmas muestran evidencias claras de contaminación cortical, la cual ha sido también observada con isótopos de osmio (Chesley et al., 2000; Lassiter y Luhr, 2001) y la presencia de xenolitos de la corteza (Valdez-Moreno et al., 2006). El grado de asimilación cortical, está relacionado con la composición y la edad de la corteza continental con la que el magma interactúa, así como con su tiempo de almacenamiento en la base de la corteza y durante su posterior ascenso hacia la

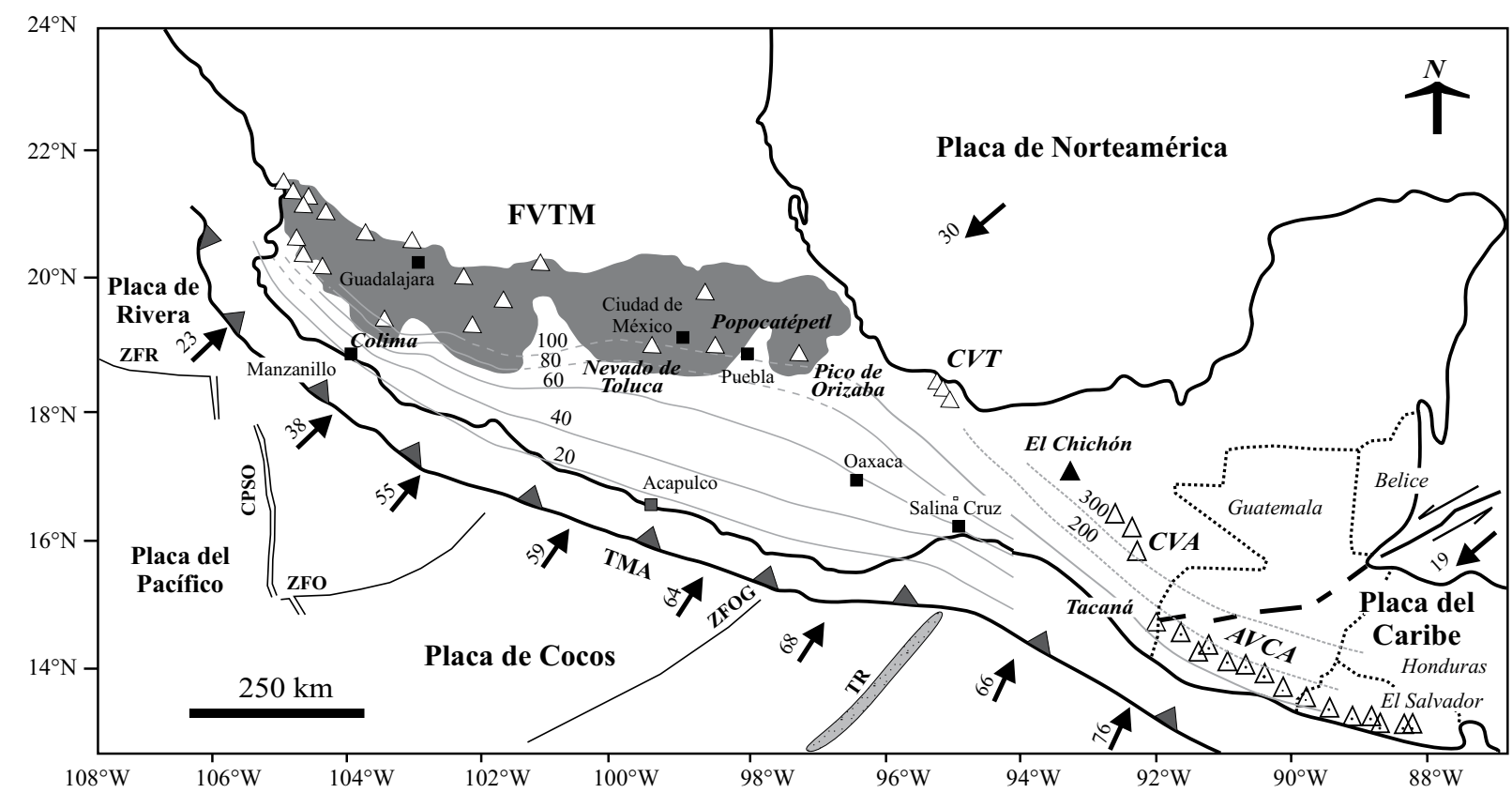

Figura 31. Marco tectónico del centro-sur de México que muestra la ubicación de la Faja Volcánica Transmexicana (FVTM), del campo volcánico de los Tuxtlas (CVT), el cinturón volcánico de Chiapas (CVA) y el arco volcánico de Centroamérica (AVCA) con respecto a las placas tectónicas. Las líneas en gris representan las curvas de igual profundidad de sismos. ZFO: Zona de Fractura de Orozco, TMA: Trinchera Mesoamericana, CPSO: Cresta Pacífica Oriental, ZFR: Zona de Fractura de Rivera, ZFOG: Zona de Fractura de O’Gorman, y TR: Ridge de Tehuantepec. Modificada de García-Palomo et al. (2004). 


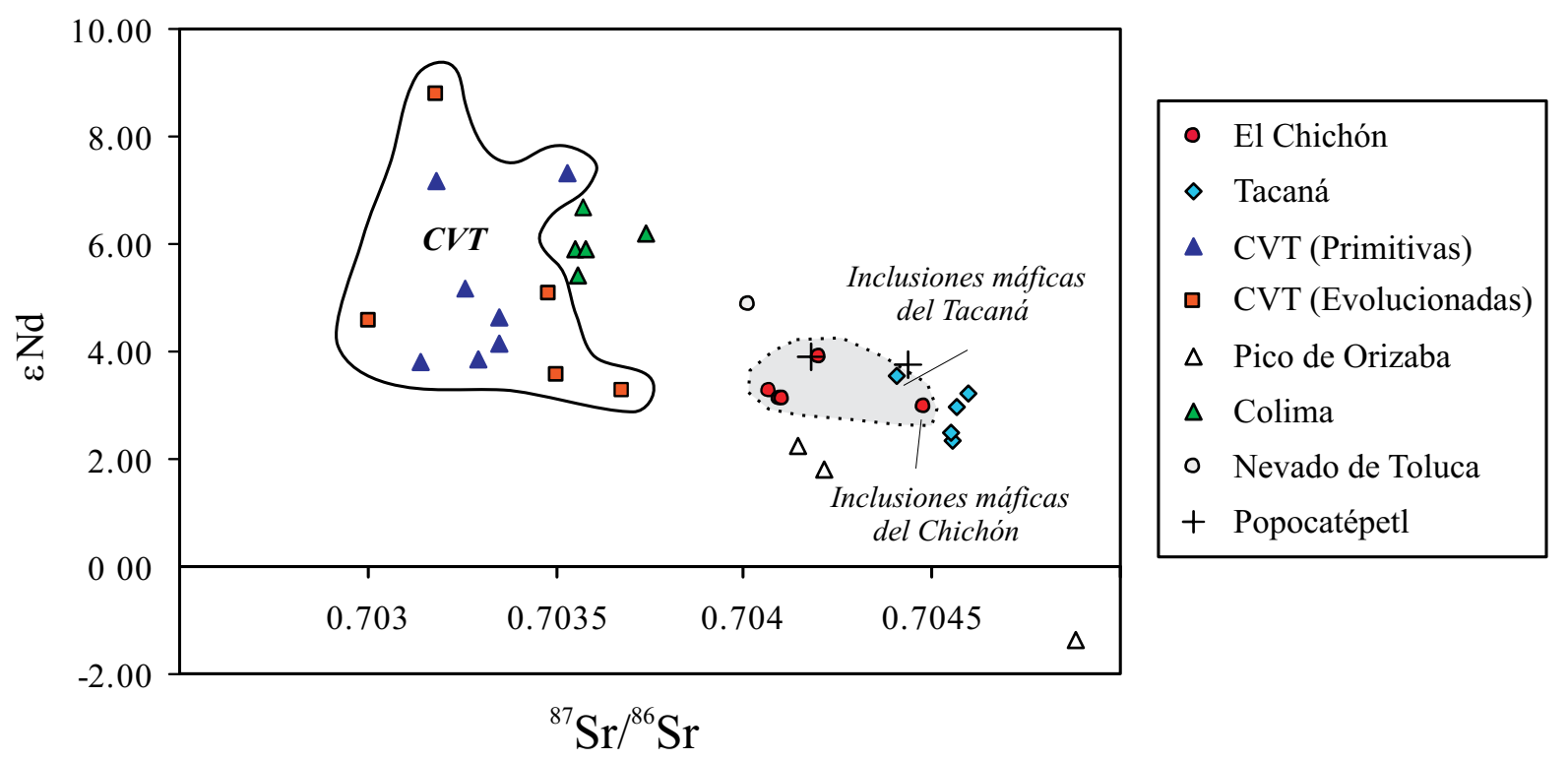

Figura 32. Relaciones isotópicas de ${ }^{87} \mathrm{Sr} /{ }^{86} \mathrm{Sr} v$ s. Epsilon neodimio de rocas de los volcanes de Colima, Nevado de Toluca, Popocatépetl, Pico de Orizaba, campo volcánico de los Tuxtlas, Chichón, y Tacaná.

superficie. De esta forma, Schaaf et al. (2004) concluyeron que las relaciones isotópicas primitivas de los magmas del volcán de Colima, se deben a que existe por debajo del mismo una corteza joven y primitiva, mientras que las relaciones isotópicas más evolucionadas de los volcanes Popocatépetl y Pico de Orizaba, tienen lugar porque por debajo de los mismos se encuentra la Formación Morelos y rocas grenvillianas, respectivamente.

En el sur de México tenemos productos volcánicos con características diferentes (Figura 32). El volcán Tacaná, esta localizado a sólo $100 \mathrm{~km}$ de la trinchera y tiene un espesor cortical aproximado de $40 \mathrm{~km}$ (Rebollar et al., 1999). Este volcán presenta productos con valores isotópicos compatibles, con un mayor grado de asimilación cortical $\left({ }^{87} \mathrm{Sr} /{ }^{86} \mathrm{Sr}\right.$ : 0.70441-0.70459; \&Nd: 2.26-3.57) (Mora et al., 2004), que las relaciones isotópicas de los volcanes Chichón (Macías et al., 2003) ubicado a $250 \mathrm{~km}$ de la trinchera y varios volcanes del campo volcánico de los Tuxtlas, situado a $350 \mathrm{~km}$ de la trinchera (Nelson et al., 1995). Las rocas del sur de México, tienen una firma calcialcalina con un contenido medio en $\mathrm{K}$, con anomalías negativas de $\mathrm{Nb}$, $\mathrm{Ti}$, y P, y enriquecimientos de las Tierras Raras ligeras, típico de ambientes de subducción.

Durante los últimos 30 años se han establecido las características composicionales de la mayoría de nuestros volcanes mediante el estudio químico de los elementos mayores, traza y Tierras Raras. A pesar de este avance, conocemos todavía muy poco sobre los procesos de generación del magma y la fusión parcial del manto que tienen lugar a profundidades superiores a $75 \mathrm{~km}$; también acerca de los procesos de asimilación y contaminación cortical originados a profundidades menores de $50 \mathrm{~km}$, y sobre los procesos de cristalización fraccionada y almacenamiento del magma antes de su erupción, que ocurren a profundidades relativamente someras, inclusive a pocos kilómetros por debajo de la superficie terrestre. En este último campo, recientemente se han llevado a cabo estudios de petrología experimental para conocer las condiciones pre-eruptivas (presión, temperatura y saturación de agua) de los magmas asociados a erupciones recientes. Por ejemplo, sabemos que las condiciones de equilibrio mineralógico del magma, de la erupción de 1998 del volcán de Colima indican que éste tenía una temperatura de $840-900^{\circ} \mathrm{C}$ y se estacionó a profundidades de 3-7 km por debajo del cráter (Mora et al., 2002). De la misma forma, se ha determinado que durante tres erupciones ocurridas entre 14000 y 10500 años (Pleistoceno tardío) en el volcán Nevado de Toluca, el magma tenía una temperatura de $814-840^{\circ} \mathrm{C}$ y se estacionó en una cámara magmática ubicada a $6 \mathrm{~km}$ de profundidad por debajo del cráter (Arce et al., 2005a). En otro estudio petrológico, se analizaron los productos emitidos durante los eventos eruptivos ocurridos entre abril de 1996 y febrero de 1998, en el volcán Popocatépetl (Straub y Martín-del Pozzo, 2001). Los resultados de este estudio indicaron que el magma híbrido emitido era el resultado de una mezcla entre dos magmas, uno andesítico $\left(55 \% \mathrm{SiO}_{2}, 1170-1085\right.$ $\left.{ }^{\circ} \mathrm{C}\right)$ saturado en olivino y espinela, probablemente formado en el Moho y otro dacítico $\left(62 \% \mathrm{SiO}_{2}, \sim 950{ }^{\circ} \mathrm{C}\right)$ con clinopiroxeno, ortopiroxeno y plagioclasa estacionado entre $\sim 4$ y $13 \mathrm{~km}$ por debajo del cráter. Wallace y Carmichael (1999) concluyeron que la temperatura de formación de algunos basaltos de olivino del campo volcánico de Chichinautzin osciló entre 1200 y $1290{ }^{\circ} \mathrm{C}$ empleando el programa MELTS. Para las lavas recientes, emitidas por los dos centros eruptivos del Volcancito en la parte oriental de la FVTM, se estimaron temperaturas de 1198 
a $1236^{\circ} \mathrm{C}$ (basalto calcialcalino del río Nolinco) y 1166 a $1175^{\circ} \mathrm{C}$ (hawaita Toxtlacuaya) (Carrasco-Núñez et al., 2005). Todos estos estudios representan un gran avance en el conocimiento de la evolución somera de los magmas, sin embargo, desconocemos procesos más profundos que podrían ser cubiertos en parte por el estudio de xenolitos (Blatter y Carmichael, 1998) y con las inclusiones fluidas (gases y líquido magmático) atrapadas en los magmas. Ya se han realizado algunos estudios en este sentido, como aquéllos de los volcanes Parícutin (Luhr, 2001) y del campo volcánico de Chichinautzin (Cervantes y Wallace, 2003). Otros estudios que nos permitirían tener una visión más completa de los procesos magmáticos son los isotópicos de Boro (Hochstaedter et al., 1996) para estimar el aporte de sedimentos al proceso de subducción, isótopos de hidrógeno para conocer las características isotópicas del agua magmática (Tarán et al., 2002), así como isótopos de $\mathrm{Sr}-\mathrm{Nd}-\mathrm{Pb}$ para evaluar los procesos petrológicos y la fuente de los magmas (Martínez-Serrano et al., 2004; Schaaf et al., 2005; Valdéz-Moreno et al., 2006).

Como se ha documentado en la primera parte de este trabajo, se han logrado avances significativos en el conocimiento de la estratigrafía de nuestros volcanes, que es indispensable para conocer su historia eruptiva. En la mayoría de nuestros volcanes, este registro es muy detallado para los últimos 50000 años, que es el periodo de tiempo cubierto por el método de ${ }^{14} \mathrm{C}$. Por ejemplo, empleando el método de ${ }^{14} \mathrm{C}$ podríamos documentar de manera detallada la historia eruptiva de los volcanes Paleofuego y volcán de Colima, pero no la historia del Nevado de Colima. En otras palabras, la mayoría de nuestros volcanes comenzaron sus etapas de formación hace 1-2 Ma, por lo que el inicio de su actividad desborda con facilidad el alcance máximo del método de ${ }^{14} \mathrm{C}$. De esta forma, para completar la evolución geológica de estos volcanes activos debemos utilizar otros métodos radiométricos de fechamiento como los de K-Ar, Ar/Ar en minerales y rocas, termoluminiscencia en minerales, ${ }^{36} \mathrm{Cl}$ para medir pulimento glaciar, etc. Ya se han iniciado esfuerzos prácticamente en todos nuestros volcanes, que en su mayoría, cuenta con algunos fechamientos de esta naturaleza, logrando apuntalar su historia geológica.

Los estudios geológicos (petrológicos, geoquímicos y vulcanológicos) junto con los registros históricos, son muy importantes para establecer el comportamiento pasado de nuestro volcanes activos y, por ende, pronosticar su comportamiento futuro. Por ejemplo, la historia eruptiva del volcán Popocatépetl indica que ha producido erupciones de tipo pliniano, durante los últimos 23000 años, por lo que es muy posible que su próxima gran erupción tenga el mismo estilo eruptivo. En cambio, el volcán de Colima ha presentado en el pasado el colapso del edificio volcánico, erupciones plinianas y otras que forman flujos piroclásticos por el empuje y destrucción parcial de un domo central. Este último tipo de actividad se ha venido verificando durante los últimos 20 años, tal y como lo hemos atestiguado en los primeros meses del año 2005. La historia geológica, única de cada uno de nuestros volcanes activos, nos obliga a preparar mapas de peligros volcánicos para cada uno de éstos. Estos mapas representan de manera gráfica las zonas que han sido afectadas en el pasado por erupciones de diferente magnitud y, por lo tanto, también muestran las áreas que podrían ser puestas en peligro por erupciones volcánicas futuras. El día de hoy, únicamente contamos con los mapas de lo volcanes Colima, Popocatépetl y Pico de Orizaba. Estos mapas representan una fuente de información básica para las autoridades de Protección Civil, para establecer planes de ordenamiento territorial, preventivos, ubicar albergues, sitios de reunión y rutas de escape en caso de una erupción inminente (Macías-Vázquez y Capra-Pedol, 2005).

La información geológica (historia eruptiva, registro histórico, mapa de peligros, química de los productos juveniles) representa, junto con la información geofísica (sismología, gravimetría, magnetometría, etc.) y geoquímica, una base muy importante para comprender el comportamiento de los volcanes activos. La erupción de 1994-presente del volcán Popocatépetl, permitió reunir toda esta información, establecer una red de monitoreo y pronosticar sus eventos eruptivos. Sin embargo, hasta esta fecha no se ha logrado establecer un modelo conceptual del funcionamiento del volcán, en donde aparezca con mayor certeza la profundidad de la cámara magmática, los tiempos de ascenso del magma a la superficie y su relación con la desgasificación observada en superficie.

Los estudios vulcanológicos en nuestro país durante las próximas décadas deberán estar encaminados a esclarecer y completar la historia eruptiva de nuestro volcanes activos, determinar los procesos geoquímicos y petrológicos que intervienen en la generación del magma a profundidad y su ascenso hacia la superficie, elaborar los mapas de peligro faltantes y actualizar los mapas de peligros existentes. Y finalmente, se requiere que la información geológica y geofísica acumulada en nuestros volcanes sea difundida entre la población. Una erupción volcánica no puede ser evitada, pero sus daños sí pueden ser aminorados para que ésta no se convierta en un desastre volcánico, como el acontecido en 1982 durante la erupción del volcán Chichón.

\section{Agradecimientos}

Este trabajo es el resultado de varios proyectos financiados por CONACYT (47226) y DGAPA. Muchas de las observaciones y notas de este estudio han sido realizadas con varios compañeros y amigos: J. M. Espíndola en los volcanes Chichón y Tacaná, C. Siebe en el Popocatépetl, R. Saucedo, J. C. Gavilanes y A. Cortés en Colima, G. Carrasco en el Pico de Orizaba y A. García, L. Capra, J. L. Arce, R. Saucedo, J. C. Mora, T. Scolamacchia, K. Scott, S. Hughes y D. Sarocchi en todos estos volcanes. Las imágenes de satélite son una cortesía de Michael Abrams del Jet Propulsión Laboratory, NASA. Los comentarios y sugerencias proporcionados por G. Carrasco y M. Ort, mejoraron la 
organización y lectura de este trabajo. Agradezco el apoyo grafico ofrecido para elaborar los mapas geológicos por C. Limón, en la búsqueda de la información bibliográfica por C. Ordaz y a Sara Solís por la corrección de la lista de referencias. Finalmente quiero agradecer el apoyo técnico brindado por A. M. Rocha y el logístico brindado por E. Segre y A. Fernández en el volcán Popocatépetl, y S. Hernández en los volcanes Chichón y Tacaná. Finalmente quiero agradecer a Reynaldo Mota, Jorge Neyra, R. Díaz y a G. Carrasco por el material que en su momento me fue proporcionado para ilustrar este trabajo.

\section{Referencias bibliográficas}

Aceves-Quesada, J.F., 1996, Geología y geomorfología del Nevado de Toluca: México, D.F., Universidad Nacional Autónoma de México, Facultad de Ciencias, Tesis de maestría, $116 \mathrm{p}$.

Aguilera, J.G., Ordóñez, E., 1895, Expedición científica al Popocatépetl: México, Oficina de la Secretaría de Fomento: Comisión Geológica Mexicana, $48 \mathrm{p}$.

Allan, J.F., 1986, Geology of the northern Colima and Zacoalco grabens in the southwest México: late Cenozoic rifting in the Mexican Volcanic Belt: Geological Society of America Bulletin, 97, 473-485.

Allan, J.F., Carmichael, I.S.E., 1984, Lamprophyric lavas in the Colima graben, SW México: Contributions to Mineralogy and Petrology, $88,203-216$.

Anderson, T., Flett, J.S., 1903, Report on the eruption of the Soufrière Vincent in 1902 and on a visit to Montagne Pelee in Martinique: Royal Society of London, Philosophical Transactions, Serie A, Physical Sciences and Engineering, 200, 353-553.

Arce-Saldaña, J.L., 2003, Condiciones pre-eruptivas y evolución de la erupción pliniana pómez Toluca superior, volcán Nevado de Toluca: México, D.F., Universidad Nacional Autónoma de México, Instituto de Geofísica, Tesis doctoral, 135 p.

Arce, J.L., Macías, J.L., Vázquez, S.L., 2003, The 10.5 KA Plinian eruption of Nevado de Toluca, México: stratigraphy and hazard implications: Geological Society of America Bulletin, 115(2), 230-248.

Arce, J.L., Macías, J.L., Gardner, J.E., Layer, P.W., 2005a, Petrologic, 40Ar-39Ar and experimental constraints on the Nevado de Toluca magma chamber, México, around 10.5 ka: Journal of Petrology, 47(3), 457-479.

Arce, J.L., Cervantes, K.E., Macías, J.L., Mora, J.C., 2005b, The 12.1 ka middle Toluca pumice: a dacitic Plinian-subplian eruption of Nevado de Toluca in Central México: Journal of Volcanology and Geothermal Research, 147, 125-143.

Armienta, M.A., De-la Cruz-Reyna, S., Macías, J.L., 2000, Chemical characteristics of the crater lakes of Popocatépetl, El Chichon, and Nevado de Toluca volcanoes, México: Journal of Volcanology and Geothermal Research, 97, 105-125.

Arreola, J.M., 1915, Catálogo de las erupciones antiguas del Volcán de Colima: Memorias y Revista de la Sociedad Científica "Antonio Alzate", 32, 443-481.

Atl., 1939, Volcanes de México. La actividad del Popocatépetl: México, Polis, $1,67 \mathrm{p}$.

Báez-Jorge, F., Rivera-Balderas, A., Arrieta-Fernández, P., 1985, Cuando ardió el cielo y se quemó la tierra; condiciones socioeconómicas y sanitarias de lo pueblos Zoques afectados por la erupción del volcán Chichonal: México: Instituto Nacional Indigenista, Colección INI, Serie Investigacions Sociales, 14, $310 \mathrm{p}$.

Bárcena, M., 1887, Informe sobre el estado actual del volcán de Colima: Anales del Ministerio de Fomento de la República Mexicana, 1, 328-365.

Bergeat, A., 1894, Zur kenntnis der jungen eruptivgesteine der Republik Guatemala: Zeitschrift der Deutschen Geologischen Gesellschaft, $46,131-157$
Bevis, M., Isacks, B.L., 1984, Hypocentral trend surface analysis: probing the geometry of Benioff zones: Journal of Geophysical Research, 89(B7), 6153-6170.

Blatter, D.L., Carmichael, I.S.E., 1998, Hornblende peridotite xenoliths from central México revealed the highly oxidized nature of the subarc upper mantle: Geology, 26(1), 1035-1038.

Bloomfield, K., Valastro, S., 1974, Late Pleistocene Eruptive History of Nevado de Toluca Volcano, Central México: Geological Society of American Bulletin, 85, 901-906.

Bloomfield, K., Valastro, S., 1977, Late Quaternary tephrochronology of Nevado de Toluca volcano, central México: Overseas Geological Mineral Resources, 46, $15 \mathrm{p}$.

Bloomfield, K., Sanchez, G.R., Wilson, L., 1977, Plinian eruptions of Nevado de Toluca volcano, México: Geologische Rundschau, 66, 120-146.

Bonet, F., 1971, Espeleología de la región de Cacahuamilpa, estado de Guerrero, México: Boletín del Instituto de Geología, Universidad Nacional Autónoma de México, 90, 88 p.

Böse, E., 1902, Breve noticia sobre el estado actual del Volcán Tacaná, Chiapas: Memorias y Revista de la Sociedad Científica "Antonio Alzate", 18, 266-270.

Böse, E., 1903, Los temblores de Zanatepec, Oaxaca a fines de septiembre de 1902 y el estado actual del Volcán de Tacaná: Parergones del Instituto Geológico de México, 1(1), 25 p.

Böse, E., 1905, Reseña acerca de la geología de Chiapas y Tabasco: Instituto Geológico de México, Boletín, 20, 116 p.

Boudal, C., 1985, Petrologie d'un grand volcan andesitique mexicain: le Popocatépetl. Le role de melanges de magma dans les dynamismes de l'activite recente: Clermont-Ferrand, Francia, Université Blaise Pascal, Tesis doctoral, $140 \mathrm{p}$.

Boudal, C., Robin, C., 1987, Relations entre dynamismes eruptifs et realimentations magmatiques d'origine profonde au Popocatepetl: Canadian Journal of Earth Sciences, 25, 955-971.

Boudal, C., Robin, C., 1989, Volcan Popocatépetl: recent eruptive history, and potential hazards and risks in future eruptions, en Latter, J.H. (ed.), Volcanic Hazards, IAVCEI Proceedings in Volcanology: Berlin, Springer Verlag, 1, 110-128.

Bretón-G.M., Ramírez, J.J., Navarro, C., 2002, Summary of the historical eruptive activity of Volcán de Colima, México 1519-2000: Journal of Volcanology and Geothermal Research, 117, 21-46.

Burbach, V.G., Frohlich, C., Pennington, D.W., Matumoto, T., 1984, Seismicity and tectonics of the subducted Cocos plate: Journal of Geophysical Research, 89(B9), 7719-7735.

Burkhart, B., Self, S., 1985, Extension and rotation of crustal blocks in northern Central America and effect on the volcanic arc: Geology, $13,22-26$.

Caballero-Miranda, M., 1996, The diatom flora of two acid lakes in central México: Diatom Research, 11, 227-240.

Caballero, M., Macías J.L., Lozano-García, S., Urrutia Fucugauchi, J., 2001, Late Pleistocene-Holocene volcanic stratigraphy and palaeoenvironments of the Upper Lerma Basin, México: Oxford, International Association of Sedimentologists, Special Publication, $30,247-261$.

Caballero, M., Valadez, F., Ortega-Guerrero, B., Metcalfe, S., Macías, J.L., Sugiura, Y., 2002, Sta Cruz Atizapan: A record of lake level changes and human occupation in the Upper Lerma Basin, Central México: Palaeogeography, Palaeoclimatology, Palaeoecology, 186, 217-235.

Calvin, E.M., Kudo, A.M., Brookins, D.G., Ward, D.B., 1989, Strontium isotope and trace element geochemistry of Pico de Orizaba-TransMexican Volcanic Belt: comparison phases II and III, en, Continental magmatism; abstracts: New México Bureau of Mines \& Mineral Resources, Bulletin, 131, 38.

Camacho, H., 1925, Apuntes acerca de la actividad del Popocatépetl en relación con la sismología: Anales del Instituto Geológico, 2 (1-3), 38-67.

Campa, M. F., Campos, M., Flores, R., Oviedo, R., 1974, La Secuencia mesozoica volcano-sedimentaria metamorfizada de Ixtapan de la Sal, México-Teloloapan, Guerrero: Boletín de la Sociedad Geológica Mexicana, 35, 7-28. 
Canul, R.F., Rocha, V.L., 1981, Informe geológico de la zona geotérmica de El Chichonal, Chiapas, México: México, D.F., Comisión Federal de Electricidad, Informe 32-81, 38 p.

Canul-Dzul, R.F., Razo-Montiel, A., Rocha-López, V., 1983, Geología e historia volcanológica del volcán Chichonal, estado de Chiapas en Sociedad Geológica Mexicana, VI Convención Geológica Nacional. El Volcán Chichonal: México, D F., Universidad Nacional Autónoma de México, Instituto de Geología, 3-22.

Cantagrel, J.M., Robin, C., Vincent, P., 1981, Les grandes etapes d'evolution d'un volcan andesitique composite: Exemple du Nevado de Toluca: Bulletin Volcanologique, 44, 177- 188.

Cantagrel, J.M., Gourgaud, A., Robin, C., 1984, Repetitive mixing events and Holocene pyroclastic activity at Pico de Orizaba and Popocatepetl, México: Bulletin Volcanologique, 47, 735-748.

Capaccioni, B., Tarán, Y., Tassi, F., Vaselli, O., Mangani, F., Macías, J.L., 2004, Source conditions and degradation processes of light hydrocarbons in volcanic gases: an example from El Chichón volcano, Chiapas State of México: Chemical Geology, 206, 8196.

Capaul, W.A., 1987, Volcanoes of the Chiapas Volcanic Belt, México: Houghton, U.S.A., Michigan Technological University, Tesis de maestría, $93 \mathrm{p}$.

Capra, L., Macías, J.L., 2000. Pleistocene cohesive debris flows at Nevado de Toluca volcano, central México: Journal of Volcanology and Geothermal Research, 102(1-2), 149-167.

Capra, L., Macías, J.L., 2002, The cohesive Naranjo debris-flow deposit $\left(10 \mathrm{~km}^{3}\right)$ : A dam breakout flow derived from the Pleistocene debrisavalanche deposit of Nevado de Colima Volcano (México): Journal of Volcanology and Geothermal Research, 117, 213-235.

Capra, L., Macías, J.L, Scott, K.M., Abrams, M., Garduño, V.H., 2002, Debris avalanches and debris flows transformed from collapses in the Trans-Mexican Volcanic Belt, México-Behavior, and implications for hazard assessment: Journal of Volcanology and Geothermal Research, 113, 70-99.

Capra, L., Poblete, M.A., Alvarado, R., 2004, The 1997 and 2001 lahars of Popocatépetl volcano (Central México): textural and sedimentological constraints on their origin and hazards: Journal of Volcanology and Geothermal Research, 131, 351-369.

Capra, L., Carreras, L., Arce, J.L., Macías, J.L., 2006, The lower Toluca pumice: a 21,700 yr B.P, Plinian eruption of Nevado de Toluca volcano, México, en: Siebe, C., Macias, J.L., Aguirre, G. J., (eds.), Neogene-Quaternary continental margin volcanism: a perspective from México: Boulder, Colorado, Geological Society of America, Special Paper, (aceptado).

Capra-Pedol, L., 2000, Colapsos de edificios volcánicos: transformación de avalanchas de escombros en flujos de escombros cohesivos. Los casos del Monte Santa Elena (EE. UU.), Nevado de Toluca y Nevado de Colima (México): México, D.F., Universidad Nacional Autónoma de México, Colegio de Ciencias y Humanidades, Unidad Académica de los Ciclos Profesionales y de Posgrado, Tesis doctoral, $177 \mathrm{p}$

Carey, S.N., Sigurdsson, H., 1986, The 1982 eruptions of El Chichón volcano-México (2): observations and numerical modeling of tephra fall distribution: Bulletin of Volcanology, 48, 127-141.

Carfantan, J.C., 1977, La cobijadura de Motozintla un paleoarco volcánico en Chiapas: Revista del Instituto de Geología, Universidad Nacional Autónoma de México, 1(2), 133-137.

Carrasco-Núñez, G. 1985, Estudio geológico del Volcán Popocatépetl: México D.F., Universidad Nacional Autónoma de México, Facultad de Ingeniería, Tesis profesional, $138 \mathrm{p}$.

Carrasco-Núñez, G., 1993, Structure-eruptive history and some major hazardous events at Citlaltepetl volcano (Pico de Orizaba), México: Hoghton, U.S.A., Michigan Technological University, Tesis doctoral, $182 \mathrm{p}$.

Carrasco-Núñez, G., 1997, Lava flow growth inferred from morphometric parameters-a case study Citlatepetl volcano: Geological Magazine, 134, 151-162.

Carrasco-Núñez, G., 1999, Holocene block-and-ash flows from summit dome activity of Citlaltepetl volcano, eastern México: Journal of Volcanology and Geothermal Research, 88, 47-66.

Carrasco-Nuñez, G., 2000, Structure and proximal stratigraphy of
Citlaltépetl volcano (Pico de Orizaba), México, en: DelgadoGranados, H., Aguirre-Díaz, G., Stock, J.M., (eds.), Cenozoic volcanism and tectonics of México: Boulder, Colorado, Geological Society of America Special Paper, 334, 247-262.

Carrasco-Núñez, G., Ban, M., 1994, Geologic map and structure sections of the summit area of Citlaltépetl volcano, México with summary of the geology of the Citlaltepetl volcano summit area: México D.F., Universidad Nacional Autónoma de México, Instituto de Geología, Cartas Geológicas y Mineras, 9, 1 mapa, texto explicativo.

Carrasco-Núñez, G., Rose, W.I., 1995, Eruption of a major Holocene pyroclastic flow at Citlaltepetl volcano (Pico de Orizaba), México, 8.5-9.0 ka: Journal of Volcanology and Geothermal Research, 69, 197-215.

Carrasco-Núñez, G., Vallance, J.W., Rose, W.I., 1993, A voluminous avalanche-induce lahar from Citlaltepetl volcano, México: Implications for hazard assessment: Journal of Volcanology and Geothermal Research, 59, 35-46.

Carrasco-Núñez, G., Righter, K., Chesley, J., Siebert, L., Aranda-Gomez, J.J., 2005, Contemporaneous eruption of calc-alkaline and alkaline lavas in a continental arc (Eastern Mexican Volcanic Belt): chemically heterogeneous but isotopically homogeneous source: Contributions to Mineralogy and Petrology, 150(4), 423-440.

Carrasco-Núñez, G., Díaz, R., Siebert, L., Hubbard, B, Sheridan, M, Rodríguez, S., en prensa, Multiple edifice-collapse events in the Eastern Mexican Volcanic Belt: the role of sloping substrate and implications for hazard assessment, en: Tibaldi, Lagmar, (eds.) Special issue on volcano tectonics "The effects of basement structural and stratigraphic heritages on volcano behaviour": Journal of Volcanology and Geothermal Research.

Carroll, M.R., Rutherford, M.J., 1987, The stability of igneous anhydrite: experimental results and implications for sulfur behavior in the 1982 El Chichon trachyandesite and other evolved magmas: Journal of Petrology, 28, 781-801.

Casadevall, T.J., De-la Cruz-Reyna, S., Rose, W.I., Bagley, S., Finnegan. D.L., Zoller, W. H., 1984, Crater Lake and Post-Eruption Hydrothermal Activity, El Chichon Volcano, México: Journal of Volcanology and Geothermal Research, 23, 169-191.

Cebull, S.E., Shurbet, D.H., 1987, Mexican Volcanic Belt: an intraplate transform?: Geofísica International, 26, 1-14.

Cervantes, P., Wallace, P., 2003, Magma degassing and basaltic eruption styles: a case study of 2000 year BP Xitle volcano in central México: Journal of Volcanology and Geothermal Research, 120, 249-270.

Cervantes-de la Cruz, K.E., 2001, La pómez blanca intermedia: depósito producido por una erupción Pliniana-subpliniana del Volcán Nevado de Toluca hace 12,100 años: México, D.F., Universidad Nacional Autónoma de México, Instituto de Geofísica, Tesis de maestría, $86 \mathrm{p}$.

Chesley, J.T., Ruiz, J., Righter, K., 2000, Source versus crustal contamination in arc magmatism: evidence for lower crustal assimilation in the Trans-Mexican Volcanic Belt: EOS, Transaction, American Geophysical Union, 81(48), F1269.

Connor C.B., West- Thomas J., Clement B.M., Xiaodan Song, Lane S.B., 1993, Continuous monitoring of high-temperature fumaroles on an active lava dome, Volcan Colima, México: evidence of mass flow variation in response to atmospheric forcing: Journal of Geophysical Research, 98(B11), 19,713-19,722.

Cortés, A., Garduño-Monroy, V.H., Navarro-Ochoa, C., Komorowski, J.C., Saucedo, R., Macías, J.L., Gavilanes, J.C., 2005, Cartas Geológicas y Mineras 10. Carta Geológica del Complejo Volcánico de Colima, con Geología del Complejo Volcánico de Colima: México D.F., Universidad Nacional Autónoma de México, Instituto de Geología, escala 1:10,000, mapa con texto explicativo 37 p., 15 figs., 2 tablas.

Cortés-Cortés, A., 2002, Depósitos de avalancha y flujos de escombros originados hace 3,600 años por el colapso del sector suroeste del Volcán de Colima: México, D.F., Universidad Nacional Autónoma de México, Instituto de Geofísica, Tesis de maestría, $121 \mathrm{p}$.

Cortés-Cortés, A., Navarro-Ochoa, C., 1992, Las avalanchas volcánicas del complejo volcánico de Colima: Una nueva y desconcertante datación C-14: Geos, Unión Geofísica Mexicana, 12(5), 66 p. 
Crausaz, W., 1994, Pico de Orizaba o Citlaltépetl: geology, archaeology, history, natural history and mountaineering routes: Ohio, Geopress International, $594 \mathrm{p}$.

Damon, P., Montesinos, E., 1978, Late Cenozoic volcanism and metallogenesis over an active Benioff Zone in Chiapas, México: Arizona Geological Society Digest, 11, 155-168.

Davidson, J., Tepley, F., Palacz, Z., Meffan-Main, S., 2000, Magma recharge, contamination and residence times revealed by in situ laser ablation isotopic analysis of feldspar in volcanic rocks: Earth and Planetary Science Letters, 184, 427-442.

De Cserna, Z., Aranda-Gómez, J.J., Mitre Salazar, L.M., 1988, Mapa fotogeológico preliminar y secciones estructurales del volcán Tacaná, México y Guatemala, Escala 1:50.000: Universidad Nacional Autónoma de México, Instituto de Geología, Carta Geológica Minera, 7, 1 mapa, texto explicativo.

De-la Cruz-Reyna, S., 1993, Random patterns of occurrence of explosive eruptions at Colima volcano, México: Journal of Volcanology and Geothermal Research, 55, 51-68.

De-la Cruz-Reyna, S., Carrasco-Nuñez, G., 2002, Probabilistic hazard analysis of Citlaltépetl (Pico de Orizaba) Volcano, eastern Mexican Volcanic Belt: Journal of Volcanology and Geothermal Research, 113, 307-318.

De-la Cruz, V., Hernández, R., 1985, Estudio geológico a semidetalle de la zona geotérmica del volcán Tacaná, Chiapas: México, Comisión Federal de Electricidad, Reporte interno, 41/85, 28 p.

De-la Cruz-Reyna, S., Armienta, M.A., Zamora, V., Juárez, F., 1989, Chemical changes in spring waters at Tacaná Volcano, Chiapas, México: Journal of Volcanology and Geothermal Research, 38, 345-353.

De-la Cruz-Reyna, S., Quezada, J.L., Peña, C., Zepeda, O., Sánchez, T., 1995, Historia de la actividad del Popocatépetl (1354-1995), en: Volcán Popocatépetl estudios realizados durante la crisis de 19941995: México, D.F., Secretaria de Gobernación, Sistema Nacional de Protección Civil, Centro Nacional de Prevención de Desastres, Universidad Nacional Autónoma de México, 3-22.

Demant, A., 1979, Vulcanología y petrografía del sector occidental del Eje Neovolcánico: Revista del Instituto de Geología, Universidad Nacional Autónoma de México, 3, 39-57.

Demant, A., 1981, L'axe Néo-Volcanique Transmexicain: etude volcanologique et pétrografique. Significacion géodynamique: Marseille, Francia, Université de Marseille de Droit, d'Economie et des Sciences d'Aix marseille, faculté des Sciences et Techniques de St. Jérome, Tesis doctoral, 259 p., 1 anexo, 106 p.

DeMets, C., Stein, S., 1990, Present-day kinematics of the Rivera Plate and implications for tectonics in southwestern México: Journal of Geophysical Research, 95(B13). 21931-21948.

Devine, J.D., Sigurdsson, H., Davis, A.N., Self, S., 1984, Estimates of sulfur and chlorine yield to the atmosphere from volcanic eruptions and potential climatic effects: Journal of Geophysical Research, $89,6309-6325$.

Díaz, S., 1906, Efemérides del volcán de Colima según las observaciones practicadas en los observatorios de Zapotlán y Colima de 1893 a 1905: México, Imprenta y Fototipia de la Secretaria de Fomento, $199 \mathrm{p}$.

Díaz-Castellón, R., 2003, Análisis de la estabilidad de edificios volcánicos del flanco oriental de la Sierra de Citlaltépetl-Cofre de Perote. D.F., Universidad Nacional Autónoma de México, Instituto de Geología, Programa de Posgrado en Ciencias de la Tierra, Tesis de maestría, $135 \mathrm{p}$.

Dollfus, A., Monserrat, E., 1867, Archives de la Commission Scientifique du Mexique, Ministére de L'Instruction Publique: El Renacimiento, $1,451-457$.

Domínguez, T., Zobin, V. M., Reyes-Davila, G.A., 2001, The fracturing in volcanic edifice before an eruption: the June-July 1998 highfrequency earthquake swarm at Volcán de Colima, México: Journal of Volcanology and Geothermal Research, 105, 65-75.

Duffield, W.A., Tilling, R.I., Canul, R., 1984, Geology of El Chichón volcano, Chiapas, México: Journal of Volcanology and Geothermal Research, 20, 117-132.

Espinasa-Pereña, R., Martín-del Pozzo, A.L., 2006, Morphostratigraphic evolution of Popocatépetl volcano, México, en: Siebe, C., Macías, J.L., Aguirre-Díaz, G. (eds.), Neogene-Quaternary continental margin volcanism: a perspective from México: Boulder, Colorado, Geological Society of America, Special Paper, 402. (en prensa)

Espíndola, J.M., Medina, F.M., De los Ríos, M., 1989, A C-14 age determination in the Tacaná volcano (Chiapas, México): Geofísica Internacional, 28, 123-128.

Espíndola, J.M., Macías, J.L., Sheridan, M.F., 1996, El Volcán Tacaná: un ejemplo de los problemas de evaluación del riesgo volcánico, en: Actas del Simposio Internacional sobre Riesgos Naturales e Inducidos en los Grandes Centros Urbanos de América Latina: Serie Scienza, 5, 62-71.

Espíndola, J.M., Macías, J.L., Tilling, R.I., Sheridan, M.F., 2000, Volcan history of El Chichón volcano (Chiapas, México) during the Holocene, and its impact on human activity: Bulletin of Volcanology, 62, 90-104.

Espíndola, J.M., Macías, J.L., Godínez, L., Jiménez, Z., 2002, La erupción de 1982 del Volcán Chichónal, Chiapas, México, en: Lugo-Hubp, J. Inbar, M. (eds.), Desastres naturales en América Latina: México, D.F., Fondo de Cultura Económica, 37-65.

Felix, J., Lenk, H., 1890, Beitraege zur Geologie und Palaeontologie: Leipzig: A. Felix; Stuttgart: E. Schweizerbartsche Verlagshandlung, $142 \mathrm{p}$.

Flores-Covarrubias, L., 1945, Cálculos para la determinación de la altura del cono del volcán del Parícutin, en: El Paricutín: México, D.F., Universidad Nacional Autónoma de México, 19-20.

Flores, T., 1906, Le Xinantecatl ou Volcan Nevado de Toluca, en: X Congress Geologique Internacionale, Guide des excursions: México, $9,16 \mathrm{p}$.

Ford, A., Rose, W.I., 1995, Volcanic ash in ancient Maya ceramics of the limestone lowlands, implications for prehistoric volcanic activity in the Guatemala highlands: Journal of Volcanology and Geothermal Research, 66, 149-162.

Foshag, W.F., Gonzalez-Reyna, J., 1956, Birth and development of Parícutin volcano: U. S., Geological Survey, Bulletin, 965-D, 355-489.

Friedlaednder, I., 1921, La erupción del Popocatépetl: Memorias y Revista de la Sociedad Científica "Antonio Alzate", 40, 219-227.

García-Martínez, B., 2000, Los nombres del Nevado de Toluca: Arqueología Mexicana, 8(43), 24-26.

García-Palomo, A., 1998, Evolución estructural en las inmediaciones de Volcán Nevado de Toluca, Estado de México: México, D.F., Universidad Nacional Autónoma de México, Colegio de Ciencias y Humanidades, Unidad Académica de los Ciclos Profesionales y de Posgrado; Instituto de Geofísica, Posgrado en Ciencias de la Tierra, Tesis de maestría, $146 \mathrm{p}$.

García-Palomo, A., Macías, J.L., Garduño, V.H., 2000, Miocene to recent structural evolution of the Nevado de Toluca Volcano region, Central México: Tectonophysics, 318, 281-302.

García-Palomo, A., Macías, J.L., Arce, J.L., Capra, L., Garduño, V.H., Espíndola, J.M., 2002, Geology of Nevado de Toluca volcano and surroundings areas, Central México: Boulder, Colorado, Geological Society of America, Map and Chart Series, MCH080, 1 mapa, 26 p. texto.

García-Palomo, A., Macías, J.L., Espíndola, J.M., 2004, Strike-slip faults and K-Alkaline volcanism at El Chichón volcano, southeastern Mexico: Journal of Volcanology and Geothermal Research, 136, 247-268.

García-Palomo, A., Macías, J.L., Arce, J.L., Mora, J.C., Hughes, S., Saucedo, R., Espindola, J.M., Escobar, R., Layer, P., 2006, Geological evolution of the Tacaná Volcanic Complex, MéxicoGuatemala, in: Rose et al. (eds.), Natural Hazards in Central America: Boulder, Colorado, Geological Society of America, Special Paper, (aceptado).

García-Tenorio, F., 2002, Estratigrafía y petrografía del complejo volcánico Iztaccíhuatl: México, D.F., Instituto Politécnico Nacional, Escuela Superior de Ingeniería y Arquitectura, Unidad Ticomán, Tesis profesional, $149 \mathrm{p}$.

Garduño, M.V., Tibladi, A., 1990, Kinematic evolution of the continental active triple junction of Western Mexican Volcanic Belt: C.R. Acad. 
Sci. Paris, t. xxx, 1-6.

Garduño-Monroy, V. H., Saucedo-Girón, R., Jiménez, S., Gavilanes-Ruiz, J. C., Cortés-Cortés, A., Uribe-Cifuentes, R.M., 1998, La Falla Tamazula, limite suroriental del bloque Jalisco, y sus relaciones con el complejo volcánico de Colima, México: Revista Mexicana de Ciencias Geológicas, 15, 132-144.

Gómez-Tuena, A., Carrasco-Núñez, G., 1999, Fragmentation, transport and deposition of a low-grade ignimbrite: the Citlaltépetl ignimbrite, eastern México: Bulletin of Volcanology, 60(6), 448-464.

González-Salazar, A., 1973, Informe preliminar de la zona Geotérmica del Volcán Chichonal, Chiapas: México, Comisión Federal de Electricidad, Reporte interno.

Gutiérrez-Coutiño, R., Moreno-Corzo, M., Cruz-Borraz, C., 1983, Determinación del volumen del material arrojado y grado de explosividad alcanzado por el Volcán Chichonal, Estado de Chiapas, en: Sociedad Geológica Mexicana, VI Convención Geologica Nacional: México, D.F., Universidad Nacional Autónoma de México, Instituto Geología, 68-80.

Havskov, J., Macías, M., 1983, A coda-length magnitude scale for some mexican stations: Geofisica Internacional, 22(3), 205-213.

Heine, K., 1988, Late Quaternary glacial chronology of the mexican volcanoes: Die Geowissenschaften, 6, 197-205.

Heine, K., Heide-Weise, H., 1973, Jungquartäre förderfolgen del Malinche vulkans und des Popocatépetl (Sierra Nevada, México) und ihreBedeutung fùr die glazialgeologie, paläoklimatologie und archälogie: Munstersche Forschungen in der Paläontologie und Geologie, 31/32, 303-322.

Hochstaedter, A.G., Ryan, J.G., Luhr, J.F., Hasenaka, T., 1996, On B/Be ratios in the Mexican Volcanic Belt: Geochimica et Cosmochimica Acta, 60(4), 613-628.

Hoskuldsson, A., 1992, Le complexe volcanique Pico de OrizabaSierra Negra-Cerro Las Cumbres (sud-est mexicain): structure, dymamismes eruptifs et evaluations del areas: Clermont-Ferrand, Francia, Université Blaise Pascal, Tesis doctoral, 210 p.

Hoskuldsson, A., Robin, C., 1993, Late Pleistocene to Holocene eruptive activity of Pico de Orizaba, eastern México: Bulletin of Volcanology, 55, 571-587.

Hoskuldsson, A., Robin, C., Cantagrel, J.M., 1990, Repetitive debris avalanche events at Volcano Pico de Orizaba, México, and their implications for future hazard zones, en: IAVCEI International Volcanological Congress, Mainz, Germany, Resumen, 47.

Hovey, E.O., 1907, Volcanoes of Colima, Toluca and Popocatépetl: Annals of the New York Academy of Sciences, 25, 646 p.

Humboldt, A., 1862, Cosmos; a sketch of the physical description of the universe: London, H.G. Bohn, 4, 575 p.

Iverson, R.M., Schilling, S.P., Vallance, J.W., 1998, Objective delination of lahar inundation hazard zones: Geological Society of America Bulletin, 110, 972-984.

Jiménez, Z., Reyes, G., Espíndola, J.M., 1995, The July 1994 episode of seismic activity at Colima Volcano, Mexico: Journal of Volcanology and Geothermal Research, Short Communication, 64, 321-326.

Jiménez, Z., Espíndola, V.H., Espíndola, J.M., 1998, Evolution of the seismic activity from the 1982 eruption of El Chichón Volcano, Chiapas, México: Bulletin of Volcanology, 61, 411-422.

Kolisnik, A.M.E., 1990, Phenocryst zoning and heterogeneity in andesites and dacites of Volcán Popocatépetl, México: Kingston, Ontario, Canada, Queen's University, Tesis de maestria, 247 p.

Komorowski, J.C., Navarro, C., Cortés, A., Siebe, C., RodríguezElizarrarás, S., 1993, Multiple collapse of Volcán Colima, Mexico, since 10000 yr BP- Implications for eruptive style, magma yield, edifice stability and volcanic risk: IAVCEI, General Assembly, Camberra, Australia, Resumen, $60 \mathrm{p}$

Komorowski, J.C., Navarro, C., Cortés, A., Saucedo, R., Gavilanes, J.C., 1997, The Colima Complex: Quaternary multiple debris avalanche deposits, historical pyroclastic sequences (pre-1913, 1991 and 1994), en: IAVCEI, Puerto Vallarta, México, 1997, Plenary Assembly, Excursión guidebook: Guadalajara, Jalisco, Gobierno del Estado de Jalisco, Secretaria General, Unidad Editorial, 1-38.

Kover, T., 1995, Application of a digital terrain model for the modelling of volcanic flows: a tool for volcanic hazard determination: Buffalo,
State University of New York at Buffalo, Tesis de maestria, 62 p.

Krueger, A.J, 1983, Sighting of El Chichon sulfur dioxide clouds with the Nimbus 7 total ozone mapping spectrometer: Science, 220, 1377-1379.

Kudo, A.M., Jackson, M.E., Husler, J.M., 1985, Phase chemistry of recent andesite, dacite, and rhyodacite of volcan Pico de Orizaba, Mexican Volcanic Belt: evidence for xenolithic contamination: Geofisica Internacional, 24, 679-689.

Lange, R., Carmichael, I.S.E., 1991, A potassic volcanic front in western México: lamprophyric and related lavas of San Sebastian: Geological Society of America Bulletin, 103, 928-940.

Lassiter, J.C., Luhr, J.F., 2001, Osmium abundance and isotope variations in mafic mexican volcanics rocks: evidence for crustal contamination and constraints on the geochemical behavior of osmium during partial melting and fractional crystallization: Geochemistry, Geophysics, and Geosystems, 2 (3), 2000GC000116.

Lowe, G.W., Lee, T.A., Martínez-Espinosa, E., 1982, Izapa: an introduction to the ruins and monuments: Provo, Utah, New World Archaeological Foundation, Brigham Young University, xix, 349 p.

Lozano-García, M.S., Ortega-Guerrero, B., 1994, Palynological and magnetic susceptibility records of Lake Chalco, central México: Palaeogeography Palaeoclimatology Palaeoecology, 109, 177191.

Lozano-García, S., Sosa-Najera, S., Sugiura, Y., Caballero, M., 2005, 23,000 yr of vegetation history of the upper Lerma a tropical high altitude basin in Central México: Quaternary Research, 64, 70-82.

Luhr, J.F., 1990, Experimental phase relations of water-and sulfur-saturated arc magmas and the 1982 eruptions of El Chichon volcano: Journal of Petrology, 31, 1071-1114.

Luhr, J.F., 2001, Glass inclusions and melt volatile contents at Parícutin Volcano, México: Contributions Mineralogy and Petrology, 142, 261-283.

Luhr, J.F., 2002, Petrology and geochemistry of the 1991 and 1998-1999 lava flows from Volcán de Colima, México: implications for the end of the current eruptive cycle: Journal of Volcanology and Geothermal Research, 117, 169-194.

Luhr, J.F., Carmichael, I.S.E., 1980, The Colima volcanic complex, México; Part I, Postcaldera andesites from Volcán Colima: Contributions Mineralogy and Petrology, 71, 343-372.

Luhr, J.F., Carmichael, I.S.E., 1981, The Colima Volcanic Complex, México. Part II, Late Quaternary cinder cones: Contributions to Mineralogy and Petrology, 76(2), 127-147.

Luhr, J.F., Carmichael, I.S.E., 1982, The Colima Volcanic Complex, México. III, Ash-and scoria-fall deposits from the upper slopes of Volcán Colima: Contributions to Mineralogy and Petrology, 80, 262-275.

Luhr, J.F., Carmichael, I.S.E., 1990a, Geology of Volcán de Colima: Universidad Nacional Autónoma de México, Instituto de Geología, Boletín, 107, 101 p., 1 mapa.

Lurh, J.F., Carmichael, I.S.E., 1990b, Petrological monitoring of cyclycal eruptive activity at Volcan Colima, México: Journal of Volcanology and Geothermal Research, 42, 235-260.

Luhr, J.F., Navarro-Ochoa, C., 2002, Excursión al Volcán Nevado de Colima, en: VIII Reunión Internacional, Volcán de Colima, Colima, México, Resúmenes, 22-25.

Luhr, J.F., Prestegaard, K. L., 1988, Caldera formation at Volcán de Colima, México, by large Holocene volcanic debris avalanche: Journal of Volcanology and Geothermal Research, 35, 335-348.

Luhr, J.F., Carmichael, I.S.E., Varekamp, J.C., 1984, The 1982 eruptions of El Chichon volcano, Chiapas, México: mineralogy and petrology of the anhydrite-bearing pumice: Journal of Volcanology and Geothermal Research, 23, 69-108.

Luhr, J.F., Nelson, S.A., Allan, J.F., Carmichael, I.S.E., 1985, Active rifting in southwestern México: manifestations of an incipient eastward spreading-ridge jump: Geology, 13, 54-57.

Luhr, J.F., Allan, J.F., Carmichael, I.S.E., Nelson, S., Asean, T., 1989, Primitive calc-alkaline and alkaline rock types from the Western Mexican Volcanic Belt: Journal of Geophysical Research, 94(4), 4515-4530.

Macías, J.L., 1994, Violent short-lived eruptions from small-size volcanoes: 
El Chichón, México (1982) and Shtyubel', Russia (1907): Buffalo, State University of New York at Buffalo, Tesis doctoral, $210 \mathrm{p}$.

Macías, J.L., Capaccioni, B., Giannini, L., Martín, M., RodríguezElizarrarás, S., 1993, Volatile elements in alkaline and calc-alkalne rocks from the Colima Graben, México contrains on their genesis and evolution: Geofísica Internacional, 32(4), 575-589.

Macías-Vázquez, J.L., Carrasco-Núñez, G., Delgado-Granados, H., Martindel Pozzo, A.L., Siebe-Grabach, C., Hoblitt, R.P., Sheridan M.F., Tilling, R.I., Bonifaz, R., Cabrera, A.L., Alvarez, R., 1995, Mapa de peligros del volcán Popocatépetl, escala 1:250,000: México, D. F., Universidad Nacional Autónoma de México, Instituto de Geofísica, 1 mapa.

Macías, J.L., Arce, J.L., García, P.A., Siebe, C., Espíndola, J.M., Komorowski, J.C., Scott, K., 1997a, Late Pleistocene-Holocene cataclysmic eruptions at Nevado de Toluca and Jocotitlan volcanoes, Central México, en: Link, K. P., Kowallis, B. J., (eds.), Proterozoic to recent stratigraphy, tectonics, and volcanology, Utah, Nevada, southern Idaho and Central México: Bringham Young Univesity, Geology Studies, 42(1), 493-528.

Macías, J.L., Espíndola, J.M., Tarán, Y., Sheridan, M.F., García, A., 1997b, Explosive volcanic activity during the last 3,500 years at El Chichón volcano, México, en: IAVCEI, Puerto Vallarta, México Plenary Assembly, Fieldtrip guidebook: Guadalajara, Jalisco, Gobierno del Estado de Jalisco, Secretaria General, Unidad Editorial, 1-53.

Macías, J.L., Sheridan, M., Espíndola, J.M., 1997c, Reappraisal of the 1982 eruptions of El Chichón Volcano, Chiapas, México: New data from proximal deposits: Bulletin of Volcanology, 58, 459-471.

Macías, J.L., Espíndola, J.M., García-Palomo, A., Scott, K.M., Hughes, S., Mora, J.C., 2000, Late Holocene Peléan style eruption at Tacaná Volcano, México-Guatemala: Past, present, and future hazards: Geological Society of America Bulletin, 112 (8), 1234-1249.

Macías, J.L., Arce, J.L., Mora, J.C., Espíndola, J.M., Saucedo, R., 2003, The 550 BP Plinian eruption of el Chichon volcano, Chiapas, México: explosive volcanism linked to reheating of a magma chamber: Journal of Geophysical Research, 108(B12), 2569, doi. 10.1029/2003JB002551, ECV3-1-ECV-3-18.

Macías, J.L., Capra, L., Scott, K. M., Espíndola, J.M., García-Palomo, A., Costa, J.E., 2004a, The 26 may 1982 breakout flow derived from failure of a volcanic dam at El Chichón Volcano, Chiapas, México: Geological Society of America Bulletin, 116, 233-246.

Macías, J.L., Arce, J.L., Mora, J.C., García-Palomo, A., 2004b, The Agua Caliente Debris Avalanche deposit a northwestern sector collapse of Tacaná volcano, México-Guatemala: IAVCEI General Assembly Pucon, Chile, Symposium 11a-07.

Macías-Vázquez, J.L, Capra-Pedol, L., 2005, Los volcanes y sus amenazas: México, D.F., Secretaria de Educación Pública, Fondo de Cul,tura Económica, Consejo Nacional de Ciencia y Tecnología, La Ciencia para todos, 210, $159 \mathrm{p}$.

Martín-del Pozzo, A.L., Romero, V.H., Ruiz-Kitcher, R.E., 1987, Los flujos piroclásticos del Volcán de Colima, México: Geofísica Internacional, 26(2), 291-307.

Martín-del Pozzo, A.L., Sheridan, M.F., Barrera, D., Lugo-Hubp, J., Vázquez, L., 1995, Mapa de peligros, Volcán de Colima, escala 1:50,000: México, D.F., Universidad Nacional Autónoma de México, Instituto de Geofísica, 1 mapa.

Martínez-Serrano, R., Schaaf, P., Solís-Pichardo, G., Hernández-Bernal, M.S.,, Hernández Treviño, T., Morales-Contreras, J.J., Macías, J.L., 2004, $\mathrm{Sr}, \mathrm{Nd}$ and $\mathrm{Pb}$ isotope and geochemical data from the Quaternary Nevado de Toluca volcano, a source of recent adakitic magmatism, and the Tenango Volcanic Field, México: Journal of Volcanology and Geothermal Research, 138, 77-110.

Martíni, M., Capaccioni, B., Giannini, L., 1987, Ripresa dell'attivita sismica e fumarolica al Vulcano di Tacana (Chiapas, Messico) dopo un quarantennio di quiescenza: Bollettino del Grupo Nazionale per la Vulcanologia, 467-470.

Matson M., 1984, The 1982 El Chichon volcanic eruptions - A satellite perspective: Journal of Volcanology and Geothermal Research, $23,1-10$.

McGee, J.J., Tilling, R.I., Duffield, W.A., 1987, Petrologic characteristics of the 1982 and pre-1982 eruptive products of El Chichón volcano,
Chiapas, México: Geofisica Internacional, 26, 85-108.

Medina-Martínez, F., 1982, El Volcán Chichón: GEOS, Boletín de la Unión Geofísica Mexicana, 2(4), 4-19.

Medina-Martínez, F., 1983, Analysis of the eruptive history of the Volcán Colima, México, 1560-1980: Geofísica Internacional, 22, 157178.

Medina-Martínez, F., 1986, Análisis de las columnas eruptivas del volcán Chichón, marzo-abril, 1982, Velocidad de salida, presión de la cámara magmática y energía cinética asociada: Geofísica Internacional, 25, 233-249.

Meneses-Rocha, J.J., 2001, Tectonic evolution of the Ixtapa Graben, an example of a strike-slip basin of southeastern México, implications for regional petroleum systems, en: Bartolini, C., Buffler, R. T., Cantú-Chapa, A. (eds.), The western Gulf of México basin: tectonics, sedimentary basins, and petroleum systems: Tulsa, Oklahoma, American Association of Petroleum Geologists, Memoir, 75, 183216.

Mercado, R., Rose, W. I., 1992, Reconocimiento geológico y evaluación preliminar de peligrosidad del volcán Tacaná, Guatemala-México: Geofísica Internacional, 31, 205-237.

Metcalfe, S.E., Street-Perrott, F.A., Perrott, R.A., Harkness, D.D., 1991, Paleolimnology of the upper Lerma basin, Central México: a record of climatic change and anthropogenic disturbance since $11600 \mathrm{yr}$ BP: Journal of Paleolimnology, 5(3), 197-218.

Miehlich, G., 1984, Chronosequenzen und anthropogene Veränderungen andesitischer Vulkanascheböden eines randtropischen Gebirges (Sierra Nevada, México), Hamburg, Germany, Universität Hamburg, Tesis postdoctora, $417 \mathrm{p}$.

Molina-Berbeyer, R., 1974, Informe preliminar de geoquímica de los fluidos geotérmicos del Volcán Chichonal, Chiapas: México, D. F., Comisión Federal de Electricidad, Informe (inédito).

Molina-Garza, R., Urrutia-Fucugauchi, J., 1993, Deep crustal structure of central México derived from interpretation of Bouguer gravity anomaly data: Journal of Geodynamics, 17(4), 181-201.

Mooser, F., 1961, Los volcanes de Colima, en Blázquez-L., Mooser, F., Reyes-lagos, A., Lorenzo, J. L. (eds.), Fenómenos geológicos de algunos volcanes mexicanos: Universidad Nacional Autónoma de México, Boletín del Instituto de Geología, 61, 49-71.

Mooser, F., 1967, Tefrocronología de la Cuenca de México para los últimos treinta mil años: México, Boletín del Instituto Nacional de Antropología e Historia, 30, 12-15.

Mooser, F., Meyer-Abich, H., McBirney, A. R.,, 1958, Catalogue of the active volcanoes of the world including solftara fields. Part VI Central America: Napoli International Volcanology Asociation, $1-36$.

Mora, J.C., 2001, Studio vulcanologico e geochimico del vulcano Tacana, Chiapas, Messico: Firenze, Italia, Universita degli Studi di Firenze, Tesis doctoral, $147 \mathrm{p}$.

Mora, J.C., Macías, J.L., Saucedo, R., Orlando, A., Manetti, P., Vaselli, O., 2002, Petrology of the 1998-2000 products of Volcán de Colima, México: Journal of Volcanology and Geothermal Research, 117, 195-212.

Mora, J.C., Macías J.L., García-Palomo, A., Espíndola, J.M., Manetti, P., Vaselli, O., 2004, Petrology and Geochemitry of the Tacaná Volcanic Complex, México-Guatemala; evidence for the last $40000 \mathrm{yr}$ of activity: Geofísica Internacional, 43, 331-359.

Mugica-Mondragón, R., 1987, Estudio petrogenético de las rocas ígneas y metamórficas en el Macizo de Chiapas: México, Instituto Mexicano del Petróleo, Informe interno, C-2009, 47 p.

Müllerried, F.K.G., 1933, El Chichón, único volcán en actividad descubierto en el estado de Chiapas: Memorias de la Sociedad Científica "Antonio Alzate", 54, 411-416.

Müllerried, F.K.G., 1951, La reciente actividad del Volcán de Tacaná, estado de Chiapas, a fines de 1949 y principios de 1950: Tuxtla Gutiérrez, Departamento de Prensa y Turismo, Sección Autográfica; Universidad Nacional Autónoma de México, Instituto de Geología, $25 \mathrm{p}$.

Navarro, C., Cortés, A., Téllez, A., 2003, Mapa de peligros del Volcán de Fuego de Colima, escala 1:100,000: México, Universidad Nacional Autónoma de México, Instituto de Geofísica; Universidad de 
Colima, 1 mapa.

Navarro-Ochoa, C., Luhr, J.F., 2000, Late-Holocene tephrochronology at the Colima Volcanic Complex, México, en: Bretón-González, M., Pérez-santa Ana, L.M., Alatorre-Chávez, E., Santiago-Jiménez, H., (recops.), Séptima Reunión Internacional Volcán de Colima, 6-10, 2000: Colima, Universidad de Colima, 44.

Navarro-Ochoa, C., Gavilanes-Ruíz, J.C., Cortés-Cortés, A., 2002, Movement and emplacement of lava flows at Volcán de Colima, México: November 1998-February 1999: Journal of Volcanology and Geothermal Research, 117 (1-2) 155-167.

Negendank, J.F.W., Emmerman, R., Krawczyc, R., Mooser, F., Tobschall, H., Werle, D., 1985, Geological and geochemical investigations on the eastern Trans-Mexican Volcanic Belt: Geofisica Internacional, 24, 477-575.

Nelson, S.A., Gonzalez-Caver, E., Kyser, T.K., 1995, Constrains on the origin of alkaline and calc-alkaline magmas from the Tuxtla Volcanic Field, Veracruz, México: Contributions to Mineralogy and Petrology, $122,191-211$

Newhall, C.G., Self, S., 1982, The Volcanic Explosivity Index (VEI): an estimate of explosive magnitude for historical volcanism: Journal of Geophysical Research, 87(C2), 1231-1237.

Newton, J.A., Metcalfe, S.E., 1999, Tephrochronololgy of the Toluca Basin, central México: Quaternary Science Reviews, 18, 1039-1059.

Nixon, G.T., 1982, The relationship between Quaternary volcanism in central México and the seismicity and structure of the subducted ocean lithosphere: Geological Society of America Bulletin, 93, 514-523.

Norini, G., Groppelli, G., Capra, L., De Beni, E., 2004, Morphological analysis of Nevado de Toluca volcano (México): new insights into the structure and evolution of an andesitic to dacitic stratovolcano: Geomorphology, 62, 47-61.

Nuñez-Cornu, F., Nava, F., A., De-la Cruz, S., Jiménez, Z., Valencia, C., García-Arthur, R., 1994, Seismic activity related to the 1991 eruption of Colima Volcano, México: Bulletin of Volcanology, 56, 228-237.

Ordoñez, E., 1894, Nota acerca de los ventisqueros del Iztaccíhuatl Memorias de la Sociedad Científica "Antonio Alzate", 8, 31-42.

Ordoñez, E., 1898, Les Volcans Colima et Ceboruco: Memorias de la Sociedad Científica "Antonio Alzate”, 11, 325-333.

Ordoñez, E., 1902, Le Xinantecatl ou Volcan Nevado de Toluca: Memorias de la Sociedad Científica "Antonio Alzate", 18, 83-112.

Ordoñez, E., 1905, El Nauhcampatepetl o Cofre de Perote: Boletín de la Sociedad Geológica Mexicana, 1, 151 p.

Orozco, M.N., 1869, Observaciones hechas en el mes de agosto de 1869 (por el ingeniero Miguel N. Orozco de los fenómenos ígneos del volcán de Colima: Colima, Imprenta. del Gobierno del Estado a cargo de L. Orosco, 12 p.

Ortega-Gutiérrez, F., Solari, L.A., Solé, J., Martens, U., Gómez-Tuena, A., Morán-Ical, S., Reyes-Salas, M., Ortega-Obregón, C., 2004 Polyphase, high-temperature eclogite-facies metamorphism in the Chuacús Complex, central Guatemala: petrology, geochronology, and tectonic implications: International Geology Review, 46, 445-470.

Ortiz-Santos, G., 1944, La zona volcánica “Colima” del estado de Jalisco: monografía: Guadalajara, Universidad de Guadalajara, Instituto de Geografía , 49 p.

Pardo, M., Suarez, G., 1993, Steep subduction geometry of the Rivera Plate beneath the Jalisco Block in western of México: Geophysical Research Letter, 20, 2391-2394.

Pardo, M., Suarez, G., 1995, Shape of the subducted Rivera and Cocos plates in southern México; seismic and tectonic implication: Journal of Geophysical Research, 100, 12357-12373.

Perret, F.A., 1937, The eruption of Mt. Pelée 1929-1932: Carnegie Institution Washington Publication, 458, iv, $126 \mathrm{p}$.

Pieschel, C., 1856, Die vulkane der republik mexiko: Berlin, Reimer, 1 p., 18 láminas.

Plunket, P., Uruñuela, G., 1999, Preclassic household patterns preserved under volcanic ash at Tetimpa, Puebla, México: Latin American Antiquity, 9, 287-309.

Plunket, P., Uruñuela, G., 2000, The archaeology of a Plinian eruption of the
Popocatépetl volcano, en: McGuire, W.J., Griffiths, D.R., Hancock, P.L., Stewart, I.S. (eds.), The archaeology of geological catastrophes: London, Geological Society, Special Publication, 171, 195-203.

Plunket, P., Uruñuela, G., 2005, Recent research in Puebla prehistory: Journal of Archaeological Research, 13, 89-127.

Ponce, L.R., Gaulon, G., Suarez, G., Lomas, E., 1992, Geometry and the state of stress of the downgoing Cocos plate in the Isthmus of Tehuantepec: Geophysical Research Letter, 19, 773-776.

Quezada-Ramírez, M.N., 1972, Los Matlatzincas: época prehispánica y época colonial hasta 1650: México, Instituto Nacional de Antropología e Historia, 22, 142 p.

Rebollar, C.J., Espíndola, V.H., Uribe, A., Mendoza, A., Pérez-Vertti, A., 1999, Distribution of stress and geometry of the Wadati-Benioff zone under Chiapas, México: Geofisica Internacional, 38, 95-106.

Richards, A.F., 1959, Geology of the Islas Revillagigedo, México, 1, Birth and development of Volcan Barcena, Isla San Benedicto: Bulletin of Volcanology, 22, 73-124.

Richards, A.F., 1965, Geology of the Islas Revillagigedo, 3, Effects of erosion on Isla San Benedicto 1952-1961 following the birth of Volcan Barcena: Bulletin of Volcanology, 28, 381-419.

Riva-Palacio Chiang, R., 1983, Informe y comentarios acerca del Volcán Chichonal, Chiapas, en: VI Convención Geológica Nacional, El Volcán Chichonal: México, D. F., Universidad Nacional Autónoma de México, Instituto Geología, 49-56.

Robin, C., 1984, Le volcan Popocatépetl (Mexique): structure, évolution petrologique et risques: Bulletin of Volcanology, 47, 1-23.

Robin, C., Boudal., 1987, A gigantic bezymianny-type event at the beginning of modern volcan Popocatépetl: Journal of Geology and Geothermal Research, 31, 115-130.

Robin, C., Cantagrel, J.M., 1982, Le Pico de Orizaba (Mexique): structure et evolution d'un gran andésitique complexe: Bulletin of Volcanology, 45, 299-315.

Robin, C., Camus, G., Gourgaud, A., 1991, Eruptive and magmatic cycles at Fuego de Colima volcano (México): Journal of Volcanolgy and Geothermal Research, 45, 209-225.

Robin, C., Mossand, P., Camus, G., Cantagrel, J. M., Gourgaud, A., Vincent, P., 1987, Eruptive history of the Colima Volcanic Complex (México): Journal of Volcanology and Geothermal Research, 31(12), 99-113.

Rodríguez-Elizarrarás, S.R., 1991, Geología del Volcán de Colima, estados de Jalisco y Colima: México, D.F.: Universidad Nacional Autónoma de México, Facultad de Ciencias, Tesis de maestría, 110 p., mapas.

Rodríguez-Elizarrarás, S.R., 1995, Estratigrafía y estructura del Volcán de Colima, México: Revista Mexicana de Ciencias Geológicas, $12,22-46$.

Rodríguez-Elizarrarás, S., Siebe, C., Komorowski, J.C., Espíndola, J.M., Saucedo, R., 1991, Field observation of pristine block-and-ash-flow deposits emplaced on april 16-17, 1991 at Volcán de Colima, México: Journal of Volcanology and Geothermal Research, 48, 399-412.

Rosas-Elguera, J., Ferrari, L., Garduño-Monroy, V.H., Urrutia-Fucugauchi, J., 1996, Continental boundaries of the Jalisco Block and their influence in the Pliocene-Quaternary kinematics of western México: Geology, 24, 921-924.

Rose, W.I., Bornhorst, T.J., Halsor, S.P., Capaul, W.A., Plumley, P.S., De-la Cruz R.S., Mena, M., Mota, R., 1984, Volcán El Chichón, México: pre-1982 S-rich eruptive activity: Journal of Volcanology and Geothermal Research, 23, 147-167.

Rossotti, A., 2005, Reconstrucción de la historia eruptiva de la Pómez Citlaltépetl (Volcán Pico de Orizaba): Universidad Nacional Autónoma de México, Centro de Geociencias, Posgrado en Ciencias de la Tierra, Juriquilla, Querétaro, Tesis doctoral, $142 \mathrm{p}$.

Rossotti, A., Carrasco-Núñez, G., 2004, Stratigraphy of the 8.5-9.0 ka B.P. Citlaltépetl pumice fallout sequence: Revista Mexicana de Ciencias Geológicas, 21(3), 353-370.

Rouwet, D., Taran, Y., Varley, N., 2004, Dynamics and mass balance of El Chichon crater lake, México: Geofísica Internacional, 43, 427-434.

Rye, R.O., Luhr, J.F., Wasserman, M.D., 1984, Sulfur and oxygen isotopes systematics of the 1982 eruptions of El Chichon volcano, Chiapas, 
México: Journal of Volcanology and Geothermal Research, 24, 109-123.

Sapper, C., 1896, La geografía física y la geografía de la Península de Yucatán: Instituto Geológico de México, 3, 58 p., 6 láms.

Sapper, C., 1897, Ueber die räumliche Anordnung der mittelamerikanischen Vulkane: Berlin, Zeitschr. Deum. Geol. Ges., 1897, 672-682.

Sapper, K., 1899, Ueper Gebirsbau und Boden des noerdlichen Mittelamerika: Petermanns Geographische Mitteilungen, 127, $119 \mathrm{p}$.

Sartorius, C., 1869, Eruption of the Volcano of Colima in june 1869: Smithsonian Report, 423 p.

Saucedo, R., Macías, J.L., Bursik, M.I., Mora, J.C., Gavilanes, J.C., Cortés, A., 2002, Emplacement of pyroclastic flows during the 1998-1999 eruption of Volcán de Colima, México: Journal of Volcanology and Geothermal Research, 117, 129-153.

Saucedo, R., Macías, J.L., Bursik, M. I., 2004a, Pyroclastic flow deposits of the 1991 eruption of Volcán de Colima, México: Bulletin of Volcanology, 66(4), 291-306.

Saucedo, R., Macías, J.L., Sheridan, M.F., Bursik, M.I., Komorowski, J.C., 2004b, Modeling of pyroclastic flows of Colima Volcano, México: implications for hazard assessment: Journal of Volcanology and Geothermal Research, 139, 103-115.

Saucedo-Girón, R., 1997, Reconstrucción de la erupción de 1913 del volcán de Colima: México, D. F., Universidad Nacional Autónoma de México, Colegio de Ciencias y Humanidades, Unidad Academica de los Ciclos Profesional y de Posgrado, Tesis de maestría, 185 p.

Saucedo-Girón, R., 2001, Erupciones de 1991 y 1998-1999 del Volcán de Colima, mecanismos de transporte y depositación de los flujos piroclásticos de bloques y ceniza: México, D. F, Universidad Nacional Autónoma de México, Instituto de Geofísica, Programa de Posgrado en Ciencias de la Tierra, Tesis doctoral, vi, 132 p.

Saucedo-Girón, R., Esquivias, H., 1988, Evaluación del riesgo volcánico en el área del Volcán Tacaná, Chiapas: México, D.F., Instituto Politécnico Nacional, Escuela Superior de Ingenieria y Arquitectura, Tesis profesional, $142 \mathrm{p}$.

Saucedo-Girón,R., Macías, J.L., 1999, La historia del Volcán de Colima: Tierra Adentro, 98, 8-14.

Schaaf, P., Stimac, J., Siebe, C., Macías, J.L., 2005, Geochemical evidence for mantle origin and crustal processes from products of Popocatépetl and surrounding monogenetic volcanoes: Journal of Petrology, 46, 1243-1282.

Scolamacchia, T., Macías, J.L., 2005, Distribution and stratigraphy of deposits produced by diluted pyroclastic density currents of the 1982 eruptions of El Chichon volcano, Chiapas, México: Revista Mexicana de Ciencias Geológicas, 22(2) 159-180.

Scolamacchia, T., Macías, J.L., Sheridan, M.F., Hughes, S., 2005, Morphology of ash aggregates from wet pyroclastic surges of the 1982 eruption of El Chichón Volcano, México: Bulletin of Volcanology, 68(2), 171-200.

Scott, K.M., Macías, J.L., Naranjo, J.A., Rodríguez, S., McGeehin, J.P., 2001, Catastrophic debris flows transformed from landslides in volcanic terrains, mobility, hazard assessment, and mitigation strategies: U.S.Geological Survey, Professional Paper, 1630, 67 p, 19 figs, 9 tabs.

Seismic Event Alert Network (SEAN), 1982, Volcanic events: El Chichón volcano: Smithsonian Institution, Seismic Event Alert Network Bulletin, 7(3), 2-6.

Secretaría de la Defensa Nacional (SEDENA), 1983, El Plan DN-III-E y su aplicación en el área del Volcán Chichonal, en: VI Contención Geológica Nacional, El Volcán Chichonal México, D.F., Universidad Nacional Autónoma de México, Instituto de Geología, 90-100.

Sedov, S., Solleiro-Rebolledo, E., Gama-Castro, J., Vallejo-Gomez, E., Gonzalez-Vazquez, A., 2001, Buried paleosols of the Nevado de Toluca: an alternative record of late Quaternary environmental change in central México: Journal of Quaternary Science, 16, 375-389.

Sedov, S., Solleiro-Rebolledo, E., Morales-Puente, P., Arias-Herrería, A., Vallejo-Gómez, E., Jasso-Castaneda, C., 2003, Mineral and organic components of the buried paleosols of the Nevado de Toluca, Central México as indicators of paleoenvironmets ans soil evolution:
Quaternary International, 106-107, 169-184.

Seele, E., 1973, Restos de milpas y poblaciones prehispánicas cerca de San Buenaventura Nealtic, Estado de Puebla: Proyecto Puebla-Tlaxcala, Comunicaciones, 7, 77-86.

Segerstrom, K, 1956, Erosion studies at Parícutin, state of Michoacán, México. Geologic investigations in the Parícutin area, México: U.S. Geological Survey, Bulletin, 965-A, 164 p., 7 láms.

Seismic Event Alert Network (SEAN), 1982, Volcanic events: El Chichón volcano: Smithsonian Institution Seismic Event Alert Network Bulletin, 7(3), 2-6.

Sheridan, M.F., Macías, J.L., 1995, Estimation of Risk Probability for Gravity-Driven Pyroclastic Flows at Volcán Colima, México: Journal of Volcanology and Geothermal Research, 66, 251-256.

Sheridan, M.F., Carrasco-Nuñez, G., Hubbard, B.E., Siebe, C., RodríguezElizarrarás, S., 2002, Mapa de peligros del Volcán Citlaltépetl (Pico de Orizaba), escala 1:25 000: Universidad Nacional Autónoma de México, Instituto de Geología, 1 mapa.

Sheridan, M.F., Hubbard, B., Carrasco-Núñez, G., Siebe, C., 2004, Pyroclastic flow hazard at Volcán Citlaltépetl: Natural Hazards, $33,209-221$.

Sheth, H.C., Torres-Alvarado, I.S., Verma, S. P., 2000, Beyond subduction and plume: A unified tectonic-petrogenetic model for the Mexican Volcanic Belt: International Geology Review, 42, 1116-1132.

Siebe, H.C., Abrams, M., Sheridan, M., 1993, Major Holocene block-andash fan at the western slope of ice-capped Pico de Orizaba volcano, México: implications for future hazards: Journal of Volcanology and Geothermal Research, 59, 1-33.

Siebe, C., Abrams, M., Macías, J.L., 1995a, Derrumbes Gigantes, Depósitos de Avalancha de Escombros y Edad del Actual Cono del Volcán Popocatépetl, en, Volcán Popocatépetl, Estudios Realizados durante la crisis de 1994-1995, Centro Nacional de Prevención de Desastres, $26 \mathrm{p}$.

Siebe, C., Macías, J.L., 2004, Volcanic hazards in the Mexico City metropolitan area from eruptions at Popocatepetl, Nevado de Toluca, and Jocotitlán stratovolcanoes and monogenetic scoria cones in the Sierra de Chichinautzin Volcanic Field: Geological Society of America, Fieldtrip Books 1, 77 p.

Siebe, C., Komorowski, J.C., Navarro, C., McHone, J.F, Delgado, H., Cortés, A., 1995a, Submarine eruption near Socorro Island, México: geochemistry and scanning electron microscopy studies of floating scoria and reticulite: Journal of Volcanology and Geothermal Research, 68, 239-272.

Siebe, C., Macías, J.L., Abrams, M., Rodríguez-Elizarrarás, R.S., Castro, R., Delgado, H., 1995b, Quaternary Explosive Volcanism and Pyroclastic Deposits in East-Central México: Implications for Future Hazards: Geological Society of America, 1, 1-48.

Siebe, C., Macías, J.L., Abrams, M., Obenholzner, J., 1996a, La destrucción de Cacaxtla y Cholula: un suceso en la historia eruptiva del Popocatépetl: Ciencias, 41, 36-45.

Siebe, C., Abrams, M., Macías, J.L., Obenholzner, J., 1996b, Repeated volcánic disasters in Prehispanic time at Popocatépetl, Central México: Past key to the future?: Geology, 24, 399-402.

Siebe, C., Macías, J.L., Abrams, M., Rodríguez, S., Castro, R., 1997, Catastrophic Prehistoric eruptions at Popocatépetl and Quaternary explosive volcanism in the Serdán-Oriental Basin, East-Central México, IAVCEI, General Assembly, 88 p.

Sigurdsson, H., Carey, S.N., Espíndola, J.M., 1984, The 1982 eruptions of El Chichón volcano, México: stratigraphy of pyroclastic deposits: Journal of Volcanology and Geothermal Research 23, 11-37.

Sigurdsson, H., Carey, S.N., Fisher, R.V., 1987, The 1982 eruptions of El Chichón volcano, México (3): Physical properties of pyroclastic surges: Bulletin of Volcanology, 49, 467- 488.

Singer, B.S., Kudo, A.M., 1986, Origin of andesites and dacites from Pico de Orizaba, Mexican Volcanic Belt: $\mathrm{Sr}$ isotope and phase chemistry: Geological Society of America, Abstracts with Programs, 18(2), 186.

Singh, S.K., Pardo, M., 1993, Geometry of the Benioff Zone and state of stress in the overriding plate in central México: Geophysical Research Letter, 20, 1483-1486.

Solleiro-Rebolledo, E., Macías, J. L., Gama-Castro, J., Sedov, S., 
Sulerzhitsky, L., 2004, Quaternary pedostratigraphy of Nevado de Toluca: Revista Mexicana de Ciencias Geológicas, 21(1), 101109.

Stoiber, R. E., Carr, M .J., 1973, Quaternary volcanic and tectonic segmentation of Central America: Bulletin Volcanologique, 37, $1-22$.

Straub, S.M, Martín Del Pozzo, A.L., 2001, The significance of phenocryst diversity in tephra from recent eruptions at Popocatépetl volcano (central México): Contributions to Mineralogy and Petrology, 140, 487-510.

Stoopes, G.R., Sheridan, M.F., 1992, Giant debris avalanches from the Colima Volcanic Complex, México: Implications for long-ronout landslides $(<100 \mathrm{~km})$ and hazard assesment: Geology, 20, 299302.

Suárez-Cruz, S., Martínez-Arreaga, S., 1993, Monografía de Cholula: Puebla, Offset Mabek, 43 p.

Taran, Y., Fischer, T.P., Pokrovsky, B., Sano, Y., Armienta, M.A., Macías, J.L., 1998, Geochemistry of the volcano-hydrothermal system of El Chichón Volcano, Chiapas, México: Bulletin of Volcanology, $59,436-449$.

Taran, Y., Gavilanes, J.C., Cortés, A., 2002, Chemical and isotopic composition of fumarolic gases and the $\mathrm{SO} 2$ flux from Volcán de Colima, México, between the 1994 and 1998 eruptions: Journal of Volcanology and Geothermal Research, 117(1-2), 105-119.

Tassi, F., Vaselli, O., Capaccioni, B., Macías, J.L., Nencetti, A., Montegrossi, G., Magro G., Buccianti, A., 2003, Chemical composition of fumarolic gases and spring discharges from El Chichon volcano, México: causes and implications of the changes detected over the period 1998-2000: Journal of Volcanology and Geothermal Research, 123(1-2), 105-121.

Tello, F.A., 1651, Libro segundo de la crónica miscelánea en que se trata de la Conquista Espiritual y temporal de la Santa Provincia de Jalisco en el Nuevo Reino de la Galicia y Nueva Vizcaína y descubrimiento del Nuevo México: Guadalajara, Imprenta de la Republica Literaria

Templos, L.A., 1981, Observaciones geoquímicas de la zona geotérmica del Chichonal, Chiapas: México, Comisión Federal de Electricidad, Informe interno.

Tepley, F.J., Davidson, J.P., Tilling, R. I., Arth, J.G., 2000, Magma mixing, recharge and eruption histories recorded in plagioclase phenocrysts from El Chichón Volcano, México: Journal Petrology, 41, 1397-1411.

Thorpe, R.S., 1977, Tectonic significance of alkaline volcanism in eastern México: Tectonophysics, 40, T19-T26.

Thorpe, R.S., Gibson, I.L., Vizcaíno. J.S., 1977, Andesitic pyroclastic flows from Colima volcano: Nature, 265, 724-725.

Tilling, R.I, Rubin, M., Sigurdsson, H., Carey, S., Duffield, W.A., Rose, W.I., 1984, Holocene eruptive activity of El Chichón volcano, Chiapas, México: Science, 224, 747-749.

Urrutia-Fucugauchi, J., Flores-Ruiz, J.H., 1996, Bouguer gravity anomalies and regional crustal structure in central México: International Geology Review, 38, 176-194.

Valdez-Moreno, G., Schaaf, P., Macías, J.L., Kusakabe, M., 2006, New Sr$\mathrm{Nd}-\mathrm{Pb}-\mathrm{O}$ isotope data for Colima volcano and evidence for the nature of the local basement, en Siebe, C., Macías, J.L., and Aguirre-Díaz, G.J., (eds.), Neogene-Quaternary continental margin volcanism: A perspective from Mexico: Geological Society of America Special Paper 402, p. 45-63, doi: 10.1130/2006.2402(02).

Varekamp, J.C., Luhr, J.F., Prestegaard, K.L., 1984, The 1982 eruptions of El Chichón volcano (Chiapas, México): character of the eruptions, ash-fall deposits, and gas phase: Journal of Volcanology Geothermal Research, 23, 39-68.
Vásquez-Selem, L., Heine, K., 2004, Late Quaternary glaciation in México, en: Ehlers, J., Gibbard, P.L., (eds.), Quaternary glaciations-Extend and chronology. Part III. South America: Elsevier, Amsterdam.

Waibel, L., 1933, Die Sierra Madre de Chiapas: Mitteilungen der Geographischen Gesellschaft in Hamburg, 43, 13-162.

Waitz, P., 1906, Le Volcan de Colima, en: X Congreso Geológico Internacional, Libreto-Guía: México, 13, 27 p.

Waitz, P., 1909, Excursión Geológica al Nevado de Toluca: Boletín de la Sociedad Geológica Mexicana, 6, 113-117.

Waitz, P., 1910-1911, Observaciones geológicas acerca del Pico de Orizaba: Boletín de la Sociedad Geológica Mexicana, 7, 67-76.

Waitz, P., 1915, El estado actual de los volcanes de México y la última erupción del Volcán de Colima (1913): Revista Volcanológica, 259-268.

Waitz, P., 1921, Popocatépetl again in activity: American Journal of Science, 1, 81-87.

Waitz, P., 1935, Datos históricos y bibliográficos acerca del Volcán de Colima: Memorias y Revista de la Academia nacional de Ciencias "Antonio Alzate", 53, 349-385.

Wallace, P.J., Carmichael, I.S.E., 1999, Quaternary volcanism near the Valley of México: implications for subduction zone magmatism and the effects of crustal thickness variations on primitive magma compositions: Contributions to Mineralogy and Petrology, 135, 291-314.

Weitzberg, F., 1922, El Ventisquero del Popocatépetl: Memorias y Revista de la Sociedad Científica "Antonio Alzate", 41, 65-90.

Whitford, D.J., Bloomfield, K., 1977, Geochemistry of late Cenozoic volcanic rocks from the Nevado de Toluca area, México: Carnegie Institution of Washington, Yearbook, 75, 207-213.

Wilcox, R.E., 1954, The petrology of Parícutin volcano: U.S. Geological Survey, Bulletin 965-C, 281-354.

Williams, S.N., Self, S., 1983, The october 1902 plinian eruption of Santa Maria volcano, Guatemala: Journal of Volcanology and Geothermal Research, 16, 33-56

Yáñez-García C., García-Durán, S., 1982, Exploración de la región geotérmica Los Humeros-Las Derrumbadas, estados de Puebla y Veracruz: México, Comisión Federal de Electricidad, Reporte Técnico, $96 \mathrm{p}$.

Yokohama, I., De-la Cruz-Reyna, S., Espíndola, J. M., 1992, Energy partition in the 1992 eruption of El Chichón volcano, Chiapas, México: Journal of Volcanology and Geothermal Research, 51, $1-21$.

Zimbelman, D., Watters, R., Firth, I., Breit, G., Carrasco-Núñez, G., 2004, Stratovolcano stability assessment methods and results from Citlaltépetl, México: Bulletin of Volcanology, 66, 66-79.

Zobin, V.M., Luhr, J.F., Taran, Y., Bretón, M., Cortés, A., De-la CruzReyna, S., Domínguez, T., Galindo, I., Gavilanes, J.C., Muñiz, J.J., 2002, Overview of the 1997-2000 activity of Volcán de Colima, México: Journal of Volcanology and Geothermal Research, 117(12), 1-19.

Manuscrito recibido: Septiembre 13, 2005

Manuscrito corregido recibido: Marzo 09, 2006

Manuscrito aceptado: Marzo 21, 2006 